\title{
Reactor Physics Parametric and Depletion Studies in Support of TRISO Particle Fuel Specification for the Next Generation Nuclear Plant
}

James W. Sterbentz Bren Phillips

Robert L. Sant

Gray S. Chang

Paul D. Bayless

September 2004

Idaho National Engineering and Environmental Laboratory Bechtel BWXT Idaho, LLC 



\title{
Reactor Physics Parametric and Depletion Studies in Support of TRISO Particle Fuel Specification for the Next Generation Nuclear Plant
}

\author{
James W. Sterbentz \\ Bren Phillips \\ Robert L. Sant \\ Gray S. Chang \\ Paul D. Bayless
}

September 2004

Idaho National Engineering and Environmental Laboratory Idaho Falls, Idaho 83415

Prepared for the U.S. Department of Energy Office of Nuclear Energy 



\section{ABSTRACT}

Reactor physics calculations were initiated to answer several major questions related to the proposed TRISO-coated particle fuel that is to be used in the prismatic Very High Temperature Reactor (VHTR) or the Next Generation Nuclear Plant (NGNP). These preliminary design evaluation calculations help ensure that the upcoming fuel irradiation tests will test appropriate size and type of fuel particles for a future NGNP reactor design. Conclusions from these calculations are expected to confirm and suggest possible modifications to the current particle fuel parameters specified in the evolving Fuel Specification.

Calculated results dispel the need for a binary fuel particle system, which is proposed in the General Atomics GT-MHR concept. The GT-MHR binary system is composed of both a fissile and fertile particle with 350- and 500micron kernel diameters, respectively. For the NGNP reactor, a single fissile particle system (single UCO kernel size) can meet the reactivity and power cycle length requirements demanded of the NGNP. At the same time, it will provide substantial programmatic cost savings by eliminating the need for dual particle fabrication process lines and dual fuel particle irradiation tests required of a binary system.

Use of a larger 425-micron kernel diameter single fissile particle (proposed here), as opposed to the 350-micron GT-MHR fissile particle size, helps alleviate current compact particle packing fractions fabrication limitations $(<35 \%)$, improves fuel block loading for higher $n$-batch reload options, and tracks the historical correlation between particle size and enrichment (10 and $14 \mathrm{wt} \%$ U-235 particle enrichments are proposed for the NGNP). Overall, the use of the slightly larger kernel significantly broadens the NGNP reactor core design envelope and provides increased design margin to accommodate the (as yet) unknown final NGNP reactor design.

Maximum power-peaking factors are calculated for both the initial and equilibrium NGNP cores. Radial power-peaking can be fully controlled with particle packing fraction zoning (no enrichment zoning required) and discrete burnable poison rods. Optimally loaded NGNP cores can expect radial powerpeaking factors as low as 1.14 at beginning of cycle (BOC), increasing slowly to a value of 1.25 by end of cycle (EOC), an axial power-peaking value of 1.30 (BOC), and for individual fuel particles in the maximum compact $<1.05$ (BOC) and an approximate value of 1.20 (EOC) due to $\mathrm{Pu}-239$ buildup in particles on the compact periphery. The NGNP peak particle powers, using a conservative total power-peaking factor ( 2.1 factor), are expected to be $<150 \mathrm{~mW} /$ particle (well below the $250 \mathrm{~mW} /$ particle limit, even with the larger 425-micron kernel size). 



\section{CONTENTS}

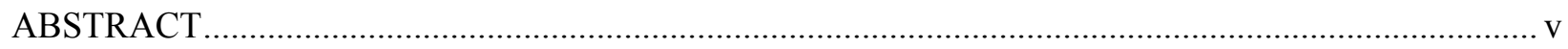

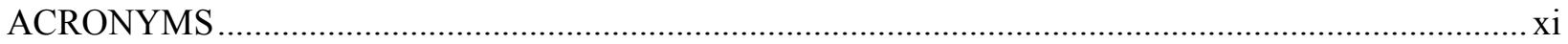

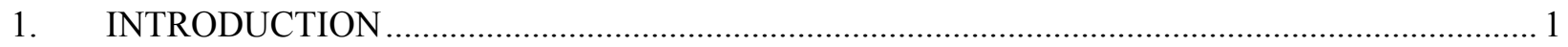

2. NEUTRONIC FUEL SPECIFICATION SUPPORT TASKS ….................................................. 4

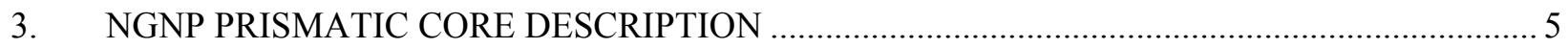

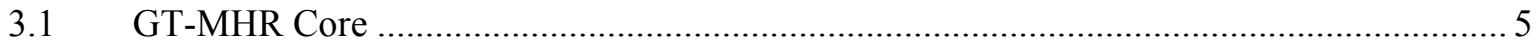

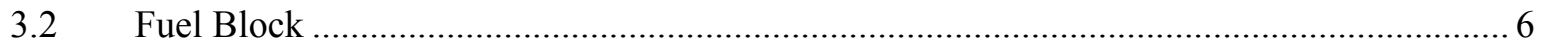

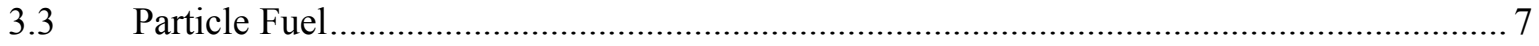

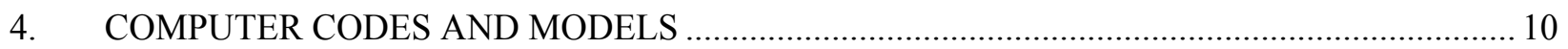

$4.1 \quad$ MCNP

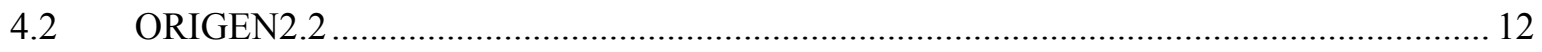

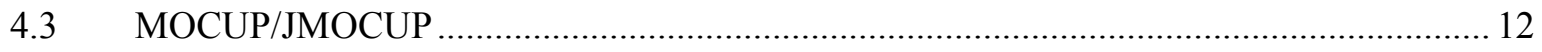

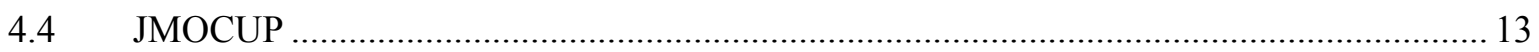

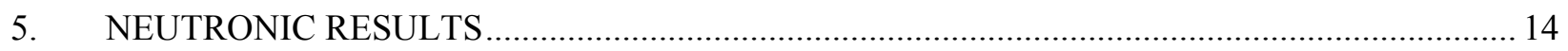

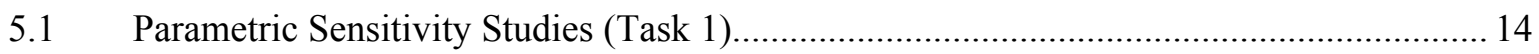

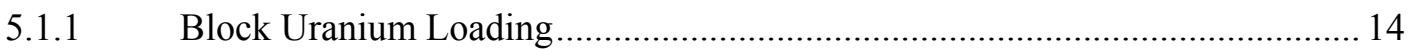

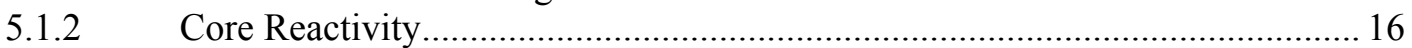

5.1.3 Additional Parametric Studies............................................................. 19

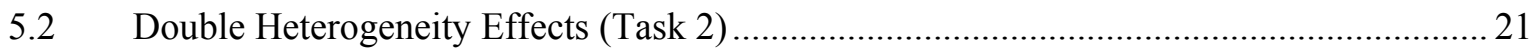

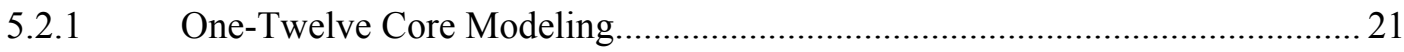

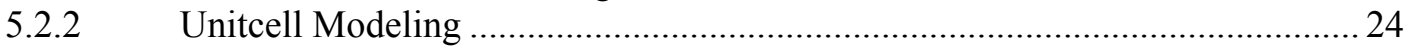

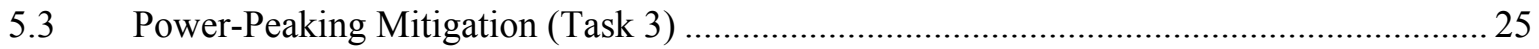

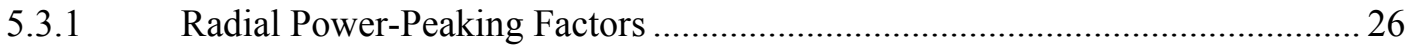

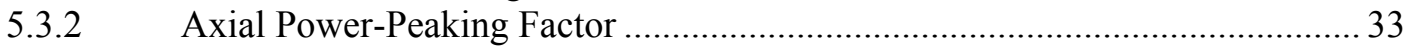

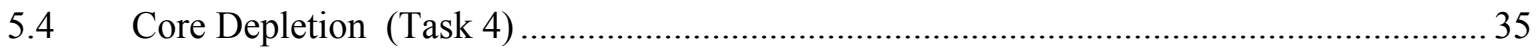

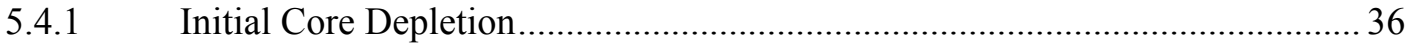

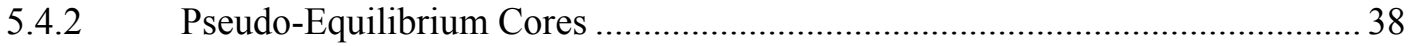




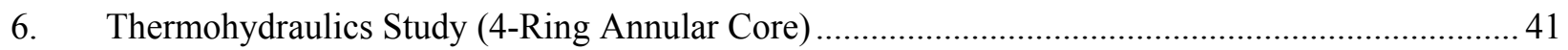

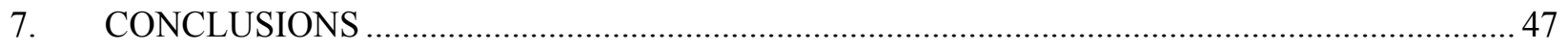

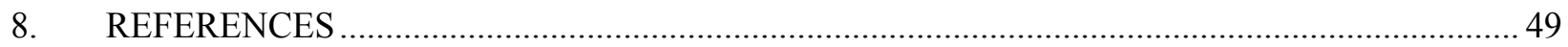

\section{FIGURES}

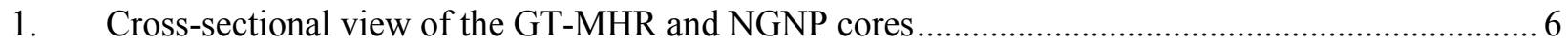

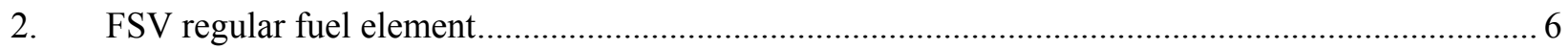

3. TRISO fuel particle, compacts, and fuel block................................................................... 7

4. MCNP unitcell model showing homogenized fuel rod (red), graphite (yellow),

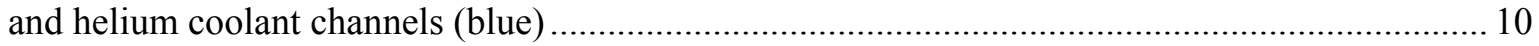

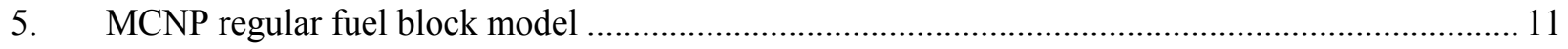

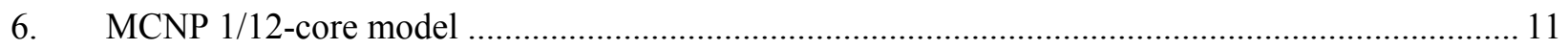

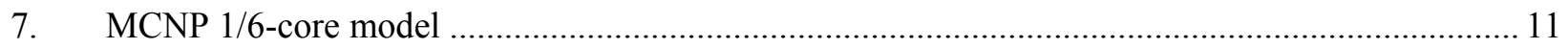

8. Uranium (U-235) loading versus uranium enrichment and packing fraction

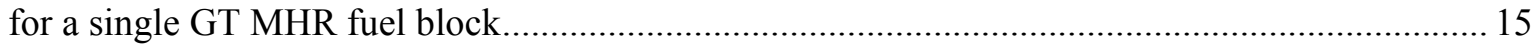

9. Uranium (U-235) loading versus packing fraction and uranium enrichment for a single GT MHR fuel block.

10. Uranium (U-235) loading versus UCO kernel diameter and packing fraction for a single GT MHR fuel block.

11. Uranium (U-235) loading versus UCO kernel density and packing fraction for a single GT MHR fuel block.

12. Unitcell lattice k-infinity versus variations in the fuel rod radius and fuel particle packing fraction for a fixed uranium enrichment of $10.36 \mathrm{wt} \% \mathrm{U}-235$

13. Unitcell lattice k-infinity versus variations in the fuel rod radius and fuel kernel diameter for a fixed uranium enrichment of $10.36 \mathrm{wt} \% \mathrm{U}-235$

14. Fuel block lattice k-infinity versus fuel particle enrichment and packing fraction ....................... 17

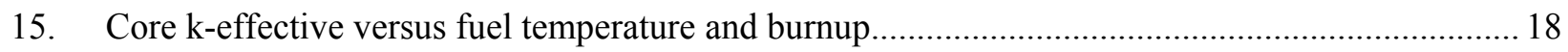

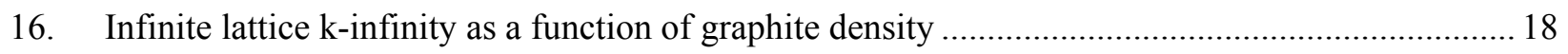

17. Relative and absolute mass quantities of six different burnable poisons excess core reactivity holddown and power-peaking suppression. Poisons are standard oxide and carbide forms in the discrete burnable poison rod locations..... 
18. 1/12-core MCNP model with a regular fuel particle array in the maximum power-peaking fuel rod location....

19. Individual fuel particle powers in the fuel compact at the maximum powerpeaking location.

20. Cross-sectional view of a double-heterogeneous triangular fuel unit lattice model with fuel particles

21. Fission power gradient profile across the peak fuel rod, and the radial fission power profile inside the fuel rod at the BOL and $118 \mathrm{GWd} / \mathrm{t}$ burnup

22. Fuel rod power-peaking radially across the annular core. Relative size of the bubbles represent magnitude of the individual fuel rod peaking. Ring 6 block is in the upper left corner of figure, Ring 7 in the middle, and Ring 8 lower right corner. The highest peaking occurs in the Ring 6 at the inner graphite reflector interface.

23. Power-peaking factors for the two fuel rods in Ring 6 deepest into the inner graphite reflector as a function of fuel particle enrichment and block total gram loading of U-235

24. Packing fraction and enrichment zoning in the first 4 fuel rod rows along the inner (yellow dots) and outer (pink dots) reflector interfaces.

25. Maximum peaking factors in fuel rods (pins) no. 305 (Row 1) and no. 272 (Row 5) in Ring 6 fuel block at the inner reflector as a function of packing fraction in rows 1-4.

26. Maximum peaking factors in fuel rods (pins) no. 305 (Row 1) and no. 272 (Row 5) in Ring 6 fuel block at the inner reflector as a function of particle enrichment in rows $1-4$

27. Discrete burnable poison rod locations

28. Maximum power-peaking factor across the radial core cross section as a function of U-2325 block loading (g/block) and fuel particle enrichment

29. Optimal radial core loading specifically designed to maximize the reduction of the maximum radial power-peaking factor across the core. Ring 6: The red, yellow, and light blue dots are $\mathrm{PF}=0.175,0.21$, and 0.27 , respectively. Ring 7: $\mathrm{PF}=0.27$. Ring 8: $\mathrm{PF}=0.21$ and 0.27 . All fuel particles have a $10 \mathrm{wt} \%$ enrichment.

30. Four regular fuel blocks showing relative fuel rod powers (size of bubble). Note: the block in the upper left hand corner is in Ring 6 and the two lower right hand side blocks are both in Ring 8. Ring 6 and 8 packing fraction zones within each block are readily visible indicated by bubble size. Also, BP rod locations are indicated by the solid (red) dots

31. Fuel rod peak-to-average factors are shown in place of the bubbles 


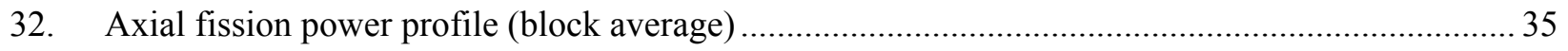

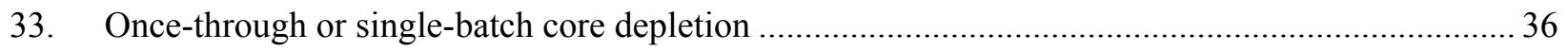

34. Maximum radial power-peaking factors as a function of burnup................................................ 38

35. Core k-infinity versus burnup for a variety of three-block radial core loadings ............................ 39

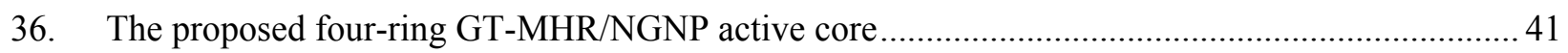

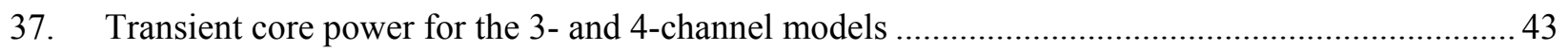

38. LPCC peak fuel temperatures for the 3 - and 4-channel models ................................................. 43

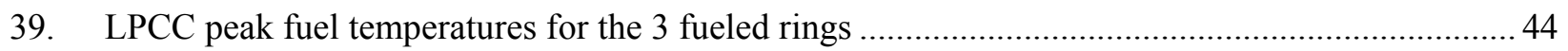

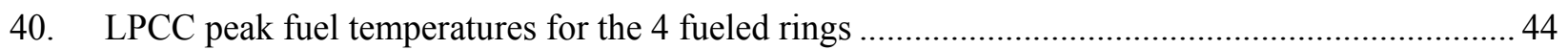

41. LPCC inner and outer reflector temperatures for the 3- and 4-channel models ............................ 45

42. LPCC peak reactor vessel temperatures for the 3- and 4-channel models .................................. 45

43. LPCC RCCS heat removal for the 3- and 4-channel models ...................................................... 46

\section{TABLES}

1. Comparison of the GT-MHR and proposed NGNP core characteristics..................................... 5

2. Fissile particle characteristics for the 350 - and 425 -micron kernel diameter particles. ................... 8

3. Peak particle powers for a $10 \mathrm{wt} \%$ enrichment and a $554 \mathrm{~g} \mathrm{U}-235$ fuel block versus kernel size. .... 8

4. Peak particle powers for a $14 \mathrm{wt} \%$ enrichment and a $776 \mathrm{~g} \mathrm{U}-235$ fuel block versus kernel size..... 8

5. Peak particle powers for a $14 \mathrm{wt} \%$ enrichment and a $1,000 \mathrm{~g} \mathrm{U}-235$ fuel block versus kernel size... 8

6. Reactivity and loading summary table for fuel design variables............................................. 19

7. Maximum power-peaking factors in the fuel particle compact array as a function of kernel size and enrichment.

8. Maximum power-peaking factors in the fuel particle compact array as function of particle enrichment.

9. Comparison of maximum power-peaking factors versus burnup ................................................. 37

10. Recommended fuel parameters for once-through cycles...................................................... 48 


\section{ACRONYMS}

AGR Advanced Gas Reactor

ATR Advanced Test Reactor

BOC beginning of cycle

BOL beginning-of-life

BP burnable poison

EFPD effective full power days

EOC end of cycle

FSV Fort St. Vrain

INL Idaho National Laboratory

MCNP4C Monte Carlo reactor physics transport code

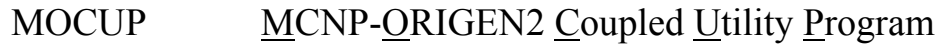

NGNP Next Generation Nuclear Plant

PF Packing fraction

RIGEN2.2 Oak Ridge Isotope Generation Version 2.2

RSS reserve shutdown system

$\mathrm{T} / \mathrm{H} \quad$ thermo-hydraulic

UCO uranium oxycarbide

VHTR Very High Temperature Reactor 



\section{Reactor Physics Parametric and Depletion Studies in Support of TRISO Particle Fuel Specification for the Next Generation Nuclear Plant}

\section{INTRODUCTION}

The Very High Temperature Reactor (VHTR), also known now as the Next Generation Nuclear Plant or NGNP, is the leading reactor concept destined for near-term deployment in the United States under the U.S. Department of Energy's Generation IV program. This reactor concept, with its relatively low core power density and large graphite mass, adheres to the under lying Generation IV safety goal of inherent safety under all accident or transient conditions. ${ }^{1}$ The NGNP's high gas outlet temperature allows for high electrical efficiency and hydrogen production, and together these attributes form the basis for making the NGNP the number one GEN IV contender and reactor candidate for near-term deployment.

The proposed nuclear fuel for the NGNP is the TRISO-coated particle fuel. Although this fuel type has been around for many years, fabrication in the United States is starting afresh, and with this renewed impetus, fuel fabrication and performance are thrust to the forefront of technical risk and uncertainty. To address these issues, the Advanced Gas Reactor (AGR) Fuel Development and Qualification program ${ }^{2}$ was established and chartered specifically with the development and qualification of the NGNP TRISOcoated particle fuel. One of the first steps in the AGR fuel development program is to define a fuel specification based on the NGNP core requirements and operating conditions needed to support fuel fabrication and the proposed multi-year fuel irradiation test program.

Since the NGNP is based on the Generation IV VHTR, the reactor could be either a prismatic graphite block or a pebble-bed reactor concept. Because the decision has not yet been made as to reactor design, the particle fuel for the prismatic block reactor has been somewhat arbitrarily chosen as the basis for the current Fuel Specification. This decision was based on the prismatic fuel expectation and will present a greater challenge for particle fuel performance in terms of higher particle packing fractions, enrichment, and burnup.

To support the development of the Fuel Specification for the prismatic fuel, specific reactor physics and thermo-hydraulic calculations were performed to help define the potential reactor operating conditions and key fuel design parameters under which the particles would need to survive. Key fuel design parameters include fuel particle size, packing fraction, and enrichment, and U-235 block loadings to meet burnup and power cycle length requirements. As a calculation basis, three preliminary top-level NGNP prismatic reactor core design requirements ${ }^{3}$ have (to date) been specified as follows: (1) total core power of at least $600 \mathrm{MW}(\mathrm{th}),(2)$ power cycle length shall be at least 18 months, and (3) an outlet helium gas temperature of $950-1000{ }^{\circ} \mathrm{C}$.

Rather than spend time designing a new NGNP reactor core, it was decided that the General Atomics GT-MHR core design ${ }^{4}$ would serve as our calculational basis. Also, we did not attempt to redesign or optimize the fuel blocks, although some parametric analyses herein suggest that optimization of the fuel blocks under the NGNP requirements would be possible and useful down the road. The primary calculational goal was to bolster our understanding of the fuel particle, fuel compact, and fuel block uranium loading needed to meet the NGNP requirements in the General Atomics GT-MHR reactor 
design, provide information to the Fuel Specification, and help answer some fundamental questions related to acceptable fuel particle implementation in the NGNP core.

Currently, the fissile TRISO-coated fuel particle is specified to have a kernel composition of $\mathrm{UC}_{0.5} \mathrm{O}_{1.5}$, kernel diameter of 350-microns $(350 \mu \mathrm{m})$, kernel density $\geq 10.5 \mathrm{~g} / \mathrm{cc}$, particle packing fraction $\leq 35 \%$, and an enrichment of $19.8 \mathrm{wt} \% \mathrm{U}-235$. These specification parameters are based primarily on the GT-MHR fissile particle and are being used in the upcoming AGR-1 irradiation test in the Advanced Test Reactor (ATR) scheduled to begin in 2006. The immediate concern is whether the current Fuel Specification is appropriate for the NGNP and its unique set of operating and design requirements, and what parameter changes might need to be made for future NGNP fuel particle test irradiations. Preliminary specifications needed to be explored for the NGNP particle fuel and this led to the present work.

The GT-MHR binary particle system (350-micron fissile particle and a 500-micron fertile particle) was originally intended to support fuel recycle. Although the NGNP fuel in the equilibrium core may be exposed to several power cycles to achieve desired burnups, there is currently no intention to recycle the fuel. Hence, without a fertile particle absorbing conversion neutrons, the NGNP should theoretically be able to utilize lower enrichment fuel to improve life cycle fuel economics.

In support of the NGNP TRISO fuel particle Fuel Specification development, three primary questions needed to be answered through reactor physics calculations: (1) can a single fissile fuel particle be used as opposed to a binary particle system, (2) what size fuel kernel and enrichment would be best suited for the expected NGNP burnup and power cycle length, and (3) what are the compact, radial, and axial power-peaking factors for a reasonable active core design and uranium loading? Secondary questions relate to the number of fissile particle enrichments, current packing fraction limitations and the impact on block uranium loadings, and fuel cycle length and maximum discharge burnups. Preliminary answers to these questions are provided in this report.

The Idaho National Engineering and Environmental Laboratory (INEEL) neutronic and thermohydraulic tasks were focused on answering these three questions and providing calculated estimates of quantities to support the answers. For the neutronic analyses (bulk of the work), the powerful and detailed geometry modeling capability of the Monte Carlo methodology was invoked specifically to provide detailed estimates of power-peaking factors for individual fuel particles and compacts or fuel rods anywhere in the core, estimates that would otherwise not be possible with deterministic codes. In addition, the Monte Carlo transport tool was used to perform parametric, compact, and block design and depletion studies to achieve viable uranium loadings to meet power cycle length requirements, with the underlying goal of minimizing fuel rod power-peaking. Particle power-peaking translates potentially into over-stress on fuel particles through elevated power-time and temperature-time history profiles.

In response to the defined physics tasks and requirements, INEEL developed a variety of neutronic models ranging from simple unitcell models up through full-core three-dimensional NGNP models using a Monte Carlo reactor physics transport code (MCNP4C). Along with the MCNP code, Monte Carlo depletion analyses were also performed with the JMOCUP and ORIGEN2.2 codes. The INEEL effort complements similar and coordinated activities performed at the Argonne National Laboratory-East (ANL-E), in which deterministic models and code tools ${ }^{5}$ for lattice and whole-core calculations are being employed to study power cycle length, discharge burnup, fluence, and power distributions ${ }^{6}$.

With the Monte Carlo approach, various levels of detail could be incorporated into the NGNP core models, depending on the desired parameter of interest. The most detailed models included individual fuel particles in a single compact. Full-core models were either 1/12- or 1/6-core wedge models of the active core with all fuel block coolant channels, fuel rods, and discrete burnable poison rod locations 
explicitly modeled. Except for the explicit particle models, each fuel rod was modeled with a homogenized material density containing the fuel particles and graphite-binding matrix.

Note that INL thermo-hydraulic $(\mathrm{T} / \mathrm{H})$ support was limited this year, due to time and available resources. A single $\mathrm{T} / \mathrm{H}$ transient analysis was however performed to evaluate a four-ring active annular core design relative to the GT-MHR/NGNP three-ring core. The radially thicker annulus core (4-ring) had several attractive features, two of which included a lower overall core power density that, in turn, produced a lower average particle power throughout the core and lower particle-packing fractions. Lower particle power ultimately produces, and in particular lower peak particle powers lead to, improved fuel performance.

Although the neutronic and thermal-hydraulic analyses herein were performed to help answer fuel particle concerns and provide Fuel Specification information, this study was specifically not intended to be an NGNP prismatic core design study. 


\section{NEUTRONIC FUEL SPECIFICATION SUPPORT TASKS}

The following four INEEL neutronic tasks were identified to support the Fuel Specification development and complement the ANL-E support work.

Task 1: Parametric Sensitivity Studies: Perform parametric studies to evaluate the sensitivity of major fuel design variables that impact the reactor core design, in particular, uranium block loading, core reactivity, and burnup. Major fuel design variables include:

1. Kernel size

2. Packing fraction $(\mathrm{PF})$

3. Enrichment

4. Kernel density.

Evaluate and identify potential areas for optimization of the FSV/GT-MHR/NGNP fuel blocks. Develop Monte Carlo unitcell, fuel block, and core models.

Task 2: Double Heterogeneity Effects: Estimate maximum individual fuel particle powers and powerpeaking factors associated with the double heterogeneity of fuel compacts. In the maximum powerpeaking fuel compacts, estimate the thermal fission power gradients across the compact.

Task 3: Power-Peaking Mitigation: Evaluate the GT-MHR reference core design to better understand the reflector/core interface fuel rod power-peaking problem. Identify and evaluate potential options to reduce the compact/fuel rod power-peaking and consider minimizing impact to fuel, block, and core design. Identify core regions in which particles are under maximum stress (fission power).

Task 4: Core Depletion: Perform core depletion calculations on potential initial and transition NGNP core designs to evaluate the burnup dependence on core reactivity and individual fuel rod powerpeaking, as it relates to particle fuel design parameters. Evaluate the effectiveness of the implemented power-peaking mitigation options (optimally-loaded block/core designs), uranium block loading, burnup, and achievable power cycle length. 


\section{NGNP PRISMATIC CORE DESCRIPTION}

This section provides a description of the GT-MHR and NGNP prismatic reactor cores in terms of materials, dimensions, and layout, fuel block, and the TRISO-coated particle fuel.

\subsection{GT-MHR Core}

Currently, the prismatic NGNP core design ${ }^{3}$ is based wholly on the General Atomics GT-MHR core description. ${ }^{4}$ The NGNP design requirements will eventually allow us to differentiate the two reactor core descriptions, but in the mean time the three preliminary NGNP design requirements (600 MW total core power, 18-month power cycle length, and $1000^{\circ} \mathrm{C}$ gas outlet temperature) will provide a preliminary basis for the NGNP core design and the neutronic analysis to support the Fuel Specification herein.

Table 1 gives key core design parameters for the GT-MHR and the NGNP, along with some core dimensional characteristics, ${ }^{3}$

Table 1. Comparison of the GT-MHR and proposed NGNP core characteristics.

\begin{tabular}{|c|c|c|}
\hline & GT-MHR & NGNP \\
\hline Power $(\mathrm{MW}(\mathrm{th})$ & $550-600$ & $600-800$ \\
\hline Average Power Density (W/cc) & 6.5 & 6.5 \\
\hline Inlet Temp $\left({ }^{\circ} \mathrm{C}\right)$ & 488 & 490 \\
\hline Outlet Temp $\left({ }^{\circ} \mathrm{C}\right)$ & 850 & 1,000 \\
\hline Temp Differential $\left({ }^{\circ} \mathrm{C}\right)$ & 362 & 510 \\
\hline Coolant Flow Direction & Downward & Downward \\
\hline Core Geometry & Annular & Annular \\
\hline Inner Reflector Eff. Radius (m) & 1.48 & 1.48 \\
\hline Active Core Eff. Radius (m) & 2.41 & 2.41 \\
\hline Outer Reflector Eff. Radius (m) & 3.33 & 3.33 \\
\hline Number of Fuel Columns & 102 & 102 \\
\hline Number of Fuel Blocks per column & 10 & 10 (600 MWt version) \\
\hline Active Core Volume $\left(\mathrm{m}^{3}\right)$ & 90.767 & 90.767 (600 MWt version) \\
\hline Active Core Height (m) & 7.93 & 7.93 (600 MWt version) \\
\hline Fuel Element Geometry & Fort St. Vrain & Fort St. Vrain \\
\hline Fuel Particle(s) & Fissile and Fertile & Fissile only \\
\hline \multirow[t]{2}{*}{ Enrichment } & 19.9 wt $\%$ U-235 & $10.0 \mathrm{wt} \% \mathrm{U}-235$ (initial core) \\
\hline & $0.711 \mathrm{wt} \% \mathrm{U}-235$ & $14.0 \mathrm{wt} \% \mathrm{U}-235$ (re-load cores) \\
\hline Capacity Factor & $84 \%$ & $>90 \%$ \\
\hline Power Cycle Length & 14-15.7 months & 18 months \\
\hline
\end{tabular}


The NGNP overall core layout is shown in Figure 1 and currently is basically identical to the GT-MHR. The core consists of an inner graphite reflector (hexagonal rings 1-5), an active core (Rings 6, 7, and 8), outer replaceable graphite reflector (Rings 9 and 10), permanent side graphite reflector, and the core barrel $(800 \mathrm{H}$ alloy or Hastalloy-X). The active core is an annular configuration composed of 102 fuel columns. Each fuel column is a stack of fuel blocks ten high (600 MWt version) for a total of 1,020 fuel blocks in the core.

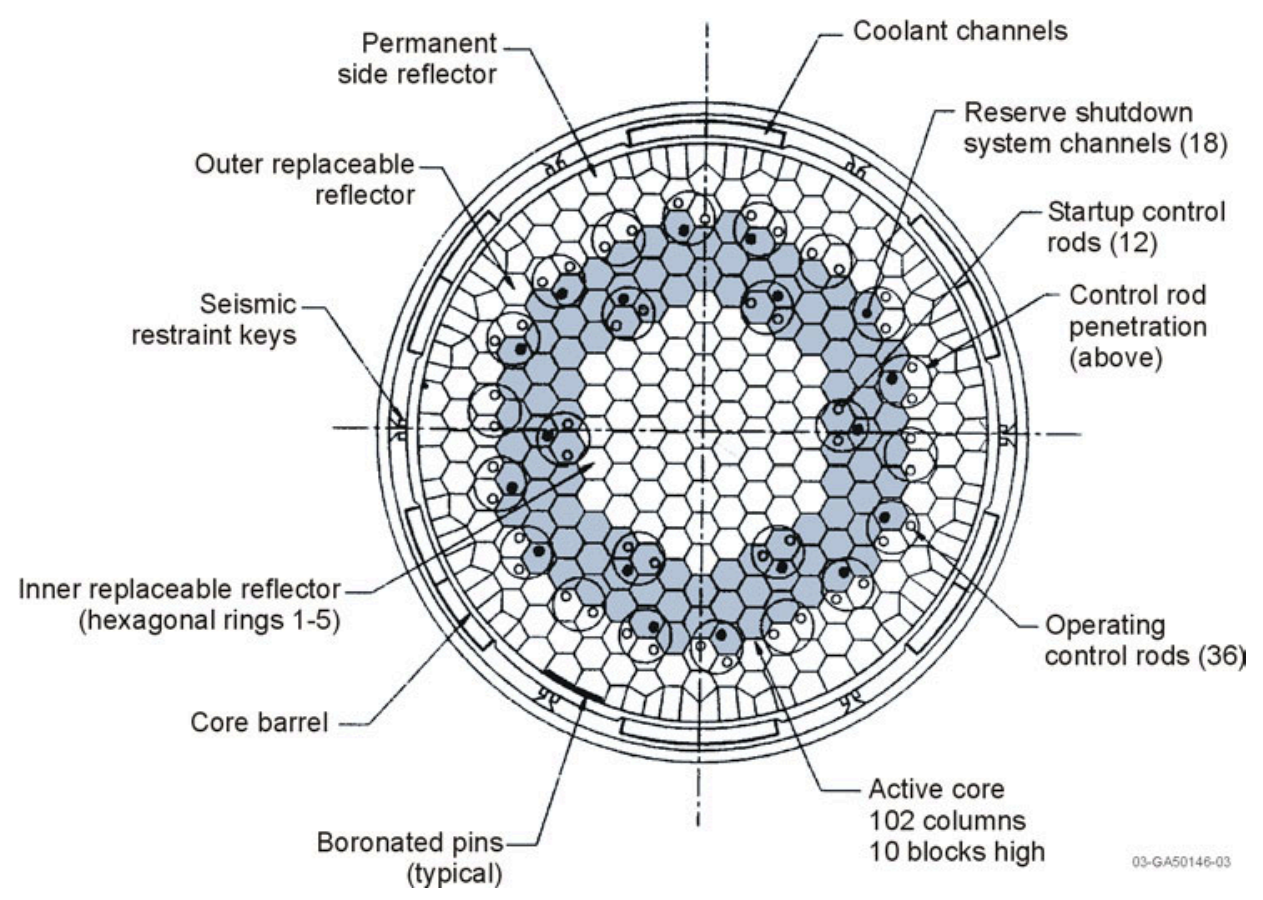

Figure 1. Cross-sectional view of the GT-MHR and NGNP cores.

\subsection{Fuel Block}

The GT-MHR and NGNP fuel element or fuel block is currently based on the old Fort St. Vrain (FSV) fuel block design. Figure 2 shows a picture of a regular or standard FSV fuel block. The GT-MHR active core is actually composed of three different fuel block types: (1) regular or standard, (2) reserve shutdown system (RSS), and (3) control rod. The RSS and control fuel block types are the same as the regular fuel block, with the exception of an additional axial channel for either $\mathrm{B}_{4} \mathrm{C}$ granules or a control rod. The regular fuel block is a hexagonal graphite block with 210 fuel rods (fuel compact radius $0.6225-\mathrm{cm}$ ), 108 coolant channels (0.635-cm radius), dowels, and a handling and tooling hole. The flat-toflat distance is $36-\mathrm{cm}$ with an axial height of $79-\mathrm{cm}$. The fuel rods contain 14- or 15-stacked cylindrical fuel compacts that, in turn, are composed of a mixture of TRISO micro-spheres or fuel particles and a graphite binder matrix. The structural bulk graphite (H451) density of the fuel blocks is $1.74 \mathrm{~g} / \mathrm{cc}$.

Results from the Task 1 parametric sensitivity study below indicate that redesign of the FSV fuel block for NGNP usage is a definite possibility for future neutronic design analyses.

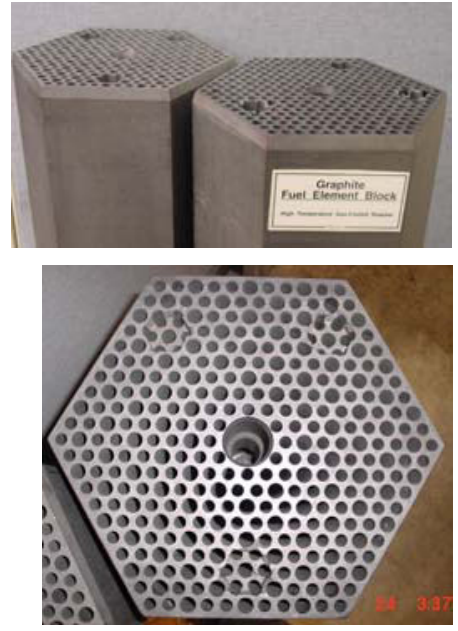

Figure 2. FSV regular fuel element. 


\subsection{Particle Fuel}

TRISO-coated (Tri-isotropic or multi-layered high- and low-density pyrolytic carbon and silicon carbide coatings) particle fuel is the current fuel design for the NGNP. Multi-layered and specially coated uranium oxycarbide (UCO) kernels for the individual micro-spheres or particles are pressed and heated together with a graphite binder into fuel compacts (Figure 3 ) with packing fractions less than $35 \%$. The individual fuel compacts $(0.6225-\mathrm{cm}$ radius, $4.93-\mathrm{cm}$ length) are then stacked in columns (14 or 15 compacts per fuel rod) in the 210 fuel rod holes in the graphite hexagonal fuel blocks.

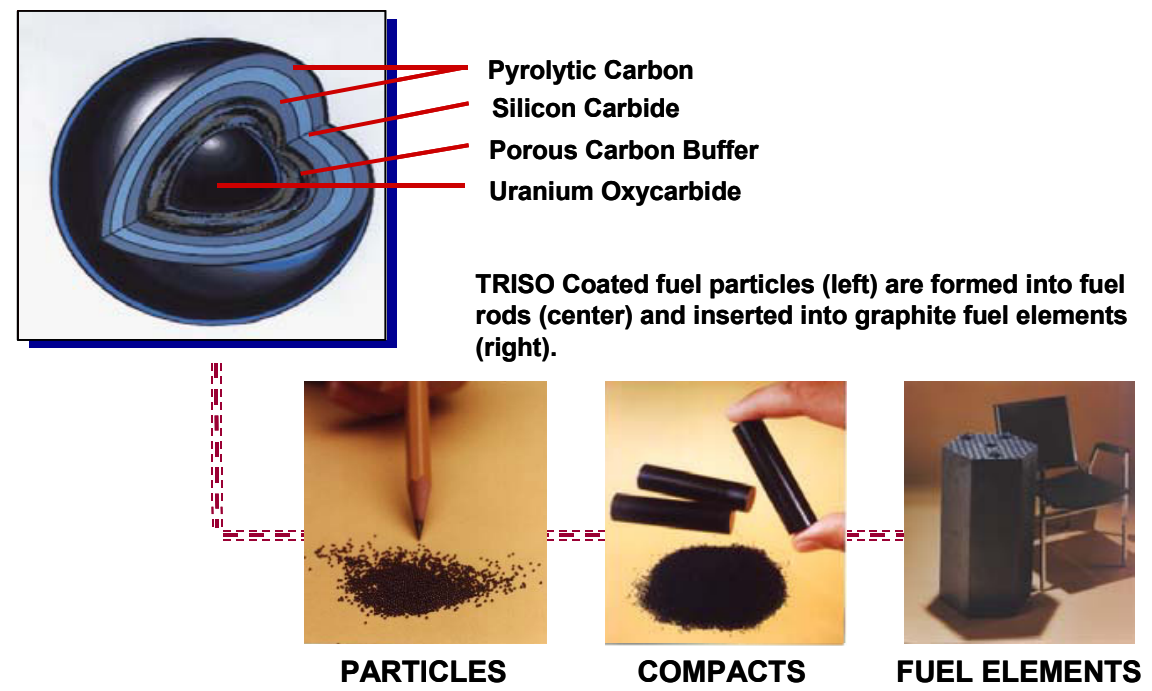

Figure 3. TRISO fuel particle, compacts, and fuel block.

The GT-MHR binary fuel particle system ${ }^{4}$ consists of a fissile particle and a fertile particle with 350- and 500-micron kernel diameters, respectively. The fissile particles have a uranium enrichment of $19.9 \mathrm{wt} \% \mathrm{U}-235$ and the fertile particles have enrichment typical of natural uranium $(0.711 \mathrm{wt} \% \mathrm{U}-235)$. The utility of a two-particle system allows for the mixing of these two particle types to easily achieve a desired effective enrichment. Effective enrichments may prove very useful for grading or zoning fuel rod rows near the reflector/active core interface in order to reduce fuel rod power-peaking and to optimize U235 block loadings.

On the other hand, eliminating the fertile particle and using only a single fissile particle can greatly simplify the particle fabrication and testing requirements to license the fuel. The preliminary analysis herein focuses on just the single particle system with a single kernel size. Fissile particle enrichments are limited to 10 and $14 \mathrm{wt} \%$. Table 2 below lists individual fuel particle characteristics for the 350 -micron fissile particle proposed for use in the GT-MHR and the NGNP and also a 425-micron fissile particle recommended specifically for the NGNP based on results of this study. Relative to the 350-micron particle, the 425-micron particle is assumed to only have a larger diameter, yet preliminarily maintains the same material coatings and coating thicknesses as the 350 -micron particle.

Tables 3, 4, and 5, as examples, give the average and peak expected particle powers as a function of kernel size (350 to 500-microns) for three different fuel block U-235 loadings, 554, 776, and 1,000 g $\mathrm{U}-235$ per block with 10,14, and $14 \mathrm{wt} \%$ enrichment particles, respectively. The peak particle power is based on the product of the maximum power-peaking factor calculated herein (approximately 2.1) and the average particle power based on a core-average block power of $0.588 \mathrm{MWth}$. 
Table 2. Fissile particle characteristics for the 350- and 425-micron kernel diameter particles.

\begin{tabular}{lcccl}
\hline \multicolumn{1}{c}{ Particle Layer } & $\begin{array}{c}\text { K50-micron } \\
\text { KERNEL Radii } \\
\text { (microns) }\end{array}$ & $\begin{array}{c}\text { 425-micron } \\
\text { KERNELRadii } \\
\text { (microns) }\end{array}$ & $\begin{array}{c}\text { Density } \\
(\mathrm{g} / \mathrm{cc})\end{array}$ & Material \\
\hline Fuel Kernel & 175 & 212.5 & 10.50 & $\mathrm{UC}_{0.5} \mathrm{O}_{1.5}$ \\
Buffer & 275 & 312.5 & 1.00 & Graphite \\
Inner isotropic & 310 & 347.5 & 1.90 & Graphite \\
Silicon Carbide & 345 & 382.5 & 3.20 & Silicon Carbide \\
Outer isotropic & 385 & 422.5 & 1.87 & Graphite \\
Particle diameter & 770.0 & 845.0 & & \\
\hline
\end{tabular}

Table 3. Peak particle powers for a $10 \mathrm{wt} \%$ enrichment and a $554 \mathrm{~g} \mathrm{U}-235$ fuel block versus kernel size.

\begin{tabular}{ccccccc}
\hline $\begin{array}{c}\text { Kernel } \\
\text { Size } \\
(\mu \mathrm{m})\end{array}$ & $\begin{array}{c}\text { Enrichment } \\
(\mathrm{wt} \% \mathrm{U}-235)\end{array}$ & $\begin{array}{c}\text { Packing } \\
\text { Fraction } \\
(\%)\end{array}$ & $\begin{array}{c}\text { U-235 } \\
\text { Loading } \\
(\mathrm{g} / \text { block })\end{array}$ & $\begin{array}{c}\text { Average } \\
\text { Compact Power } \\
(\mathrm{W} / \mathrm{cc})\end{array}$ & $\begin{array}{c}\text { Average } \\
\text { Particle Power } \\
(\mathrm{mW} / \text { particle) }\end{array}$ & $\begin{array}{c}\text { Peak } \\
\text { Particle Power } \\
(\mathrm{mW} / \text { particle })\end{array}$ \\
\hline 350 & 10 & 33.5 & 554 & 31.1 & 22.2 & 45.9 \\
375 & 10 & 30.0 & 554 & 31.1 & 27.3 & 56.4 \\
400 & 10 & 27.1 & 554 & 31.1 & 33.2 & 68.6 \\
425 & 10 & 24.715 & 554 & 31.1 & 39.8 & 82.3 \\
450 & 10 & 22.7 & 554 & 31.1 & 47.2 & 97.6 \\
475 & 10 & 21.1 & 554 & 31.1 & 55.4 & 114.5 \\
500 & 10 & 19.6 & 554 & 31.1 & 64.7 & 133.7 \\
\hline
\end{tabular}

Table 4. Peak particle powers for a $14 \mathrm{wt} \%$ enrichment and a $776 \mathrm{~g} \mathrm{U}-235$ fuel block versus kernel size.

\begin{tabular}{ccccccc}
\hline $\begin{array}{c}\text { Kernel } \\
\text { Size } \\
(\mu \mathrm{m})\end{array}$ & $\begin{array}{c}\text { Enrichment } \\
(\mathrm{wt} \% \text { U-235) }\end{array}$ & $\begin{array}{c}\text { Packing } \\
\text { Fraction } \\
(\%)\end{array}$ & $\begin{array}{c}\text { U-235 } \\
\text { Loading } \\
(\mathrm{g} / \mathrm{block})\end{array}$ & $\begin{array}{c}\text { Average } \\
\text { Compact Power } \\
(\mathrm{W} / \mathrm{cc})\end{array}$ & $\begin{array}{c}\text { Average } \\
\text { Particle Power } \\
(\mathrm{mW} / \text { particle) }\end{array}$ & $\begin{array}{c}\text { Peak } \\
\text { Particle Power } \\
(\mathrm{mW} / \text { particle })\end{array}$ \\
\hline 350 & 14 & 33.5 & 776 & 31.1 & 22.2 & 45.9 \\
375 & 14 & 30.0 & 776 & 31.1 & 27.3 & 56.4 \\
400 & 14 & 27.1 & 776 & 31.1 & 33.2 & 68.6 \\
425 & 14 & 24.715 & 776 & 31.1 & 39.8 & 82.3 \\
450 & 14 & 22.7 & 776 & 31.1 & 47.2 & 97.6 \\
475 & 14 & 21.1 & 776 & 31.1 & 55.5 & 114.7 \\
500 & 14 & 19.6 & 776 & 31.1 & 64.7 & 133.7 \\
\hline
\end{tabular}

Table 5. Peak particle powers for a $14 \mathrm{wt} \%$ enrichment and a 1,000 g U-235 fuel block versus kernel size.

\begin{tabular}{ccccccc}
\hline $\begin{array}{c}\text { Kernel } \\
\text { Size } \\
(\mu \mathrm{m})\end{array}$ & $\begin{array}{c}\text { Enrichment } \\
(\mathrm{wt} \% \mathrm{U}-235)\end{array}$ & $\begin{array}{c}\text { Packing } \\
\text { Fraction } \\
(\%)\end{array}$ & $\begin{array}{c}\text { U-235 } \\
\text { Loading } \\
(\mathrm{g} / \mathrm{block})\end{array}$ & $\begin{array}{c}\text { Average } \\
\text { Compact Power } \\
(\mathrm{W} / \mathrm{cc})\end{array}$ & $\begin{array}{c}\text { Average } \\
\text { Particle Power } \\
(\mathrm{mW} / \text { particle) }\end{array}$ & $\begin{array}{c}\text { Peak } \\
\text { Particle Power } \\
(\mathrm{mW} / \text { particle })\end{array}$ \\
\hline 350 & 14 & 43.2 & 1,000 & 31.1 & 17.2 & 35.6 \\
375 & 14 & 38.6 & 1,000 & 31.1 & 21.2 & 43.8 \\
400 & 14 & 35.0 & 1,000 & 31.1 & 25.7 & 53.1 \\
425 & 14 & 31.9 & 1,000 & 31.1 & 30.8 & 63.7 \\
450 & 14 & 29.3 & 1,000 & 31.1 & 36.6 & 75.7 \\
475 & 14 & 27.1 & 1,000 & 31.1 & 43.1 & 89.1 \\
500 & 14 & 25.3 & 1,000 & 31.1 & 50.1 & 103.6 \\
\hline
\end{tabular}


From the estimated peak particle powers listed in Tables 3, 4, and 5, the peak powers are well below the AGR-1 fuel specification limit of less than $400 \mathrm{~mW} /$ particle instantaneous peak power per particle for irradiation testing, and the NGNP goal of less than $250 \mathrm{~mW} /$ particle maximum particle power limit. Also note that the packing fraction for the 425-micron kernel in all three cases is less than $35 \%$. The three block loadings (554, 776, and 1,000 g U235) would correspond approximately to block loadings for the initial core, 2-batch reload, and a 3-batch reload, respectively. 


\section{COMPUTER CODES AND MODELS}

The reactor physics computer codes MCNP4C, ORIGEN2.2, and MOCUP/JMOCUP have been used exclusively to perform all neutronic analyses presented in this section of this report. Each computer code, associated models, and code usage are briefly discussed below.

\subsection{MCNP}

The MCNP (Monte Carlo N-Particle) code ${ }^{7}$ Version 4C (MCNP4C) is a general purpose, continuous energy, generalized geometry, coupled neutron-photon-electron Monte Carlo transport code. The geometry capability allows for very explicit, three-dimensional representations of the reactor core and prismatic block details. With reflective boundary conditions applied to the six sides and on the top and bottom planes of the hexagonal fuel block models, lattice k-infinity values can be calculated. Partialand full-core models can also be developed for core k-effective, control rod worth, and depletion calculations.

MCNP also has a powerful tally capability to calculate neutron fluxes and nuclear reaction rates averaged over any cell volume in a model. This allows the analyst to estimate flux spectral and spatial characteristics, fuel rod fission power, neutron fluence, radionuclide production rates, and neutron cross sections [fission, radiative capture, $(n, 2 n),(n, 3 n),(n, p),(n, d),(n, t)$, and $(n, \alpha)$ ]. The neutron cross sections are used directly in the ORIGEN2.2 depletion calculations via the JMOCUP execution sequence.

The continuous-energy neutron cross sections typically range from $10^{-5}$ to $20 \mathrm{MeV}$. The photon energy range is from $1 \mathrm{keV}$ to $100 \mathrm{MeV}$, and the electron energy is from $1 \mathrm{keV}$ to $1,000 \mathrm{MeV}$. A wide variety of nuclide cross-section and reaction data are available from the Evaluated Nuclear Data Files version 5 and 6, or ENDF/B-V and ENDF/B-VI. In addition, MCNP cross sections at high temperatures have been specially created for application to the NGNP $\left(1000-2200{ }^{\circ} \mathrm{C}\right)$.

Because the MCNP computer code is a Monte Carlo code, the calculated results are reported by the code with an associated statistical uncertainty or relative error. The relative errors translate into onesigma statistical uncertainty values by multiplication of the relative error and the calculated result. Twosigma and three-sigma confidence intervals are obtained by further multiplying the one-sigma values by a factor of two and three, respectively. The confidence levels associated with one-, two-, and three-sigma values are 68.3, 95.4, and 99.7\%, respectively. All statistical error values reported in this study are onesigma values, unless otherwise stated. Error bars on calculated data are often smaller than the plotted symbol and therefore not visible.

A variety of MCNP models have been developed and implemented for specific computational neutronic analyses over the course of this project. These models include the triangular unitcell (Figure 4) and the fully explicit regular fuel block models (Figure 5), used primarily in the parametric sensitivity studies. The unitcell and block models have reflective boundary conditions applied to all external surfaces to create infinite lattice arrays. Full-core models, both 1/12-core (Figure 6) and 1/6-core (Figure 7) azimuthal wedges with single block axial extent and full-core axial extent (10 fuel block height with top and bottom graphite reflectors), have also been developed. The full-core model with single block axial extent had reflective boundaries

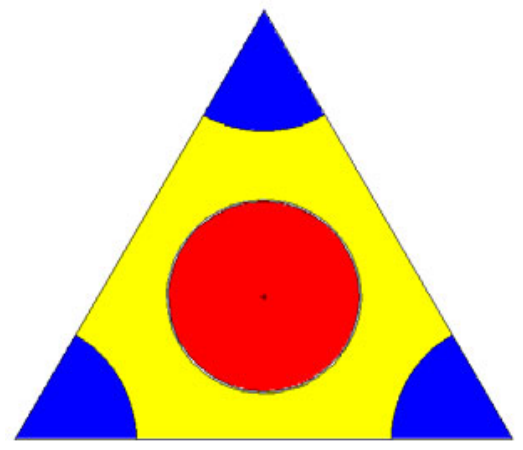

Figure 4. MCNP unitcell model showing homogenized fuel rod (red), graphite (yellow), and helium coolant channels (blue). 


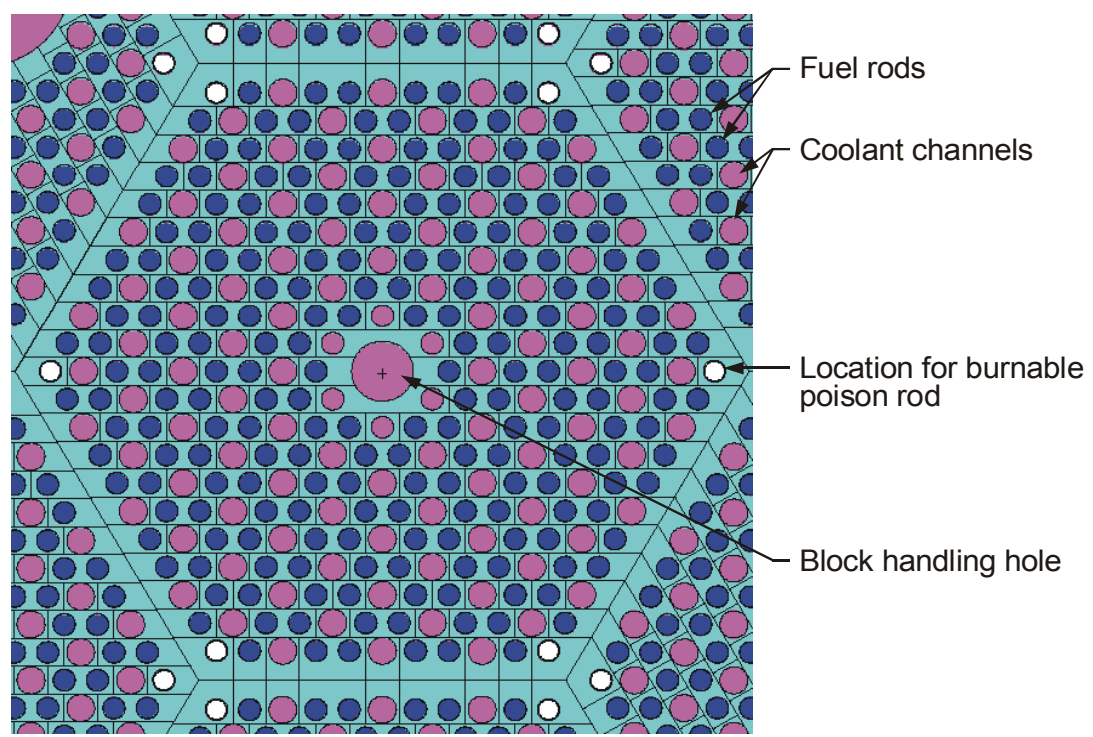

Figure 5. MCNP regular fuel block model.

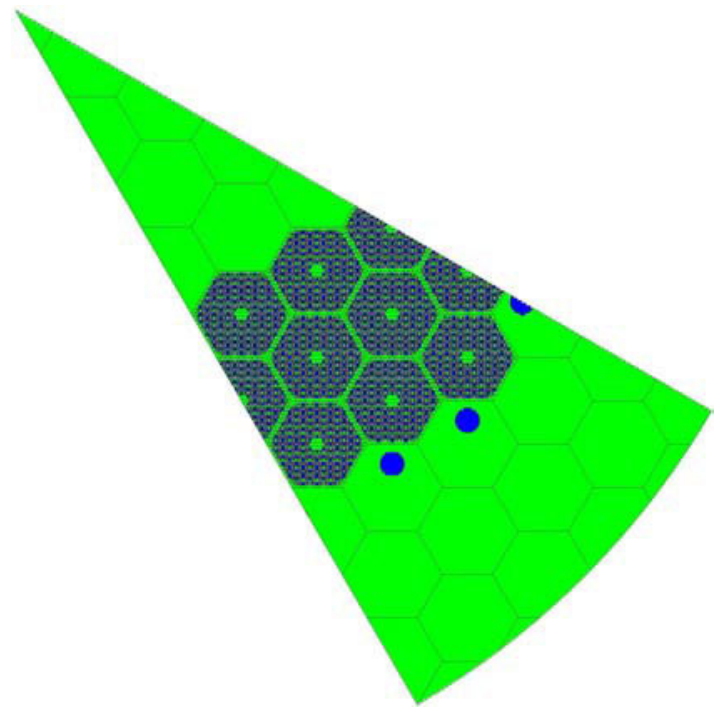

Figure 6. MCNP 1/12-core model.

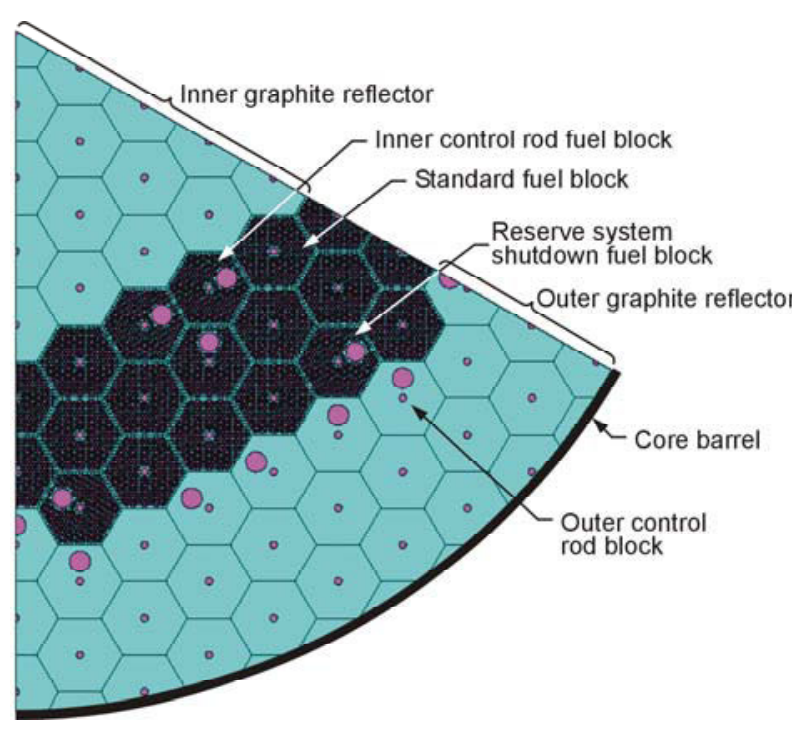

Figure 7. MCNP 1/6-core model.

applied on the radial surfaces and top and bottom planes to create and infinite axial extent core which is a very good representation of the actual GT-MHR and the full-core model with the 10 fuel blocks and top and bottom graphite reflectors. The 1/12-core model is composed of only regular fuel blocks with no RSS or control rod fuel blocks. This was done to simplify power normalizations in the depletion model calculations and to eliminate block difference effects that might mask subtle parametric effects.

Both the single block and full-axial extent (10-block) full-core models predict very similar core keffective values indicative of low axial neutron leakage.

The three-dimensional block and core models include some very specific features, including the fuel-handling hole, tooling hole, dowels, fuel rod gas gaps, and the fuel rod axial end caps. The models 
do not, however, include the beveled edges on the block, nor the gas gaps between the blocks. These features can readily be incorporated in future models.

All MCNP models utilize primarily ENDF-VI cross-section data. Some fission product crosssection data from ENDF-V is also used in the depletion calculations. The fuel rods are assumed, in all cases, to be composed of a homogenized and uniform mixture of particle fuel (microspheres) and graphite binder matrix material, in proportions congruent with the assumed particle enrichment, PF, material densities, and particle dimensions. The fuel temperature is assumed to be at a temperature of $1,000^{\circ} \mathrm{C}$ and the graphite temperature (structural fuel block and inner and outer graphite reflector blocks) $927^{\circ} \mathrm{C}$, unless stated or varied otherwise.

\subsection{ORIGEN2.2}

The ORIGEN2.2 (Oak Ridge Isotope Generation) Version 2.2 code $^{8}$ was used to calculate the complex time-dependent and coupled behavior of both radioactive and stable isotopes under constant power production time profiles. This includes the natural and radioisotope buildup due to production and destruction mechanisms, which include transmutation (radiative capture), fission, threshold particle reactions, and radioactive decay processes. The code mathematical basis uses the matrix exponential method to solve large numbers of coupled ordinary differential equations relating isotopic concentrations with a high degree of accuracy. This code is used here to perform depletion or burnup calculations for NGNP 1/12-core models, in conjunction with the MCNP4C and JMOCUP computer codes.

ORIGEN2.2 input data include specific fuel rod power (MWt), calculated one-group neutron reaction cross sections, and heavy metal loading. For the 1/12-core model depletion calculations, 630 individual fuel rods were simultaneously depleted in three regular fuel blocks, one block in Ring 6, 7, and 8 of the active core.

ORIGEN2.2 will output isotopic concentrations (moles, curies, grams), activities, and decay heats for over 1,700 activation products, actinide and daughter products, and fission product isotopes. Decay and cross-section libraries come with the standard code issue. One of these libraries is the hightemperature gas-cooled reactor cross-section library or the "htgrxslibd" library; this library is used as our base library, which is updated to reflect cross-section changes at each timestep in the burnup calculation.

A special feature in the ORIGEN2.2 code allows the analyst to update or modify the standard cross-section library with user-calculated cross sections, thereby allowing a depletion calculation to be reactor specific. ORIGEN2.2 performs a depletion calculation using effective one-group cross sections calculated, in our case, with MCNP calculated tally data. The ORIGEN2.2 models were developed in standard format.

\subsection{MOCUP/JMOCUP}

The MOCUP (MCNP-ORRIGEN2 $\underline{\text { Coupled }}$ Utility Program) code $^{9}$ is a system of external processors that links input and output files from the MCNP and ORIGEN2 codes in order to perform a time-dependent burnup or depletion calculation. MOCUP is composed of three processing modules, namely mcnpPRO, origenPRO, and compPRO. Each module performs a specific, sequential task during each burnup iteration. No modifications are required to the MCNP or ORIGEN2 codes in order to run the MOCUP code system.

The MOCUP code system performs a multitude of data manipulations, but only two main functions. These two functions include: (1) read MCNP flux and reaction rate output data, convert these 
data to one-group cross sections, and load them into the ORIGEN2 input file so they can update cross sections in the base library, and (2) read the ORIGEN2 isotopic concentration output punch file and create a new MCNP fuel composition. The new MCNP composition reflects the changes in heavy metal and fission product isotopic depletion or buildup as the result of burnup during the time step.

\subsection{JMOCUP}

The JMOCUP code (Jim's MCNP-ORRIGEN2 Coupled Utility Program) code is functionally similar to the MOCUP code. The author is J.W. Sterbentz (Jim). The primary code difference between JMOCUP and MOCUP is that JMOCUP is written in FORTRAN 77 and consists of two external processors, and MOCUP is written in the C-language and consists of three external processors. In addition, JMOCUP can read the fission power tallies from the MCNP output for each fuel rod and calculate a core or block power-normalization factor to appropriately adjust individual fuel rod powers, and then insert these individual fuel rod powers into the appropriate fuel rod ORIGEN2.2 input file. Also, the JMOCUP system utilizes a set of scripts to run on the supercomputer cluster in order to reduce the computational runtime by using multiple CPUs running in parallel (pvm), which greatly accelerates the MCNP execution and the depletion calculations, overall.

JMOCUP has been written, tested, debugged, and executed in order to perform the necessary depletion calculations and help answer the Fuel Specification questions.

The JMOCUP depletion models currently include fuel rod cross-section updates for 16 individual fission products, 6 actinides, and 1 burnable poison. A fission product study involving depletion of a single unitcell was performed in order to determine a minimum number of fission products required for an accurate depletion calculation. A reduced set of 16 fission product isotopes was evaluated against a more complete set of 78 fission products and found to be adequate. The reduced set can account for greater than $91 \%$ of the total negative fission product inventory reactivity, and together with the six major actinides, accounted for $98.8 \%$ of the total negative reactivity. Selection of the 16 fission products was based on the middle-of-cycle fission product concentrations and radiative capture cross sections. The reduced fission product inventory was initially selected in order to reduce what was expected to be excessive computer time to run the depletion calculations with 630 fuel rods. However, each depletion calculation was only approximately 1.5 days with 6 CPUs. Future depletion calculations should be able to expand the number of fission products, actinides, and burnable poison without much problem.

The fission product and actinide cross sections are updated at desired burnup increments or time steps over the depletion or power cycle. Updated cross sections include $(n, \gamma),(n, 2 n),(n, \alpha)$, and $(n, p)$ for the fission products, $(n, \gamma),(n, 2 n),(n, 3 n)$, and $(n, f)$ for the actinides, and $(n, \alpha)$ for the B-10 burnable poison. These updated cross sections are then loaded into the ORIGEN2.2 model for the next burnup increment. 


\section{NEUTRONIC RESULTS}

The neutronic analyses focused on answering the critical questions mentioned above, questions of strong interest to the fuel development group, and those planning future TRISO particle fuel irradiation tests. Is a single fissile particle sufficient for the NGNP? What UCO kernel size or kernel size range is required to meet NGNP U-235 block loadings and burnups? Where in the NGNP core do particles experience maximum fission power exposure and what is the time-dependence and corresponding powerpeaking factors?

To answer these questions, the INL neutronic work was subdivided into four major task areas:

Task 5.1, Parametric Sensitivity Studies

Task 5.2, Double Heterogeneity Effects

Task 5.3, Power-peaking Mitigation

Task 5.4, Core Depletion.

Calculated results for each of these tasks are discussed below.

\subsection{Parametric Sensitivity Studies (Task 1)}

The goal of the parametric sensitivity studies was to identify the important fuel design parameters and evaluate their sensitivity and impact on the NGNP reactor core design, specifically, uranium block loading and core reactivity. The following four fuel particle variables and range were considered in the parametric studies:

1. Kernel size: $\quad 300-500$ micron diameter

2. Packing fraction: $20-50 \%$

3. Enrichment: $6-20 \mathrm{wt} \% \mathrm{U} 235$

4. Kernel density: $10-11 \mathrm{~g} / \mathrm{cc}$

These variables along with the fuel rod radius, carbon-to-uranium atom ratio $(\mathrm{C}: \mathrm{U})$, fuel temperature, and graphite bulk density were also considered to a limited extent in the sensitivity studies.

In addition, extensive parametric studies were performed to optimize the NGNP core to reduce radial power-peaking. These sensitivity studies are only listed at the end of this section, with selected results presented in Section 5.3 outlining the progressive development of the final "optimally-loaded" radial core (minimal power-peaking) used in the core depletion studies.

\subsubsection{Block Uranium Loading}

Figures 8-11 show the U-235 uranium block loading for a single regular NGNP fuel block as a function of uranium enrichment, packing fraction, kernel size, and kernel density. In these figures, the base case assumes a 350-micron kernel diameter, $10.36 \mathrm{wt} \% \mathrm{U}-235$ enrichment, and $10.5 \mathrm{~g} / \mathrm{cc} \mathrm{UCO}$ density. 


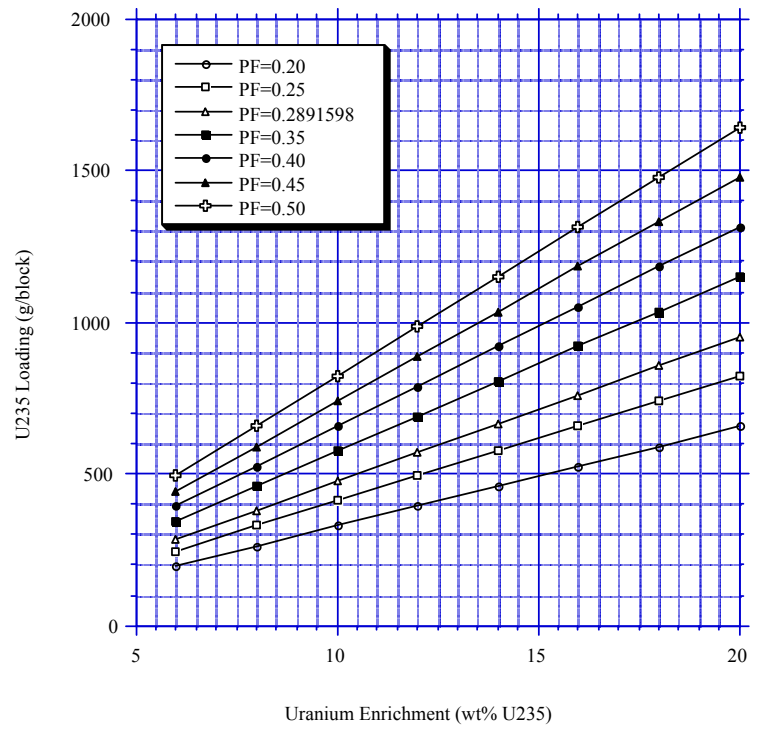

Figure 8. Uranium (U-235) loading versus uranium enrichment and packing fraction for a single GT MHR fuel block.

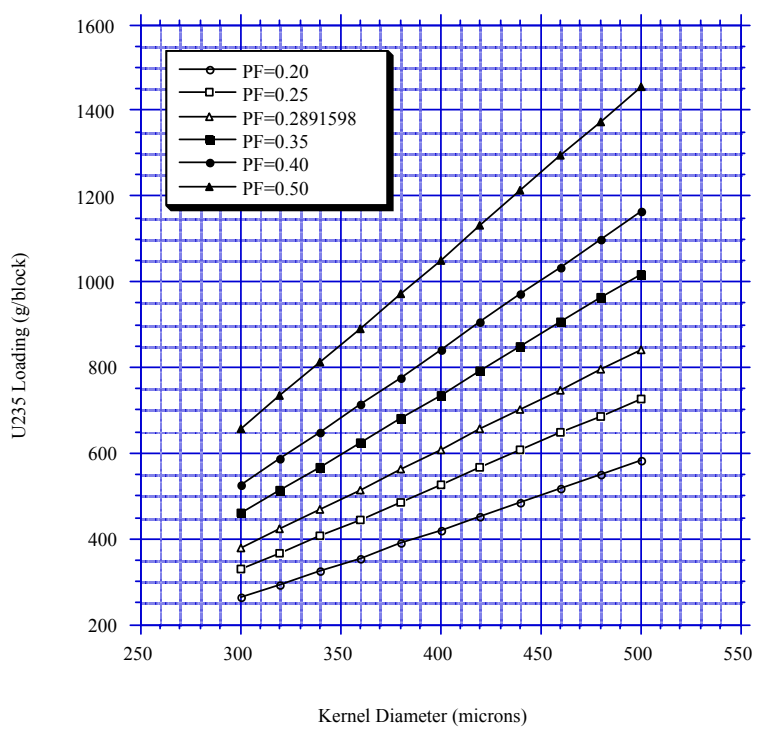

Figure 10. Uranium (U-235) loading versus UCO kernel diameter and packing fraction for a single GT MHR fuel block.

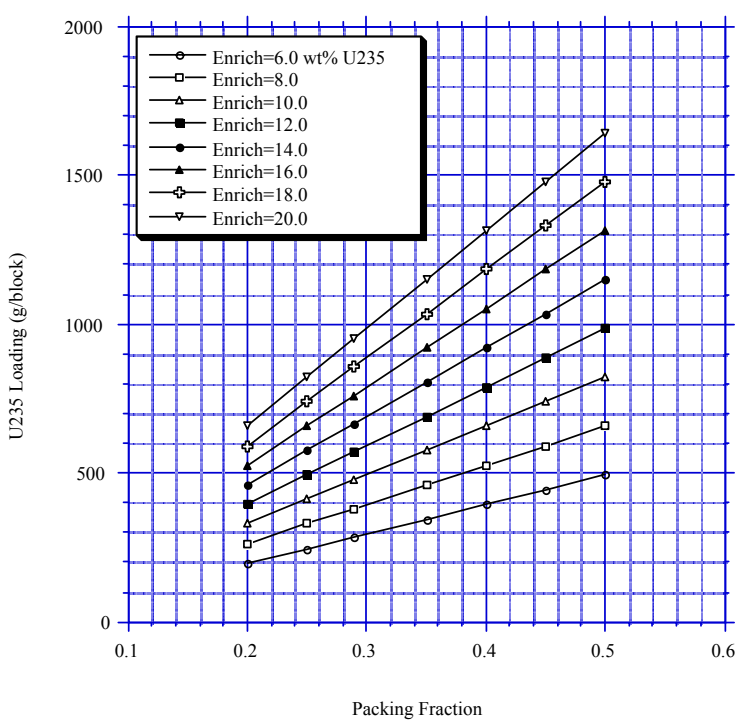

Figure 9. Uranium (U-235) loading versus packing fraction and uranium enrichment for a single GT MHR fuel block.

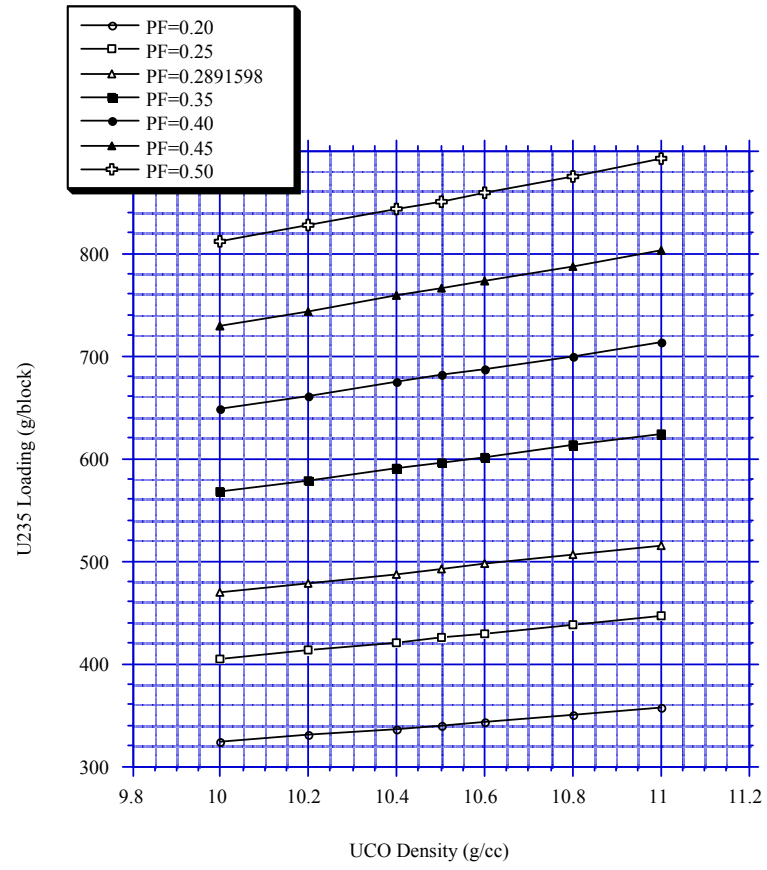

Figure 11. Uranium (U-235) loading versus UCO kernel density and packing fraction for a single GT MHR fuel block. 
From these figures, it is apparent that the three variables, enrichment, packing fraction, and kernel diameter have the greatest impact on fuel block uranium loading over the assumed ranges. Also, an increase in one of these three variables would permit reductions in the other two. For example, since the packing fraction is limited to $\leq 35 \%$ and lower enrichments are most desirable, this would naturally drive the fuel kernel size to a larger diameter. We have, therefore, proposed an increase in the kernel diameter from 350- to 425-microns as an attractive means to achieve higher U-235 mass loadings in the fuel blocks, and simultaneously allow for a wider design envelope for the particle fuel, fuel blocks, and reactor core designs.

\subsubsection{Core Reactivity}

The following five figures are selected examples of core reactivity (actually infinite lattice or core eigenvalues) versus fuel rod radius, enrichment, packing fraction, kernel size, temperature, and graphite density. The fuel rod radius variable clearly demonstrates the importance of the C:U atom ratio and the non-optimal and under-moderated condition of the current FSV fuel block for NGNP applications.

Figure 12 shows an example of the unitcell eigenvalue (k-infinity) as a function of the fuel rod radius for a range of packing fractions and a fixed $10.36 \mathrm{wt} \%$ enrichment. The fuel rod radius for the reference NGNP prismatic fuel block is 0.6225 $\mathrm{cm}$. It is apparent that lattice reactivity is very sensitive to changes in fuel rod radius. This is the result of the carbon-touranium $(\mathrm{C}: \mathrm{U})$ atom ratio. As the fuel rod radius becomes smaller, the $\mathrm{C}: \mathrm{U}$ ratio increases and makes the lattice less undermoderated. At the peak reactivity, the optimal $\mathrm{C}: \mathrm{U}$ ratio ranges from approximately 1,300 to 1,500 . Reduction of the fuel rod radius is a possible mechanism to increase the core reactivity and optimize the NGNP fuel block for higher burnups. Small changes can produce relatively large increases in reactivity. The down side of decreasing the fuel

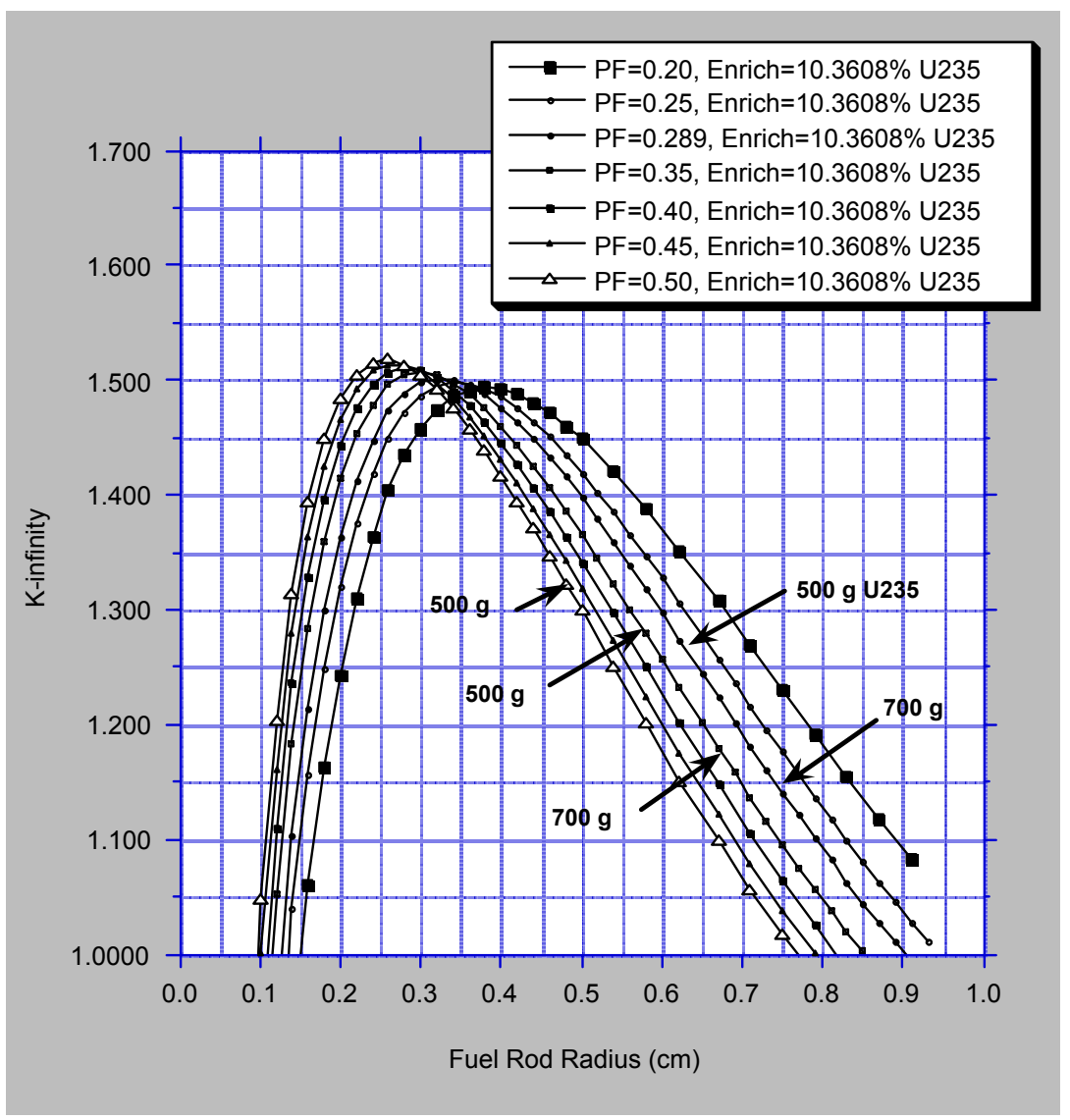

Figure 12. Unitcell lattice k-infinity versus variations in the fuel rod radius and fuel particle packing fraction for a fixed uranium enrichment of $10.36 \mathrm{wt} \% \mathrm{U}-235$. rod radius is a reduction in uranium block loading. However, small increases in kernel size, packing fraction, and/or enrichment can be used to compensate and bolster the uranium block loading.

Figure 13 shows the unitcell eigenvalue (k-infinity) as a function of the fuel rod radius for three different fuel kernel diameters. The uranium enrichment is again fixed at $10.36 \mathrm{wt} \%$ enrichment. For a 
fixed fuel rod radius, increasing the kernel diameter decreases core reactivity, but increases fuel block U-235 loading, an effect similar to simply increasing the packing fraction (see Figure 14). The reactivity can be regained by decreasing the fuel rod radius. For a fixed uranium block loading to meet a given burnup requirement, (for example, $500 \mathrm{~g} \mathrm{U}-235$ per block), changing the kernel size from 350-microns to 500-microns, and changing the fuel rod radius from $0.6225-\mathrm{cm}$ to approximately $0.45-\mathrm{cm}$ - the $500 \mathrm{~g} \mathrm{U}-235$ per block can be maintained and yet increase the overall lattice reactivity by a significant $0.075 \Delta \mathrm{k}$. Figure 14 shows the infinite lattice eigenvalue as a function of fuel particle enrichment and particle packing fraction. The reactivity increases with enrichment, but decreases with increasing packing fraction.

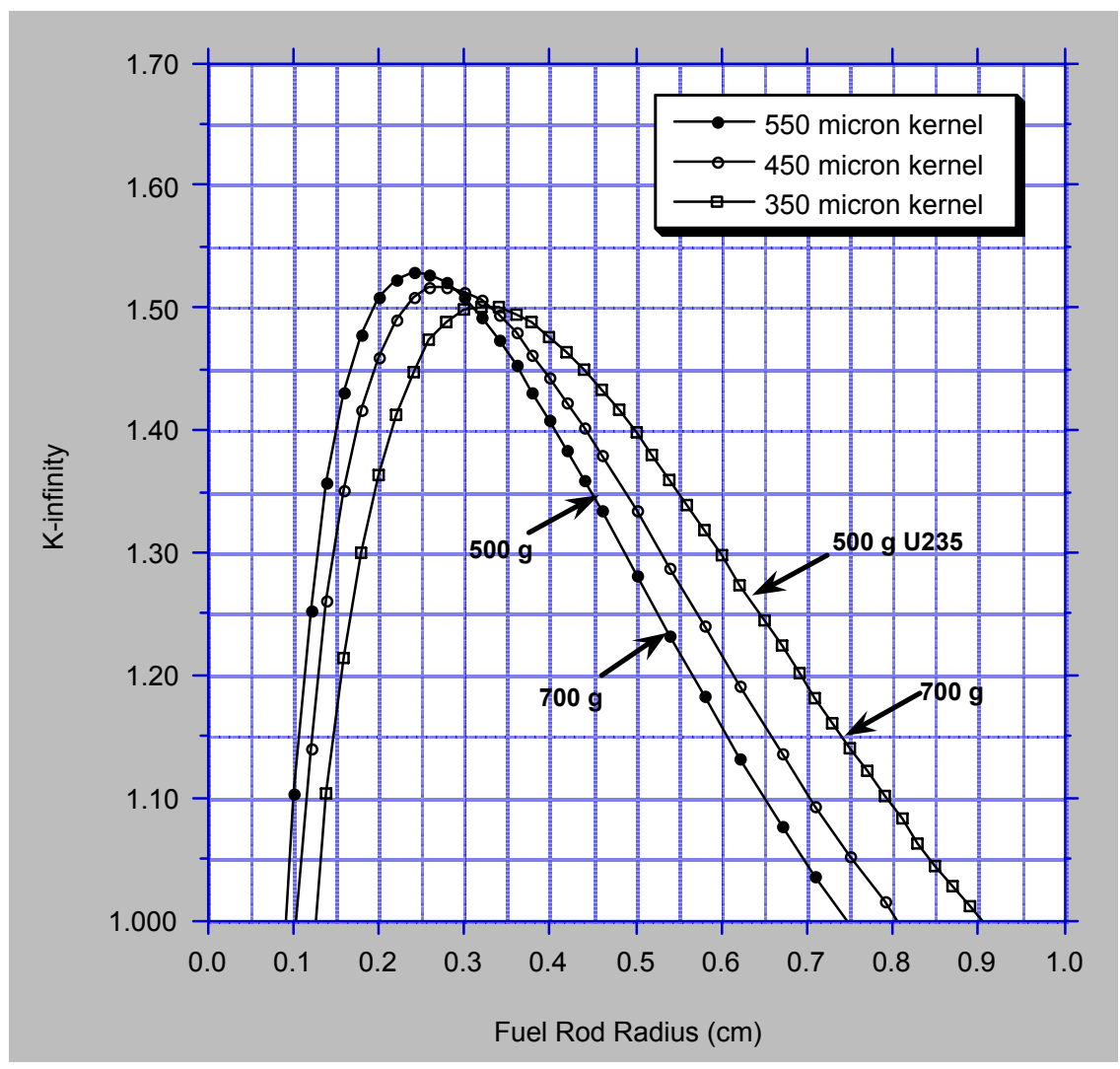

Figure 13. Unitcell lattice k-infinity versus variations in the fuel rod radius and fuel kernel diameter for a fixed uranium enrichment of $10.36 \mathrm{wt} \% \mathrm{U}-235$.

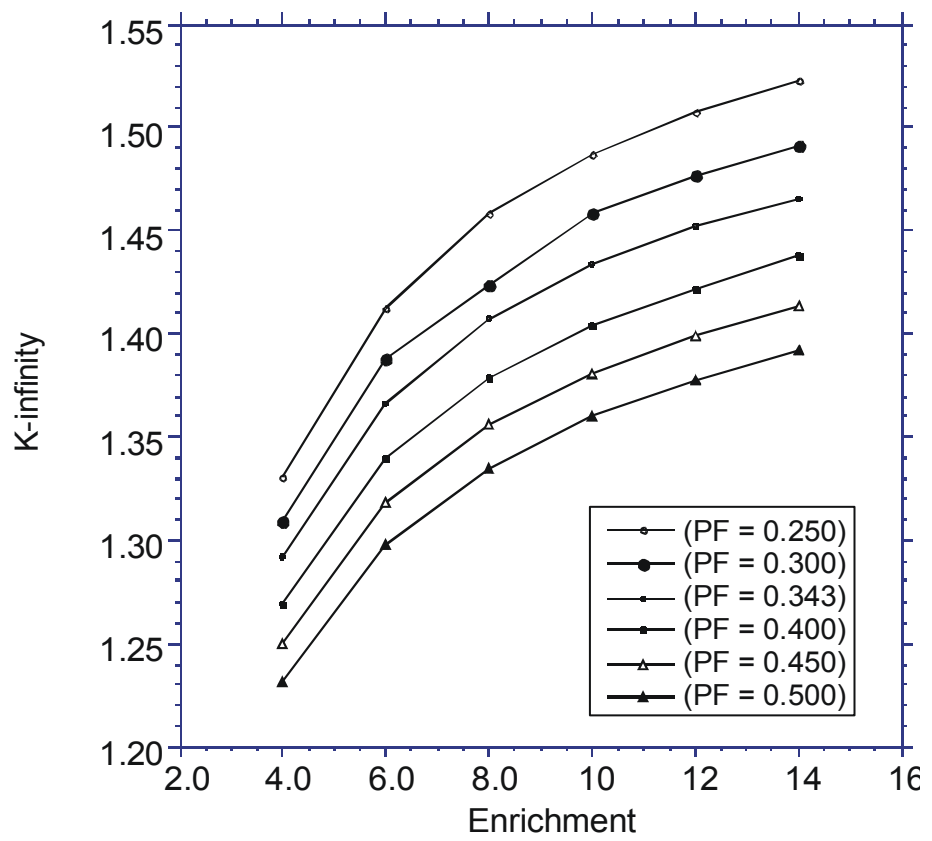

Figure 14. Fuel block lattice k-infinity versus fuel particle enrichment and packing fraction. 
Figure 15 shows the core k-effective eigenvalue as a function of fuel temperature. The reactivity decreases rapidly with increasing fuel temperature and gives the NGNP a negative Doppler temperature coefficient of reactivity.

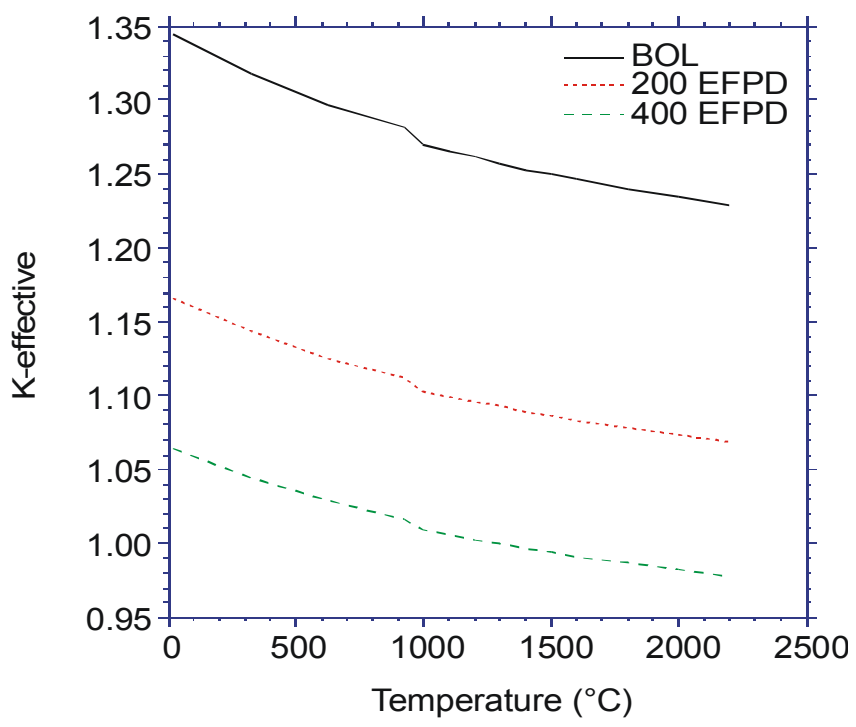

Figure 15. Core k-effective versus fuel temperature and burnup.

The last sensitivity study here varied the structural graphite density of the fuel block. Figure 16 shows the infinite lattice k-infinity as a function of graphite density. As the density is increased over the range of 1.64 to $1.84 \mathrm{~g} / \mathrm{cc}$, the lattice reactivity slowly increases as expected, since the C:U also increases. Currently, the graphite density used in the neutronic calculations uses a density of $1.74 \mathrm{~g} / \mathrm{cc}$.

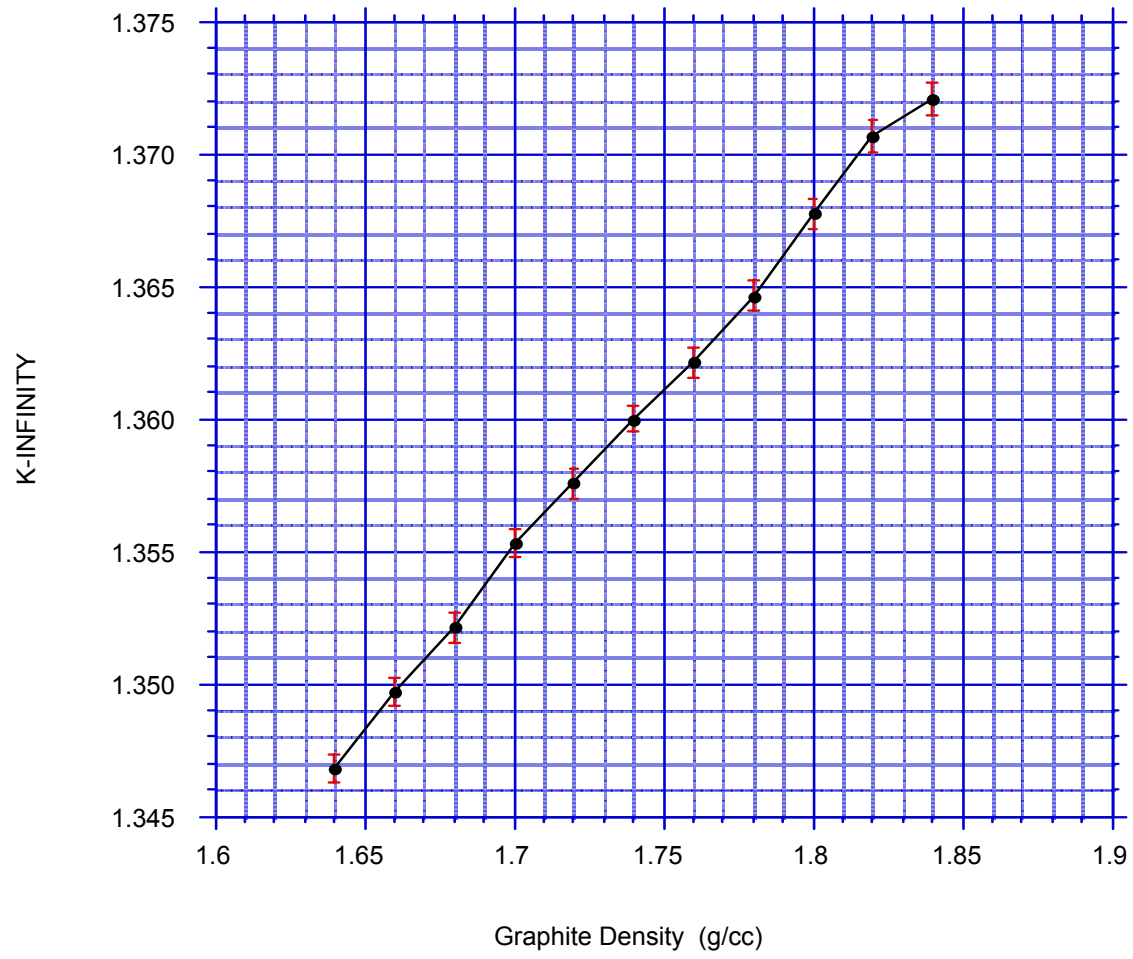

Figure 16. Infinite lattice k-infinity as a function of graphite density. 
The parametric study examples above are just a fraction of the total parametric studies actually performed, but the selected studies are intended to give the reader a feel for the parameter sensitivity to block loading and core reactivity. Table 6 summarizes the reactivity and block loading effect due to an increase or decrease in a particular variable.

Table 6. Reactivity and loading summary table for fuel design variables.

\begin{tabular}{llcc}
\hline \multicolumn{1}{c}{ Variable } & Change & Reactivity Effect & U-235 Loading Effect \\
\hline Fuel Rod Diameter & decrease & $\mathrm{k} \uparrow$ & $\mathrm{U}-235 \downarrow$ \\
Enrichment & increase & $\mathrm{k} \downarrow$ & $\mathrm{U}-235 \uparrow$ \\
& decrease & $\mathrm{k} \downarrow$ & $\mathrm{U}-235 \downarrow$ \\
PF & increase & $\mathrm{k} \uparrow$ & $\mathrm{U}-235 \uparrow$ \\
& decrease & $\mathrm{k} \uparrow$ & $\mathrm{U}-235 \downarrow$ \\
Temperature & increase & $\mathrm{k} \downarrow$ & $\mathrm{U}-235 \uparrow$ \\
& lower & $\mathrm{k} \uparrow$ & $\mathrm{U}-235 \downarrow$ \\
B-10 & higher & $\mathrm{k} \downarrow$ & $\mathrm{U}-235 \uparrow$ \\
& lower & $\mathrm{k} \uparrow$ & $\mathrm{U}-235 \downarrow$ \\
Kernel Diameter & higher & $\mathrm{k} \downarrow$ & $\mathrm{U}-235 \uparrow$ \\
& decrease & $\mathrm{k} \uparrow \mathrm{a}, \mathrm{k} \downarrow \downarrow$ & $\mathrm{U}-235 \downarrow$ \\
Kernel Density & increase & $\mathrm{k} \downarrow \mathrm{a}, \mathrm{k} \uparrow \mathrm{b}$ & $\mathrm{U}-235 \uparrow$ \\
a. PF constant and U loading change. & increase & $\mathrm{k} \uparrow$ & $\mathrm{U}-235 \downarrow$ \\
b. PF varies \& U loading constant. & & $\mathrm{k} \downarrow$ & $\mathrm{U}-235 \uparrow$ \\
\hline
\end{tabular}

It can be concluded from these parametric studies that there are definite advantages to be gained by choosing a kernel size greater than 350-micron. The larger kernel would ease the packing-fraction limitation and facilitate increased uranium block loadings ( $>500 \mathrm{~g} \mathrm{U}-235$ per block, for example 700 $1,000 \mathrm{~g} \mathrm{U}-235$ per block) necessary for 2- or 3-batch reloads. Also, a larger kernel size would, as mentioned, reduce compact packing fractions and the potential for kernel-to-kernel contact and damage to individual kernels during fabrication. In addition, if the fuel rod radius were to be reduced in diameter to increase the C:U ratio and overall core reactivity, the larger kernel particle would be very desirable. The parametric sensitivity studies here provided the impetus to increase the fuel particle kernel size. Although the larger 425-micron particle was used in the subsequent neutronic analyses, an optimal particle size may be somewhere in the 375-475 micron range, depending to some degree on the actual particle enrichment chosen and the final NGNP requirements.

It is clear, too, that a single fissile particle can easily meet the reactivity and U-235 loading requirements. These preliminary calculations also suggest, as will be demonstrated in Section 5.4 (Core Depletion), that the burnup or power cycle requirements can also be met using a single fissile particle system.

\subsubsection{Additional Parametric Studies}

Additional parametric studies have also been performed, but with the larger 425-micron diameter kernel size. These parametric studies focused on optimizing the FSV fuel blocks in the core by minimizing fuel rod power-peaking as a function of fuel rod enrichment, packing fraction, and U-235 block loading. These studies formed the basis for Section 5.3 (Power-peaking Mitigation-Task 3) and the 
results provided the beginning-of-life (BOL) optimal fuel block loadings for Section 5.4 Core Depletion. A list and short synopsis of each study is given below:

1. Uniform core U-235 block loadings as a function of enrichment (packing fraction varied). Block loadings were fixed at 500, 700, and $900 \mathrm{~g} \mathrm{U}-235$ in order to meet power cycle lengths and 1-, 2-, and 3-batch reloads. The enrichment varied from 8, 10, 12, 14, and $16 \mathrm{wt} \%$ U235. Power-peaking was not a strong function of enrichment, but increased just slightly with decreasing enrichment. The block loading was, however, a strong function of the maximum power-peaking, for example, $1.70,1.90$, and 2.10 for 500, 700, $900 \mathrm{~g} \mathrm{U}-235$ loaded blocks, respectively.

2. Uniform core block loading of $554 \mathrm{~g} \mathrm{U}-235 \mathrm{with} 10 \mathrm{wt} \%$ enrichment, and enrichment variation in fuel rods in rows 1-4 in the fuel blocks adjacent to the inner reflector/core interface. Row 1-4 enrichments were varied from $2,4,6,8$, and $10 \mathrm{wt} \% \mathrm{U} 235$. The goal was to reduce the maximum power-peaking factor. The enrichment of $8 \mathrm{wt} \%$ dropped the peaking factor from 1.75 down to 1.47 .

3. Same as (2), but the optimal enrichment was iteratively determined. The optimal enrichment for Rows 1-4 was approximately $7.9 \mathrm{wt} \%$ U235.

4. Uniform core block loading of $554 \mathrm{~g} \mathrm{U}-235$ and a $10 \mathrm{wt} \%$ enrichment, and packing fraction variation in fuel rods in rows 1-4 in the fuel blocks adjacent to the inner reflector/core interface. Row $1-4$ packing fractions were varied from $0.12,0.14,0.16,0.18,0.20,0.22$, and 0.24715 . The goal again was to reduce the maximum power-peaking factor. The packing fraction of $0.18-0.20$ dropped the peaking factor from 1.75 down to 1.49 .

5. Same as (4), but the optimal packing fraction was iteratively determined. The optimal packing fraction was approximately 0.195 in Rows $1-4$.

6. Uranium loading variations in fuel blocks in Rings 6 and 8, which included two enrichments (10 and 14\%), with Ring 7 blocks fixed with a $14 \%$ enrichment.

7. Use of discrete rod burnable poison (BP) rods in the core fuel blocks. Determination of the number of poison rods, poison rod location, and poison rod loading to reduce fuel rod peaking-power and suppress BOL core excess reactivity. Use of boron- 10 burnable poison in the form of $\mathrm{B}_{4} \mathrm{C}$ particles. Focused in on fuel blocks in Rings 6 and 8 (three discrete BP rods per block). Goal was to determine the BP gram loadings to achieve BOL k-infinity $=1.05$ for 500, 700, $900 \mathrm{~g} \mathrm{U}-235$ block loadings uniform over the core.

8. Similar to (7) but focused on a $10 \mathrm{wt} \%, 554 \mathrm{~g} \mathrm{U}-235$ uniform loaded core with BPs (initial core).

9. Two-batch reload core configuration with Ring 7 at $14 \%$ and $776 \mathrm{~g} \mathrm{U}-235$ per block, and Rings 6 and 8 at 10 and/or 14\% and $554 \mathrm{~g} \mathrm{U}-235$ per block, all rings with/without BPs - again to look at the effect of loading on power peaking.

10. Extensive and detailed optimization study to maximize reduction in the power peaking factors for the initial core at $10 \mathrm{wt} \%$ enrichment and $554 \mathrm{~g} \mathrm{U}-235$ per block. This study resulted in optimizing the BP loading and fuel block/ring packing fraction zoning. The final case proved to substantially reduce the radial power peaking factor to $<1.15$.

Selected results from these studies will be presented in Sections 5.3 Power-Peaking Mitigation.

Finally, burnable poison parametric studies were performed that included poisons other boron-10, namely, erbium (Er), gadolinium (Gd), hafnium (Hf), samarium (Sm), and europium (Eu). Figure 17 shows the absolute and relative mass amounts of these five burnable poisons relative to boron that would be required to suppress BOL core reactivity down to an eigenvalue of 1.05 , under the assumption of poison loaded into those poison rods shown in Figure 17. 


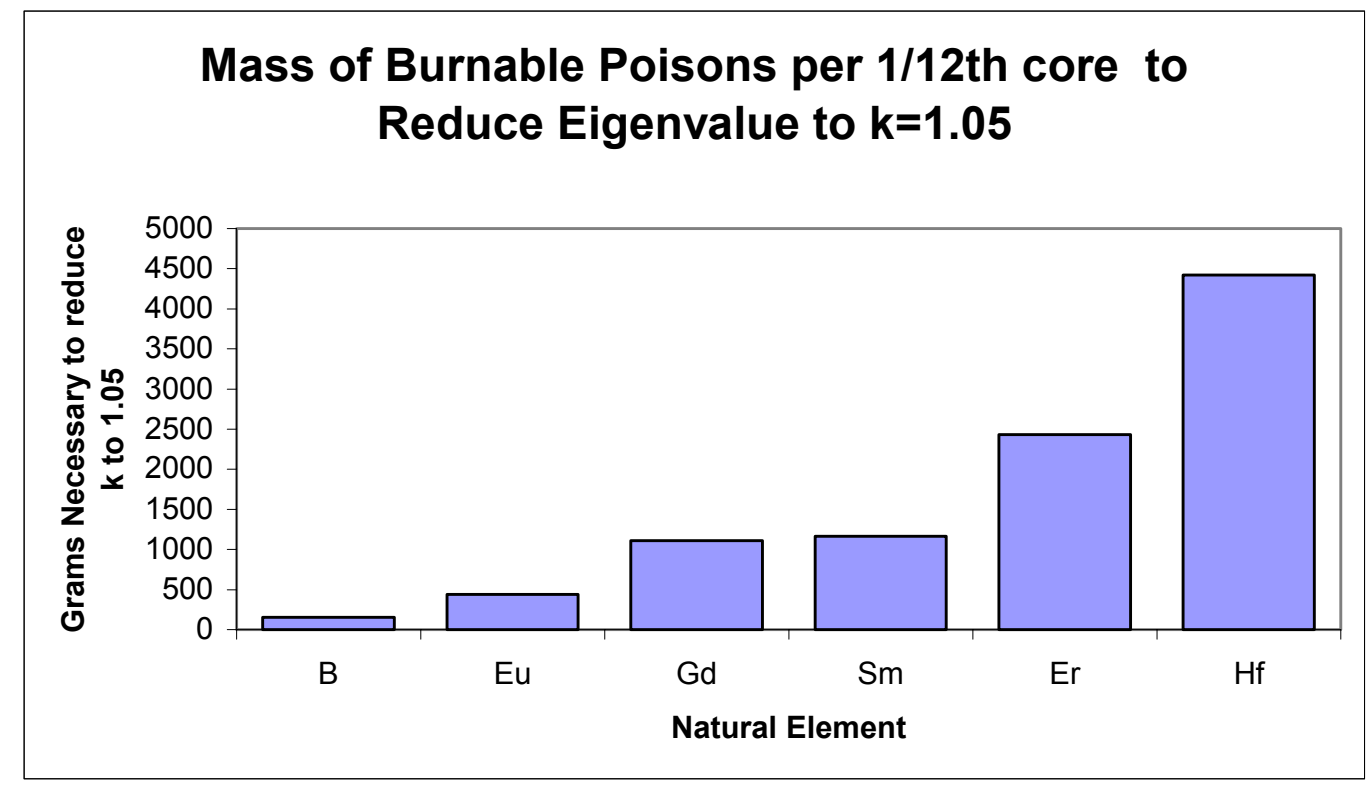

Figure 17. Relative and absolute mass quantities of six different burnable poisons excess core reactivity holddown and power-peaking suppression. Poisons are standard oxide and carbide forms in the discrete burnable poison rod locations.

\subsection{Double Heterogeneity Effects (Task 2)}

The double heterogeneity work was designed specifically to estimate individual particle powerpeaking factors in those fuel rods at the core/reflector interface where power-peaking and thermal flux gradients have been identified to be the greatest in the NGNP active core regions.

The double heterogeneity work is divided into two complementary tasks: (1) use of the 1/12-core model with explicitly modeled fuel micro-spheres in a single fuel compact at the inner reflector/core interface, in order to calculate fission power gradients across the fuel compact, and estimate individual particle peak-to-average values, and (2) use of a unitcell model with explicitly modeled fuel microspheres in the fuel rod to estimate individual particle peaking factors as a function of fuel rod radius and burnup (BOL and $118 \mathrm{GWD} / \mathrm{MTU}$ ).

\subsubsection{One-Twelve Core Modeling}

The use of an MCNP 1/12-core model with explicitly modeled fuel micro-spheres in a single fuel compact at the inner reflector/core interface will accurately capture the neutron spectra and spatial characteristics necessary to calculate the true fission power-peaking in the individual fuel particles. Although the fuel particles in an actual fuel compact would be randomly dispersed in the compact, a regular rectangular array of fuel spheres was chosen and modeled in order to more easily visualize and calculate any gradients across the compact. Figure 18 shows the 1/12-core model and the single fuel rod with explicitly modeled fuel particles located at the inner graphite reflector/core interface. This particular rod location is in the maximum power-peaking and thermal flux gradient location for the NGNP core with a BOL uniform enrichment and loading. 


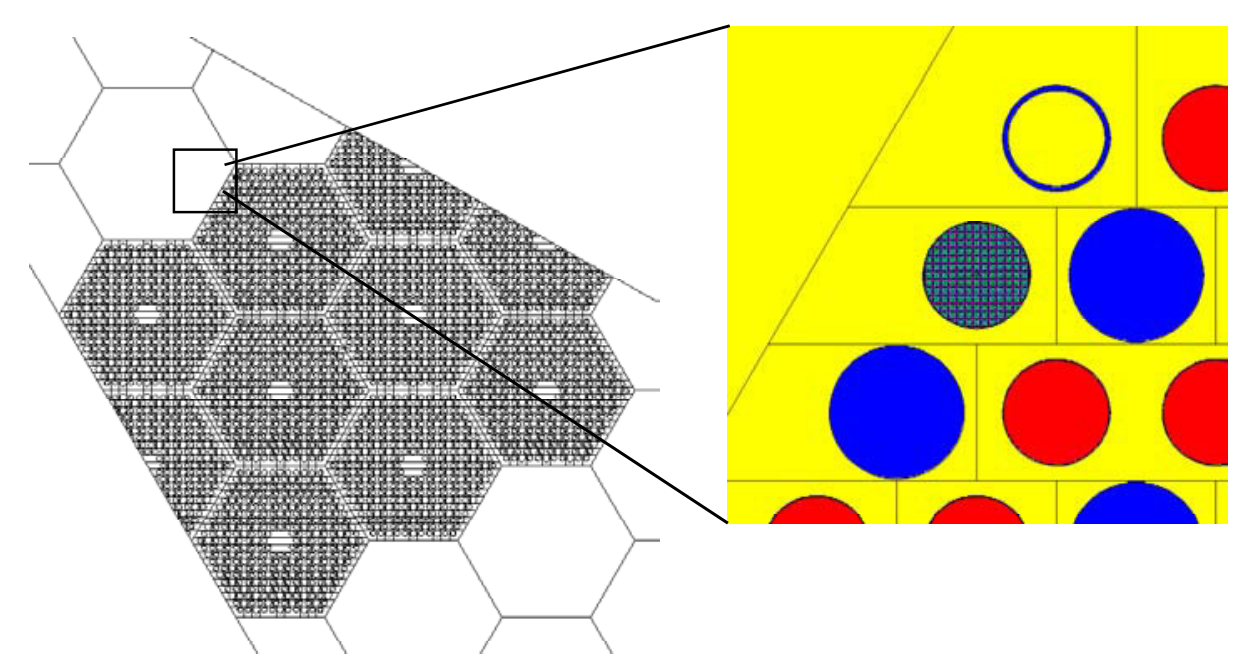

Figure 18. 1/12-core MCNP model with a regular fuel particle array in the maximum power-peaking fuel rod location.

Modeling the individual particle micro-spheres in a regular rectangular array resulted in some of the spheres being cut by the compact cylindrical surface. Because of these cut particles, it was necessary to adjust the packing fraction slightly in order to maintain a constant compact uranium loading. To achieve the desired uranium loading in the fuel compact containing the array of fuel spheres, the packing fraction was changed in an iterative manner until the desired fuel loading matched the surrounding homogenized fuel rod loadings. This required calculating the volume of intersection between the spherical and cylindrical surfaces, which is accomplished using the following equation:

$$
\operatorname{Vol}(r, R, b)=4 \cdot \int_{\max (b-R,-r)}^{\min (b+R, r)} \int_{0}^{\min \left(\sqrt{R^{2}-(x-b)^{2}}, \sqrt{r^{2}-x^{2}}\right)} \sqrt{r^{2}-x^{2}-y^{2}} d y d x
$$

where

$$
\begin{array}{lll}
r & = & \text { radius of sphere } \\
R \quad & = & \text { radius of cylinder } \\
b \quad & = & \text { smallest distance between axis of cylinder and center of sphere. }
\end{array}
$$

Note: The double heterogeneous 1/12-core model was also reduced in the axial extent to increase the tally effectiveness. The fuel block extended axially only 15 particle layers in height or approximately 1.27-cm. In order to achieve the infinite axial extent of the 2D and 3D 1/12-core models described above, reflective boundaries were again applied to the top and bottom model surfaces.

Two parametric studies were performed with the 1/12-core model. The first study involved calculating the power peaking in the fuel sphere array for two different U-235 enrichments (10 and 14\%) and two different fuel kernel sizes (350 and 425-microns), with packing fractions of 0.2891598 and 0.24715 , respectively. These parameters were applied to the single fuel compact with the explicitly modeled particles along with the rest of the homogenized fuel rods in the core. The peak-to-average power-peaking factors are given in Table 7.

The second parametric study varied the particle enrichment from 10, 14, 17, and $20 \mathrm{wt} \% \mathrm{U}-235$ holding the packing fraction (0.24715) and particle size (425-microns) constant. The rest of the core was fixed at a homogenized loading corresponding to a 425 -micron particle, $10 \mathrm{wt} \%$ enrichment, and 
$\mathrm{PF}=0.24715$. The peak-to-average factors are given in Table 8. Figure 19 shows an example of the calculated fission power gradient across the fuel compact at the interface. The larger bubbles signify a larger relative fission power, and notice the gradient from the bottom right to the top left, the direction from the fuel rod into the inner reflector.

Table 7. Maximum power-peaking factors in the fuel particle compact array as a function of kernel size and enrichment.

\begin{tabular}{clcc}
\hline Case & \multicolumn{1}{c}{ Description } & Maximum Ratio & Minimum Ratio \\
\hline 1 & $\begin{array}{l}\mathrm{U}-235=10 \%, \text { kernel diameter }=350 \mu \mathrm{m}, \\
\text { reference packing fraction }=0.2891598\end{array}$ & 1.033 & 0.971 \\
2 & $\begin{array}{l}\mathrm{U}-235=14 \%, \text { kernel diameter }=350 \mu \mathrm{m}, \\
\text { reference packing fraction }=0.2891598\end{array}$ & 1.045 & 0.958 \\
3 & $\begin{array}{l}\mathrm{U}-235=10 \%, \text { kernel diameter }=425 \mu \mathrm{m}, \\
\text { reference packing fraction }=0.24715\end{array}$ & 1.038 & 0.966 \\
4 & $\begin{array}{l}\mathrm{U}-235=14 \%, \text { kernel diameter }=425 \mu \mathrm{m}, \\
\text { reference packing fraction }=0.24715\end{array}$ & 1.048 & 0.964 \\
\hline
\end{tabular}

Table 8. Maximum power-peaking factors in the fuel particle compact array as function of particle enrichment.

\begin{tabular}{cccc}
\hline & U-235 Enrichment in Fuel Sphere Array & & \\
Case & $\begin{array}{c}\text { (Core held at } \begin{array}{l}\text { Maximum } \\
\text { packing fraction }=0.24715)\end{array} \\
\text { Ratio }\end{array}$ & $\begin{array}{c}\text { Minimum } \\
\text { Ratio }\end{array}$ \\
\hline 1 & $10 \%$ & 1.030 & 0.973 \\
2 & $14 \%$ & 1.028 & 0.969 \\
3 & $17 \%$ & 1.043 & 0.966 \\
4 & $20 \%$ & 1.039 & 0.974 \\
\hline
\end{tabular}

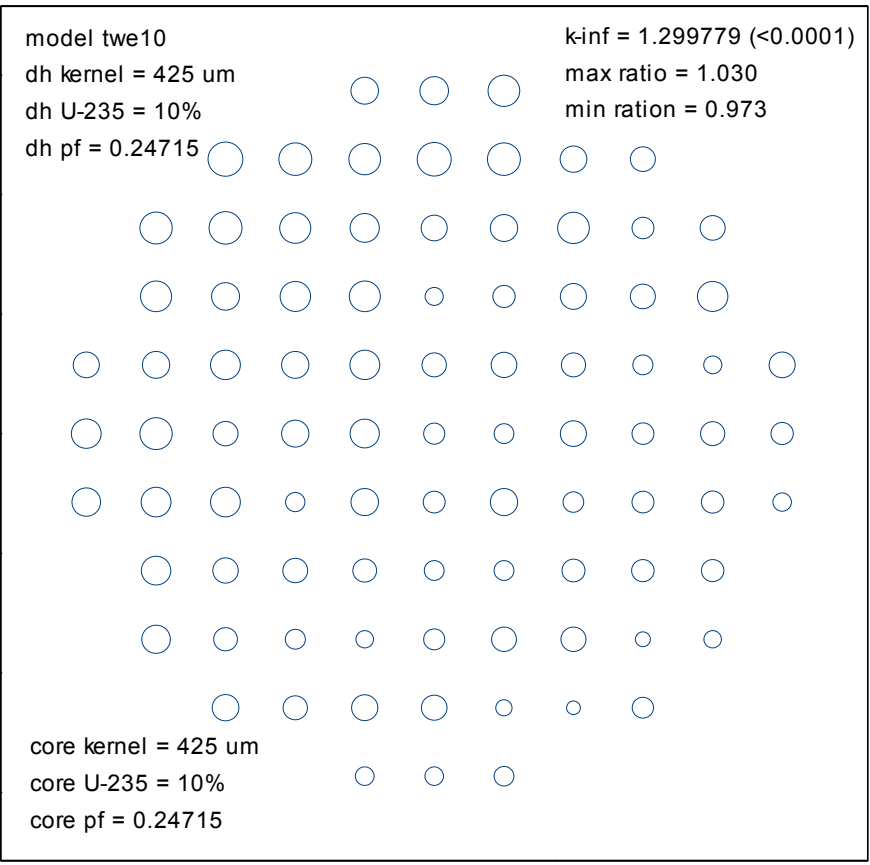

Figure 19. Individual fuel particle powers in the fuel compact at the maximum power-peaking location. 
For both parametric studies, the maximum power-peaking factors (peak-to-average) across the micro-sphere array were found to be relatively small, less than or equal to approximately 1.05 , and to be relatively insensitive to kernel size, enrichment, and packing fraction, although the parametric ranges were somewhat limited in extent.

\subsubsection{Unitcell Modeling}

A double-heterogeneous MCNP unitcell model (Figure 20) with a hexagonal lattice, based on the reference FSV prismatic fuel block geometry and dimensions, was used in this study. A depletion calculation was performed which tracked the burnup of each particle in the unitcell model. Individual particle peak-to-average factors have been calculated both at the beginning-of-life $(0.0 \mathrm{GWD} / \mathrm{MTU})$ and at end-of-life (118.0 GWD/MTU) burnup.

Figure 21 shows the results of the calculated peak-to-average values for the two burnups. Note the relatively flat particle power distribution at BOL and the accentuated power-peaking at the compact periphery for the $118 \mathrm{GWD} / \mathrm{t}$ burnup case. The peaking is presumably due to the "rim effect" or Pu-239 buildup in the particles near the compact periphery.

Therefore, particle power-peaking can apparently increase with compact burnup. Based on Figure 21 (yellow dots), one could conservatively estimate a rather significant power-peaking factor of approximately 1.20 at EOL. However, this 1.20 peak factor would only apply to a relatively small number of particles at the compact periphery, with the bulk of the particles all below a factor of 1.06, and both the 1.20 and 1.06 factors apply only at EOL, meaning the particle peaking factors were not at these values during the entire burnup, but rather built up over time. On the other hand, this burnup-dependent peaking factor would necessarily apply to all fuel compacts/rods in the core (not just those at the reflector/core interfaces) and in particular those with high burnups.

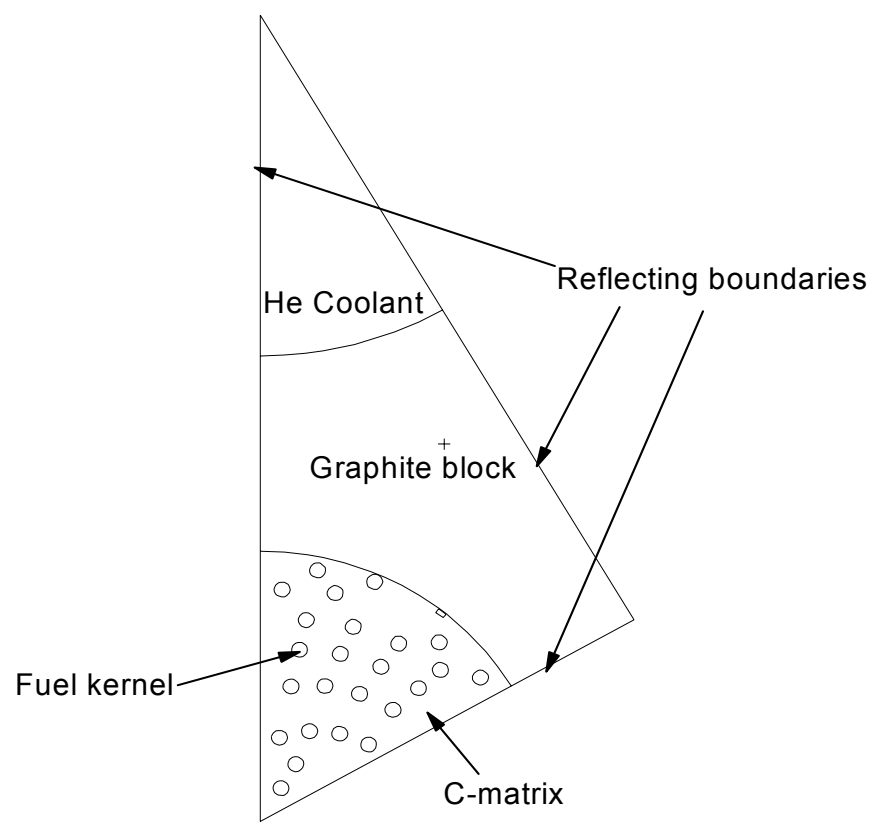

Figure 20. Cross-sectional view of a double-heterogeneous triangular fuel unit lattice model with fuel particles. 


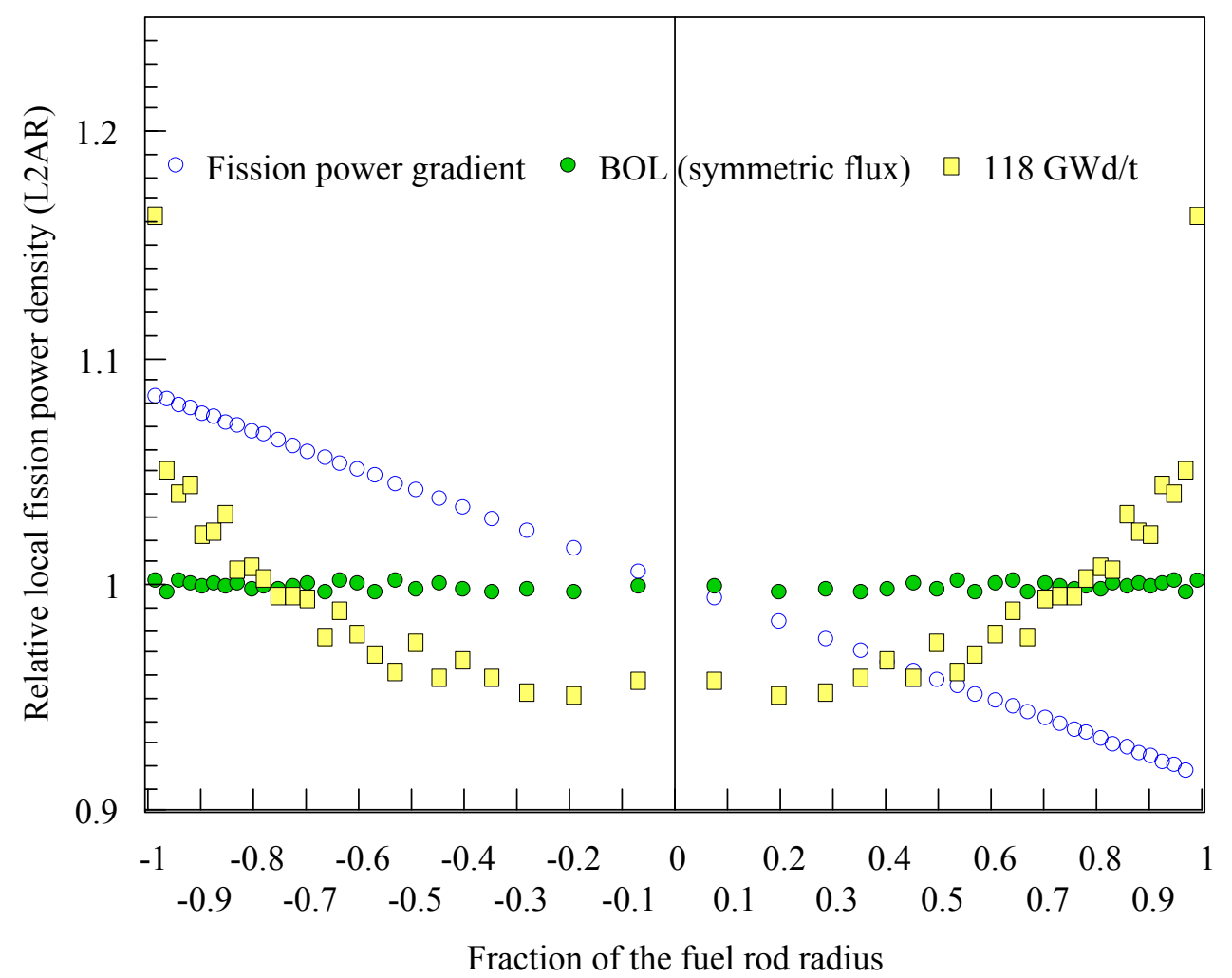

Figure 21. Fission power gradient profile across the peak fuel rod, and the radial fission power profile inside the fuel rod at the BOL and $118 \mathrm{GWd} / \mathrm{t}$ burnup.

Also shown on Figure 21 is a fission power gradient estimate (blue dots) across the fuel compact based on a gradient predicted by the 1/6-core model between adjacent fuel rods with homogenized fuel compositions. This gradient estimate is more conservative and less accurate relative to the more accurate 1/12-core model predictions just discussed in the previous section.

\subsection{Power-Peaking Mitigation (Task 3)}

To estimate radial power-peaking factors in the prismatic NGNP annular reactor core, reasonably optimized fuel block designs had to be developed with power-peaking mitigation techniques applied as part of the block designs. Several of the mitigation techniques identified and preliminarily studied last year in the point design work ${ }^{4}$ were re-evaluated and selected, based on the simplicity and feasibility of implementation in the block designs. As it turns out, substantial reduction of radial power-peaking can be achieved with the combination of just two mitigation techniques.

A large number of parametric sensitivity studies were required to re-evaluate the mitigation techniques identified last year, along with some new ideas, and then combine the "best" techniques for maximal effect. Mitigation techniques identified last year and new ones identified this year include the following:

1. Loading of discrete burnable poison rods with $\mathrm{B}_{4} \mathrm{C}$ in the designated corner pin locations in the hexagonal blocks.

2. Placement of discrete burnable poison rods with $\mathrm{B}_{4} \mathrm{C}$ in fuel rod Rows 1-4 nearest the core/reflector interface that would involve substitution of burnable poison rods for fuel rods. 
3. Variation of the particle-packing fraction in the fuel rods in Rows 1-4 nearest the interface.

4. Variation of the particle uranium enrichment in the fuel rods in Rows 1-4 nearest the interface.

5. Multiple particle-packing fraction zones across the fuel blocks in Rings 6 and 8.

6. Multiple particle uranium enrichment zones across the fuel blocks in Rings 6 and 8 .

7. Mixing of burnable poison micro-spheres containing $\mathrm{B}_{4} \mathrm{C}$ with fuel rods in Rows 1-4 nearest the interface.

8. Burnable poison $\mathrm{B}_{4} \mathrm{C}$ mixed into the graphite reflector blocks in a 5.08-cm thick buffer zone band along the interface.

9. Use of different burnable poisons (other that B-10, for example, Gd, Er, Eu, Sm, Hf, etc.)

Other mitigation techniques may be possible, but the combination of items 1-3-5 above and 1-4-6 worked superbly in reducing the radial power-peaking across the core. Of these two triplet combinations, the 1-3-5 combination, i.e. strategic location and number of discrete burnable poison rods in the hexagonal block corners ( 3 rods in the Ring 6 fuel block, 0 in Ring 7, and 3 or 4 in Ring 8 depending on block location), constant and lowest particle packing fraction in Rows 1-5, and multiple particle packing fraction zones by block ( 3 zones in Ring 6,1 zone in Ring 7, and 2 zones in Ring 8) was deemed the best combination. This particular design solution for the radial power-peaking problem essentially answered the binary versus single particle system question. The entire core peaking problems could be solved through the packing fraction variable alone without the need for graded enrichments or enrichment zoning. Hence, although the 1-4-6 mitigation items above were studies in some detail, mainly for comparison purposes with the 1-3-5 combination, the final analysis concluded that the 1-3-5 was the best mitigation design option to meet NGNP goals. Note: most of the other mitigation items above raised concerns relative to homogeneity, burnout, complexity, logistics, fabrication and implementation, and were not pursued further in the analyses herein.

It is noted that the "optimized" or "optimally-loaded" block designs developed herein are not intended to be the final design solutions, but rather solutions that make a major stride in the direction of reducing the radial power-peaking. Further refinement in the optimization process is surely possible. Therefore, the radial power-peaking factors at BOL given in this section and the power-peaking factors given the next section as a function of burnup represent slightly conservative over-estimates of the actual radial power-peaking factors that one would expect to find in a future fully optimized NGNP prismatic core. The optimized fuel blocks were used as the beginning-of-life (BOL) block loadings for the core depletion studies.

\subsubsection{Radial Power-Peaking Factors}

Results from selected parametric studies listed at the end of Section 5.1 will be presented here. In particular, just those studies that actually lead up to the design of the "optimally-loaded" fuel blocks and the core design that minimized radial power-peaking will be presented.

The first study involved uniform-loaded cores, cores completely unmitigated (no burnable poison rods and no attempt to zone the core by enrichment or packing fraction or other means). The goal was to identify those specific fuel rods with the highest fission powers and then calculate the maximum radial power-peaking factors across the core, and later apply mitigation techniques to target these high power regions of the core.

Figure 22 shows the three regular fuel blocks or three-block segment that are a reasonable representation of the annular core characteristics as a whole. The upper left fuel block in this figure is in Ring 6 (inner active core annulus ring). The middle block is in Ring 7 (middle active core ring or driver 


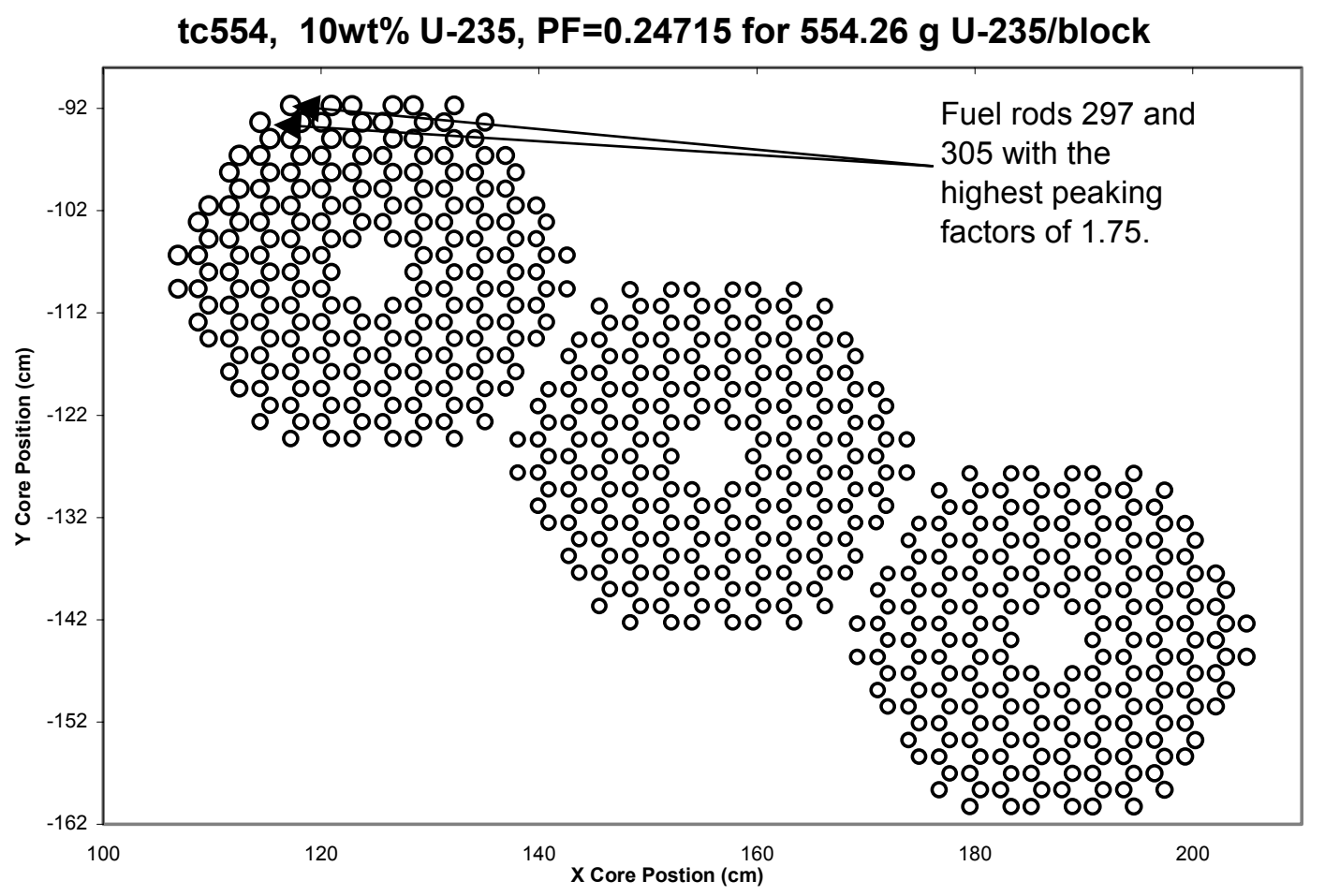

Figure 22. Fuel rod power-peaking radially across the annular core. Relative size of the bubbles represent magnitude of the individual fuel rod peaking. Ring 6 block is in the upper left corner of figure, Ring 7 in the middle, and Ring 8 lower right corner. The highest peaking occurs in the Ring 6 at the inner graphite reflector interface.

core) and the lower right block is in Ring 8 (outer active core annulus ring). Note: All subsequent figures with these same three block configurations will represent the same corresponding blocks in the core. This particular case (Figure 22) is for a uniformly loaded core with all fuel blocks containing $10 \mathrm{wt} \%$ enrichment particles with a packing fraction of 0.24715 and corresponding $554 \mathrm{~g} \mathrm{U}-235$ per block loading (typical of the initial core loading).

Significant fuel rod power-peaking is shown in Figure 22 near the inner reflector/core interface. Note: larger bubbles represent higher relative fission power-one bubble per fuel rod. The two fuel rods (nos. 297 and 305) identified in the figure have the highest peaking factors (1.75) and occur in the Ring 6 fuel blocks. These two fuel rods penetrate deepest into the inner graphite reflector and experience the highest thermal flux intensity and gradient of all the fuel rods in the core.

For uniform loaded cores, Figure 23 shows a plot of the maximum fuel rod power-peaking factors (again for fuel rods 297 and 305) versus fuel particle enrichment. Two observations can be drawn from this figure. First, and of lesser importance, the higher the particle enrichment, the slightly lower the fuel rod power-peaking. This is due to a slight inward shift in core power due to reduced U-238 absorption in Rings 6 and 8. The second, and more important observation, is that for a fixed enrichment, the peaking factors increase significantly with increased U-235 loading per block. For example, for a fixed $10 \mathrm{wt} \%$ enrichment, the peaking factor increases from 1.75 to 1.93 to 2.14 , for the 500,700 , and $900 \mathrm{~g} \mathrm{U}-235$ per block cases, respectively. The increase in U-235 loading corresponds directly to an increase in the particle-packing fraction for a fixed enrichment. It turns out that the fuel rod power-peaking factor is directly related to the amount of U-235 in the fuel rods at the interface that can be adjusted equally by 


\section{Maximum Peaking Factors as a Function of Enrichment for Various Core Loadings}

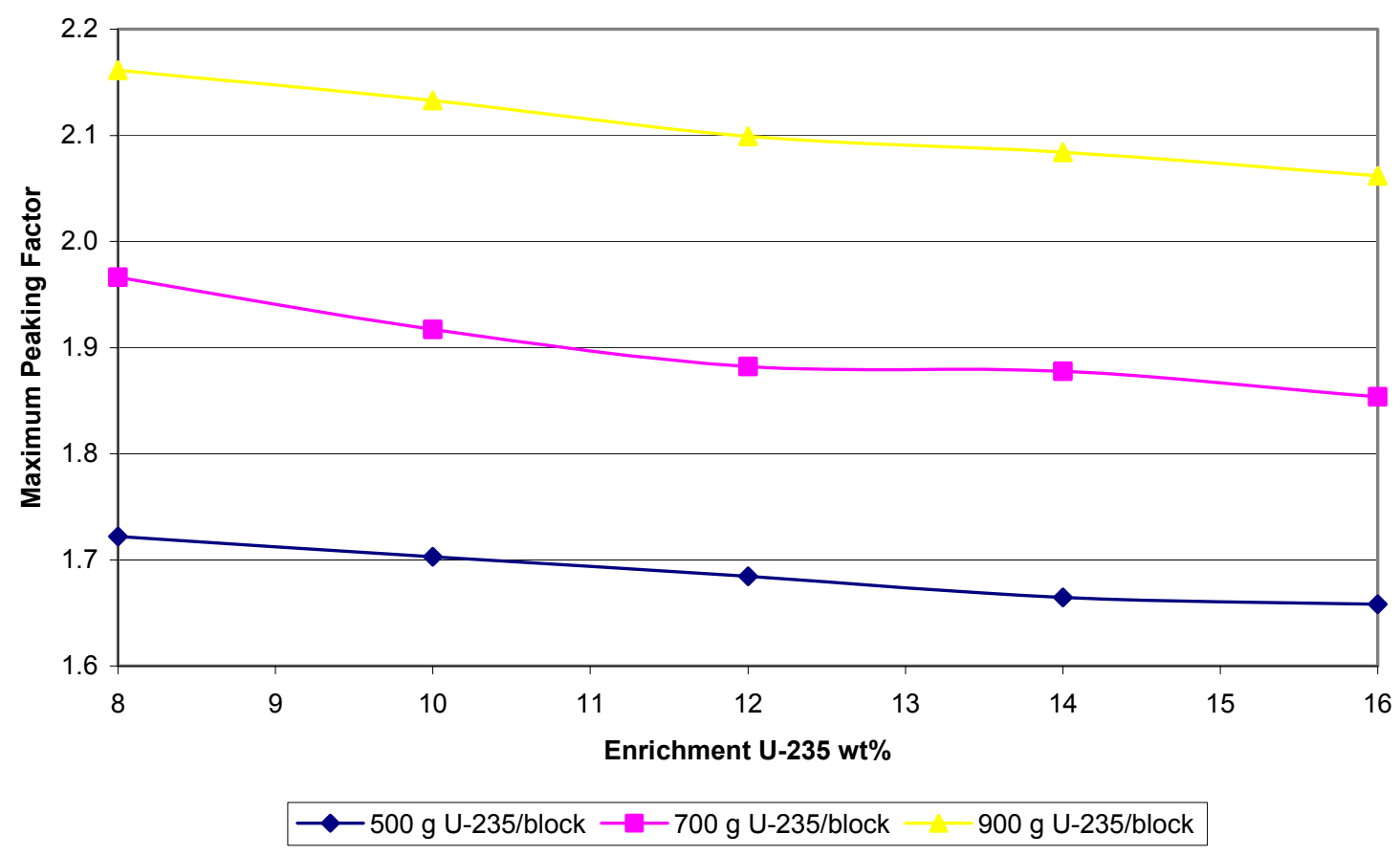

Figure 23. Power-peaking factors for the two fuel rods in Ring 6 deepest into the inner graphite reflector as a function of fuel particle enrichment and block total gram loading of U-235.

either changing the packing fraction or enrichment. We chose to adjust the packing fraction rather than the enrichment for fuel block loading optimization, since our secondary goal was to demonstrate core radial power-peaking reduction using a single fissile particle with a single enrichment.

The next study shows the utility was using reduced particle-packing fraction or enrichment in the fuel rod rows at the interfaces. Consideration was initially given to both packing fraction and enrichment zoning in the just first 4 fuel rod rows in Rings 6 and 8 fuel blocks adjacent to and along graphite reflector/core interfaces. Figure 24 shows the affected fuel rod rows. This particular case was for a 10 $\mathrm{wt} \%$ enrichment and a $\mathrm{PF}=0.24715$ for a $554 \mathrm{~g} \mathrm{U}-235$ per block loading uniform across the core, except in the Rows 1-4 where the packing fraction or enrichment was varied.

By varying the packing fraction or enrichment in the Rows 1-4, the maximum power-peaking factor shifted between fuel rod no. 305 (Row 1) and no. 272 (Row 5) in the Ring 6 fuel block at the inner reflector interface. Figures 25 and 26 show the variation of the two fuel rod peaking factors for packing fraction and enrichment variation, respectively. In the case of the packing fraction variation (Figure 25), the packing fraction where the two fuel rod peaking factors are equal occurs at approximately 0.195 , and in the case of the enrichment variation (Figure 26), this occurs at an enrichment of approximately 8.0 $\mathrm{wt} \%$. In both cases, the power-peaking factor drops significantly from 1.73 to 1.46.

Three interesting results come out of this study. First, the radial power-peaking factor can be reduced from 1.75 down to $<1.50$, a significant reduction. Second, the difference in the packing fraction and the enrichment in the Rows 1-4 do not vary significantly from the rest of the uniformly loaded core, 


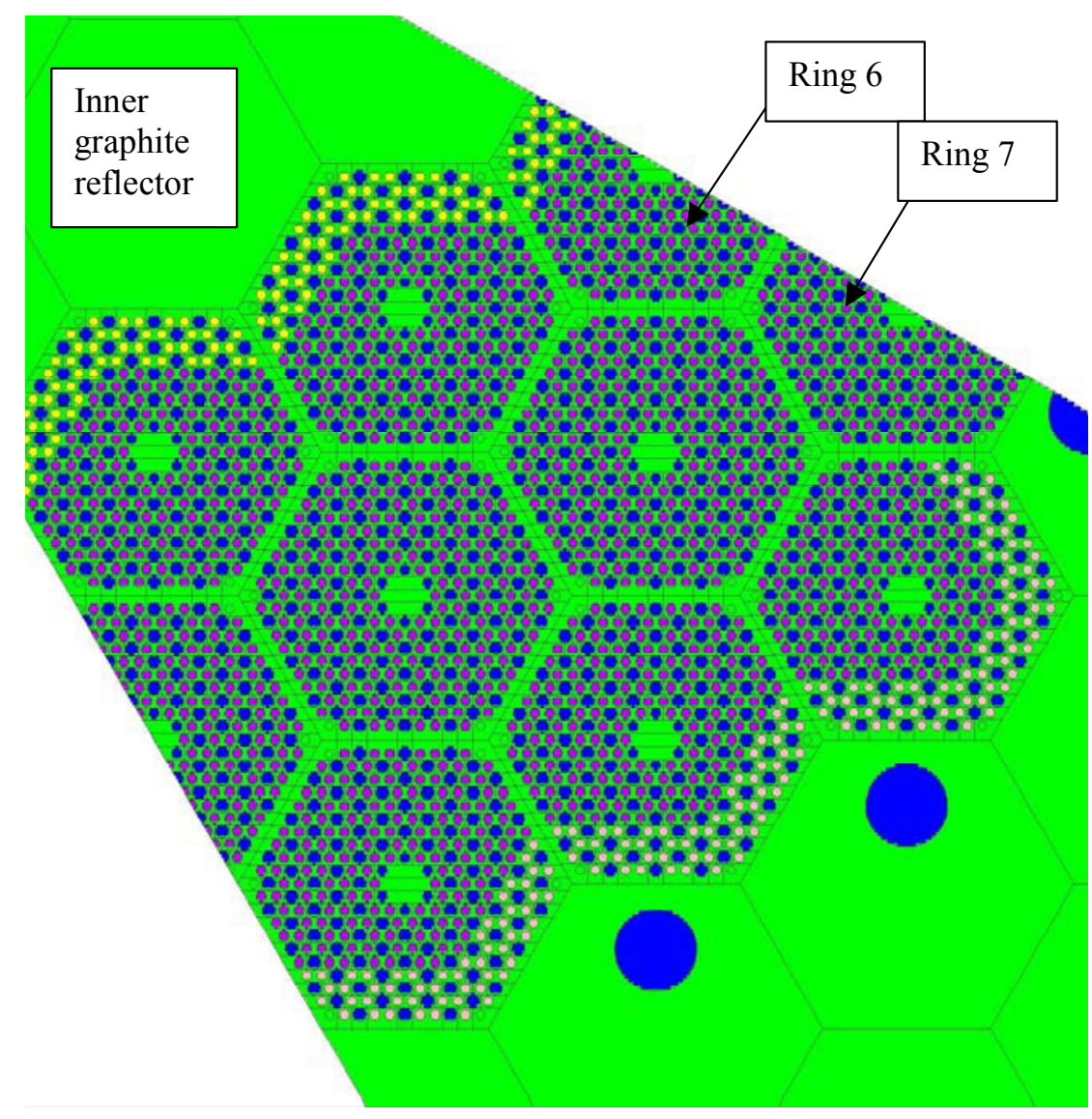

Figure 24. Packing fraction and enrichment zoning in the first 4 fuel rod rows along the inner (yellow dots) and outer (pink dots) reflector interfaces.

indicating that a smooth or small incremental transition between zones is appropriate. Third, when one compares the amount of U-235 in the fuel rods at the optimal packing fraction and optimal enrichment (i.e. the packing fraction or enrichment when the peaking factor is the same for pins no.305 and 272), the amount is almost identically equal. This is an important piece of information pertinent to assessing the usage of a single fissile particle and a single enrichment particle system. In other words, reduction of radial, and axial power-peaking factors can be achieved with packing fraction variation alone, without the need for another particle enrichment. As we will see in the next section, a single 425-micron particle is used with two particle enrichments (10 and $14 \mathrm{wt} \%)$. The $10 \mathrm{wt} \%$ enrichment was used for the initial core loading and the $14 \mathrm{wt} \%$ for a reload core. In principle, either the 10 or $14 \mathrm{wt} \%$ enrichment could be used wholly in the core for the initial or equilibrium reloads. However, further fuel studies are necessary to determine how to best achieve cycle, burnup, and economics with single, double, or multiple enrichments using a single fissile particle size.

Another parametric study to reduce radial power-peaking involved the use of discrete burnable poison rods with $\mathrm{B}_{4} \mathrm{C}$ particles. The example discussed here is for a $10 \mathrm{wt} \% \mathrm{U}-235$ enrichment uniform core loading in which the uranium block loading is varied (500, 700, and $900 \mathrm{~g} \mathrm{U} 325$ per block) as is the corresponding amount of B-10 in the poison rods. The amount of B-10 added was the amount needed to reduce the k-infinity of the $1 / 12$-core $2 \mathrm{D}$ model down to 1.05 , or $5 \%$ excess reactivity. Figure 27 shows the typical discrete poison rod locations along with the fuel rods. 


\section{Power Peaking vs. Outer Row U-235 PF for Pins 305 \& \\ 272}

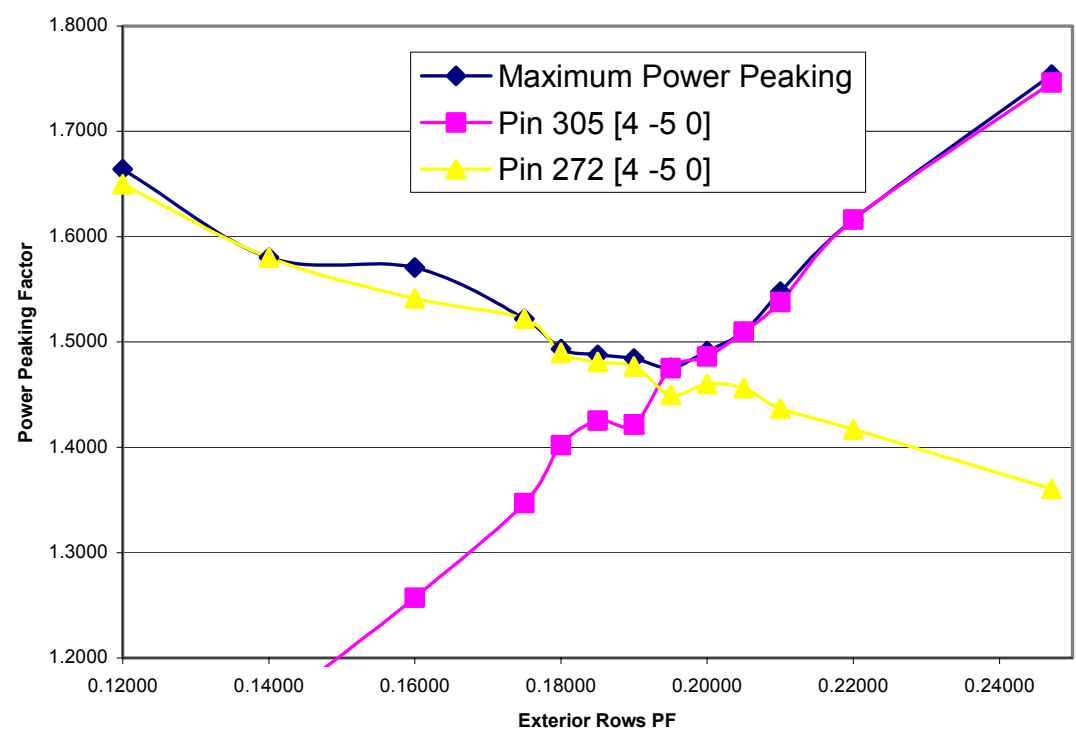

Figure 25. Maximum peaking factors in fuel rods (pins) no. 305 (Row 1) and no. 272 (Row 5) in Ring 6 fuel block at the inner reflector as a function of packing fraction in rows 1-4.

Power Peaking vs. Outer Row U-235 Enrichment for Pins 305 and 272

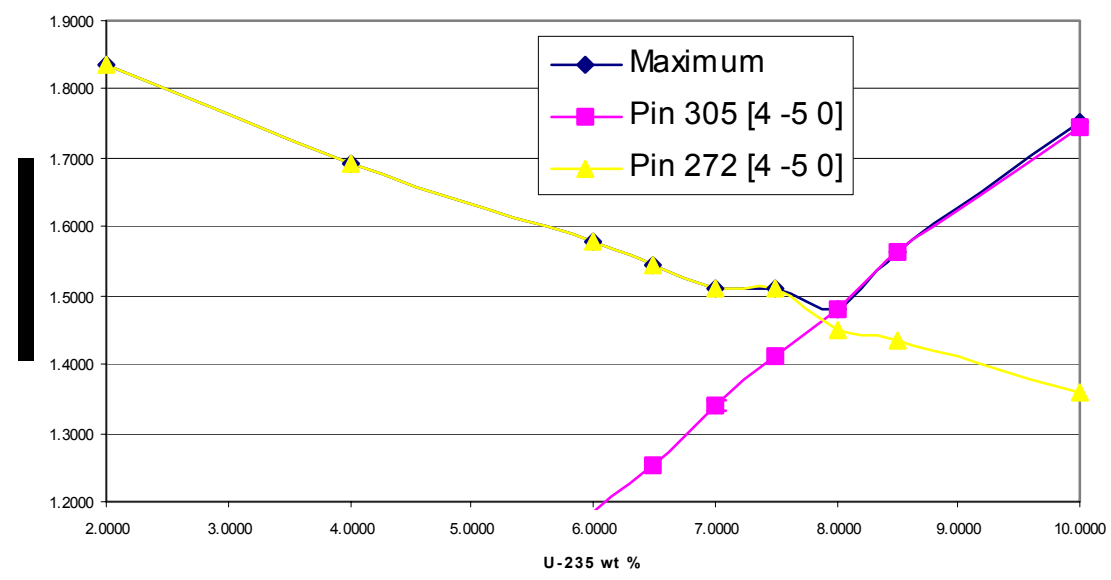

Figure 26. Maximum peaking factors in fuel rods (pins) no. 305 (Row 1) and no. 272 (Row 5) in Ring 6 fuel block at the inner reflector as a function of particle enrichment in rows 1-4. 


\section{Burnable Poisions Locations}

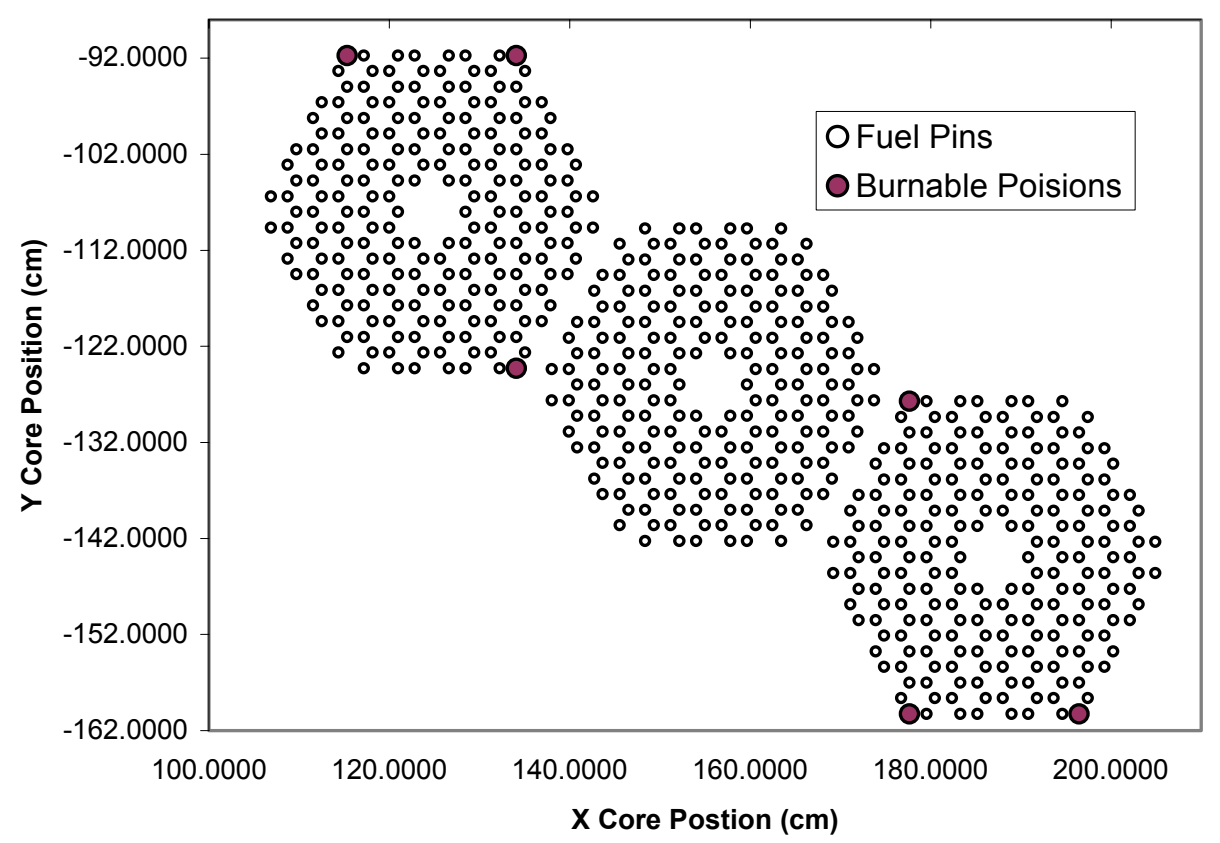

Figure 27. Discrete burnable poison rod locations.

Figure 28 shows the maximum power-peaking across the three regular fuel blocks as a function of uranium loading and B-10 mass in each discrete poison rod. It is apparent that the burnable poison rods drop the maximum peaking factors significantly. In the case of the $10 \mathrm{wt} \%$ uniform enriched core $(500 \mathrm{~g}$ U-235 per block), the maximum radial peaking factor drops from 1.75 to 1.42 .

The final example here is a combination of three mitigation techniques that results in an "optimalloaded" radial core with $10 \mathrm{wt} \%$ enrichment. The three techniques used are (1) discrete burnable poison rods in the corners of the hexagonal fuel block (0.86 g B-10 per rod), (2) packing fraction zoning of the fuel rod Rows 1-4 at both reflector/core interfaces, along with a couple of fuel pins in Row 5, and (3) unique blockwise packing fraction zoning in fuel blocks in the three separate active core rings (Rings 6, 7, and 8). Specifically, the Ring 6 blocks have three packing fraction zones, $P F=0.175,0.21$, and 0.27 , for a total BOL block loading of $472 \mathrm{~g} \mathrm{U}-235$. Ring 7 blocks have a single packing fraction zone, $\mathrm{PF}=0.27$, for a total BOL block loading of $605 \mathrm{~g} \mathrm{U}-235$. And Ring 8 blocks have two packing fraction zones, $\mathrm{PF}=0.21$ and 0.27 , for a total BOL block loading of $562 \mathrm{~g} \mathrm{U}-235$. Figure 29 shows the "optimally-loaded" radial core zone loadings.

The combination of the three mitigation techniques (really just two separate techniques: packing fraction zoning and discrete burnable poison rods) reduces the BOL radial power-peaking factor down to 1.14. This is a significant drop in the radial power-peaking factor relative to the original uniform loaded core value of 1.75 with no mitigation applied. Figure 30 below shows the relative BOL (bubble size) fuel rod fission powers and Figure 31 gives the 840 fuel rod peak-to-average factors for the four regular fuel blocks shown ( 1 block in Ring 6,1 block in Ring 7, and 2 blocks in Ring 8). These figures allow one to see where the 1.14 peaks occur. There are actually several fuel rods with the 1.14 peak in the Ring 6 fuel block (Figure 31). In the next section (Section 5.4 Core Depletions), the 1.14 peak values will increase slowly and shift from one fuel rod to another with burnup, and at end-of-cycle the peak radial factor will have risen to approximately 1.25 . 


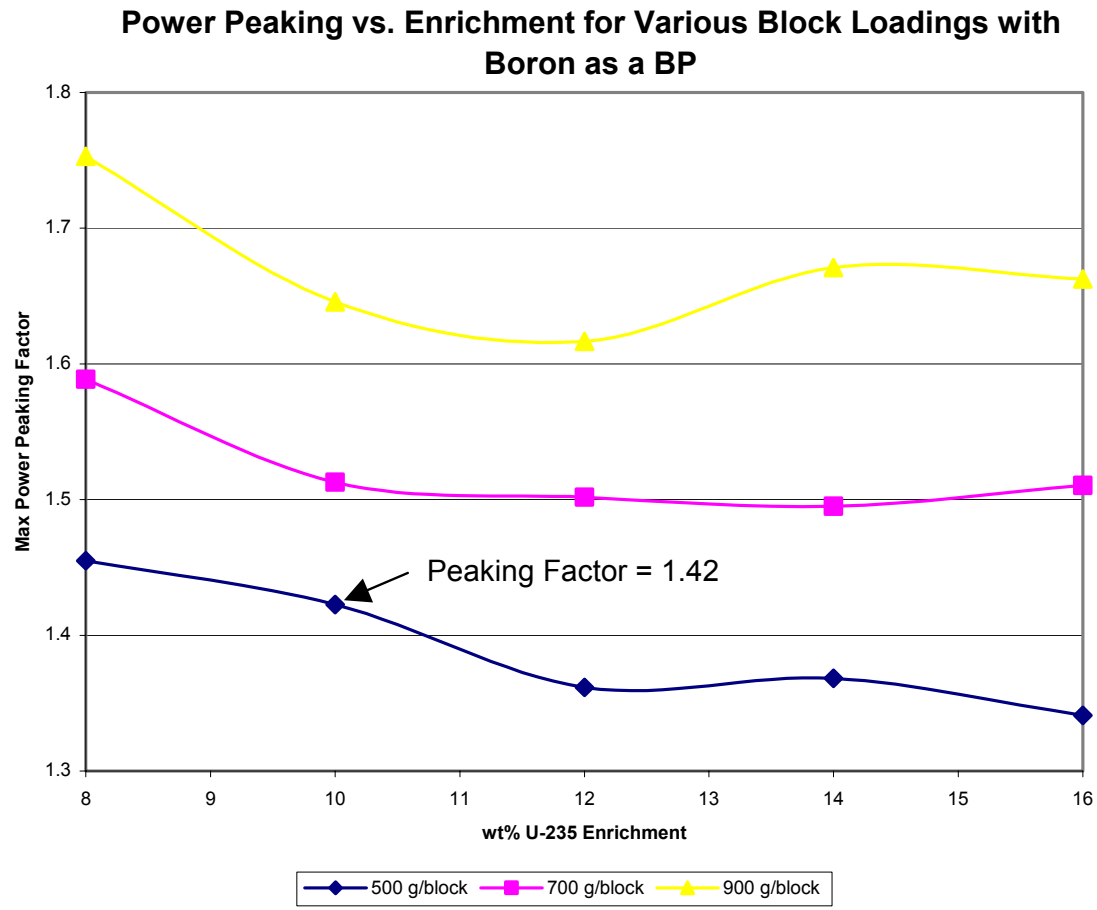

Figure 28. Maximum power-peaking factor across the radial core cross section as a function of U-2325 block loading ( $\mathrm{g} / \mathrm{block}$ ) and fuel particle enrichment.

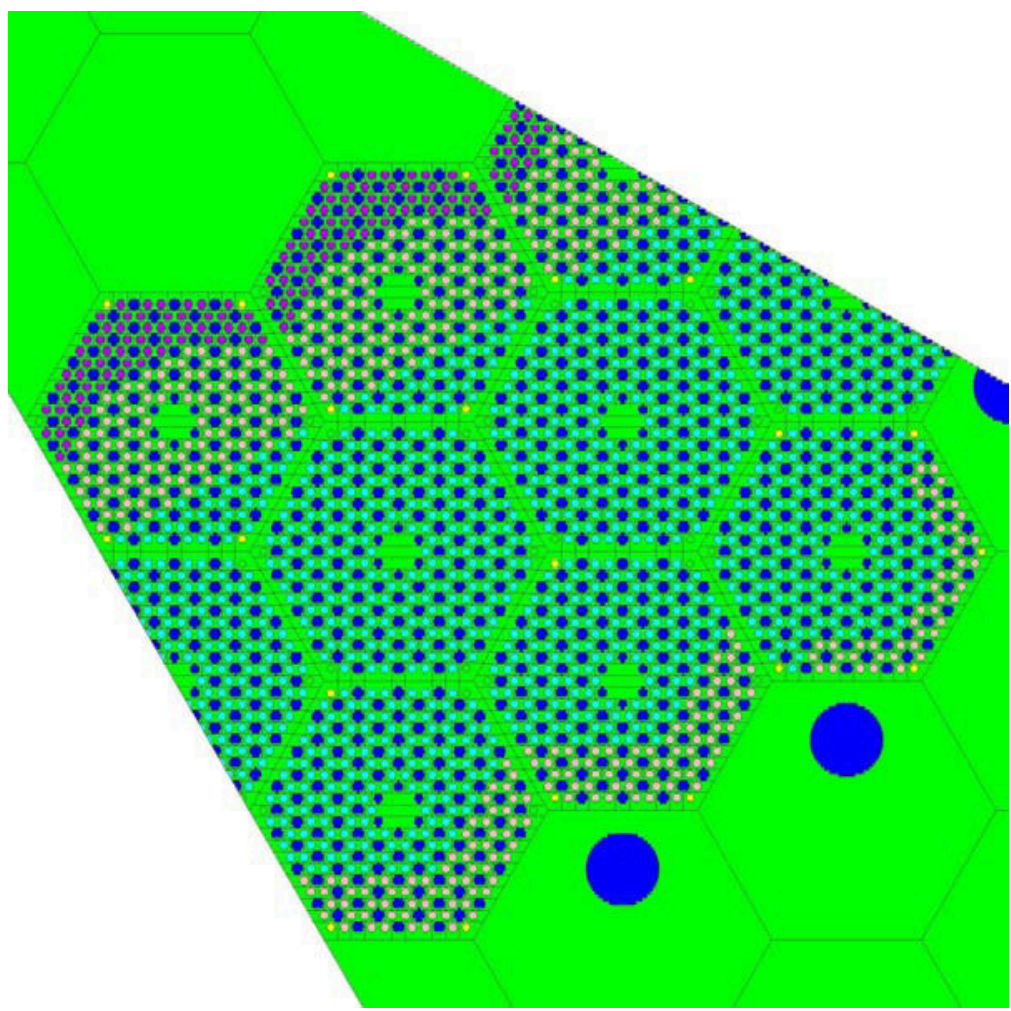

Figure 29. Optimal radial core loading specifically designed to maximize the reduction of the maximum radial power-peaking factor across the core. Ring 6: The red, yellow, and light blue dots are $\mathrm{PF}=0.175$, 0.21 , and 0.27 , respectively. Ring 7: $P F=0.27$. Ring $8: P F=0.21$ and 0.27 . All fuel particles have a $10 \mathrm{wt} \%$ enrichment. 
t54b10, 10 wt\%, 605g U-235/reg block PF graded from 0.175, 0.21, 0.27, Grading in Special Block in Ring 8. FBP $0.86 \mathrm{~g}$ of B-10/pin, and Extra FBP Pin Added in Ring 6.

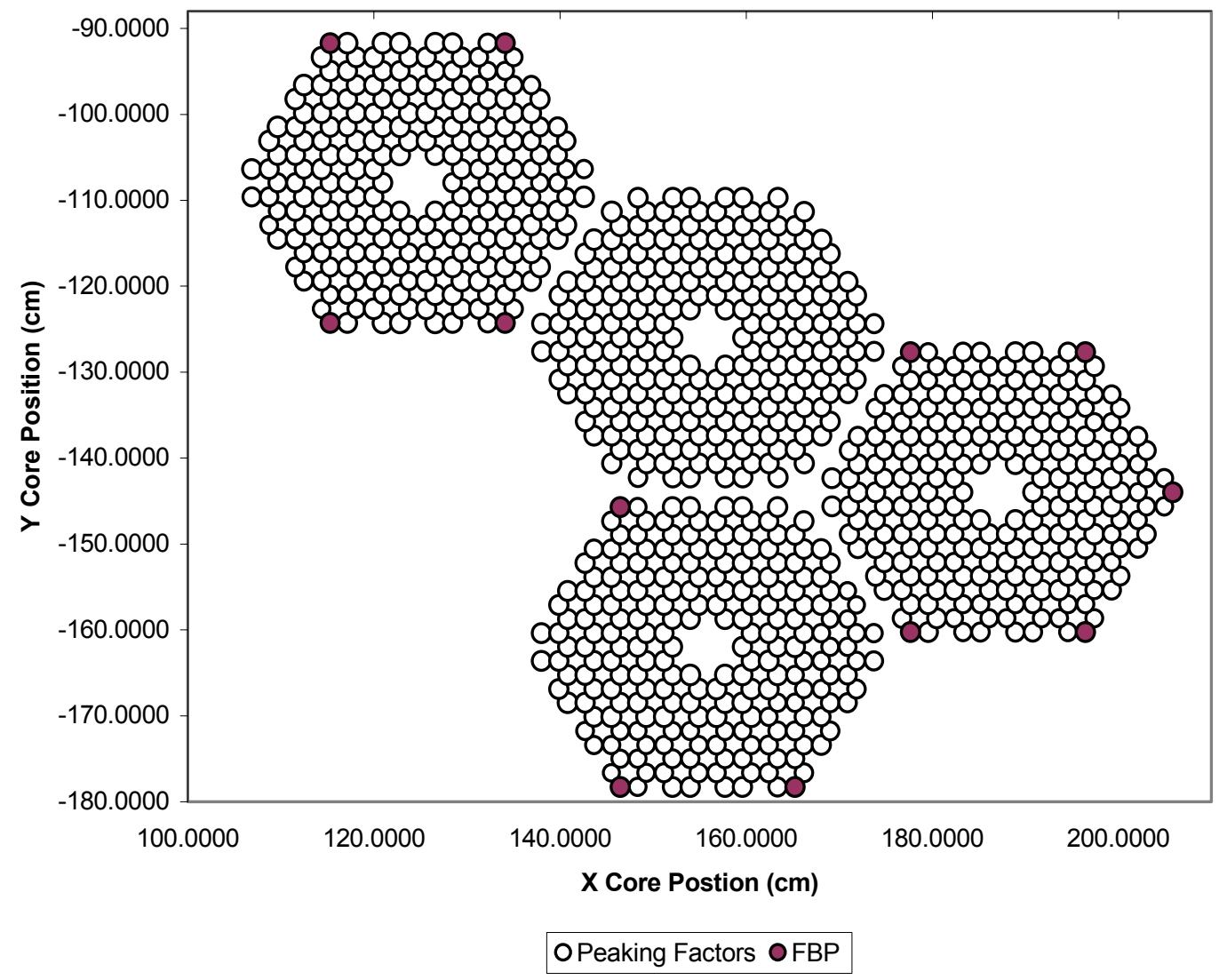

Figure 30. Four regular fuel blocks showing relative fuel rod powers (size of bubble). Note: the block in the upper left hand corner is in Ring 6 and the two lower right hand side blocks are both in Ring 8. Ring 6 and 8 packing fraction zones within each block are readily visible indicated by bubble size. Also, BP rod locations are indicated by the solid (red) dots.

Although we have shown only the optimal case for a $10 \mathrm{wt} \%$ enrichment, very similar packing fraction zoning and burnable poison rod deployment will work just as well for other enrichments, including the $14 \mathrm{wt} \%$ case. One difference, of course, is a slightly higher B-10 loading requirement for higher particle enrichments in order to hold down additional excess core reactivity.

\subsubsection{Axial Power-Peaking Factor}

The main goal was to estimate a conservative axial peaking factor for the NGNP core. A full-core 3D MCNP model was required to estimate the maximum axial peak-to-average factor. This model was similar to the 2D 1/12-core model used in the previous studies, but now includes the full 10-block-high active core, plus top and bottom graphite reflectors. The active core fuel was assumed to have a uniform $10 \mathrm{wt} \%$ enrichment and an axially uniform $1000^{\circ} \mathrm{C}$ fuel temperature and BOL initial conditions.

Figure 32 shows the peak-to-average axial profile. The peak value of approximately 1.30 occurs at the core midplane - due to the assumed uniform axial temperature profile, fresh uniform BOL loading, and unrodded core. The 1.30 value probably represents the maximum axial power-peaking value that one 


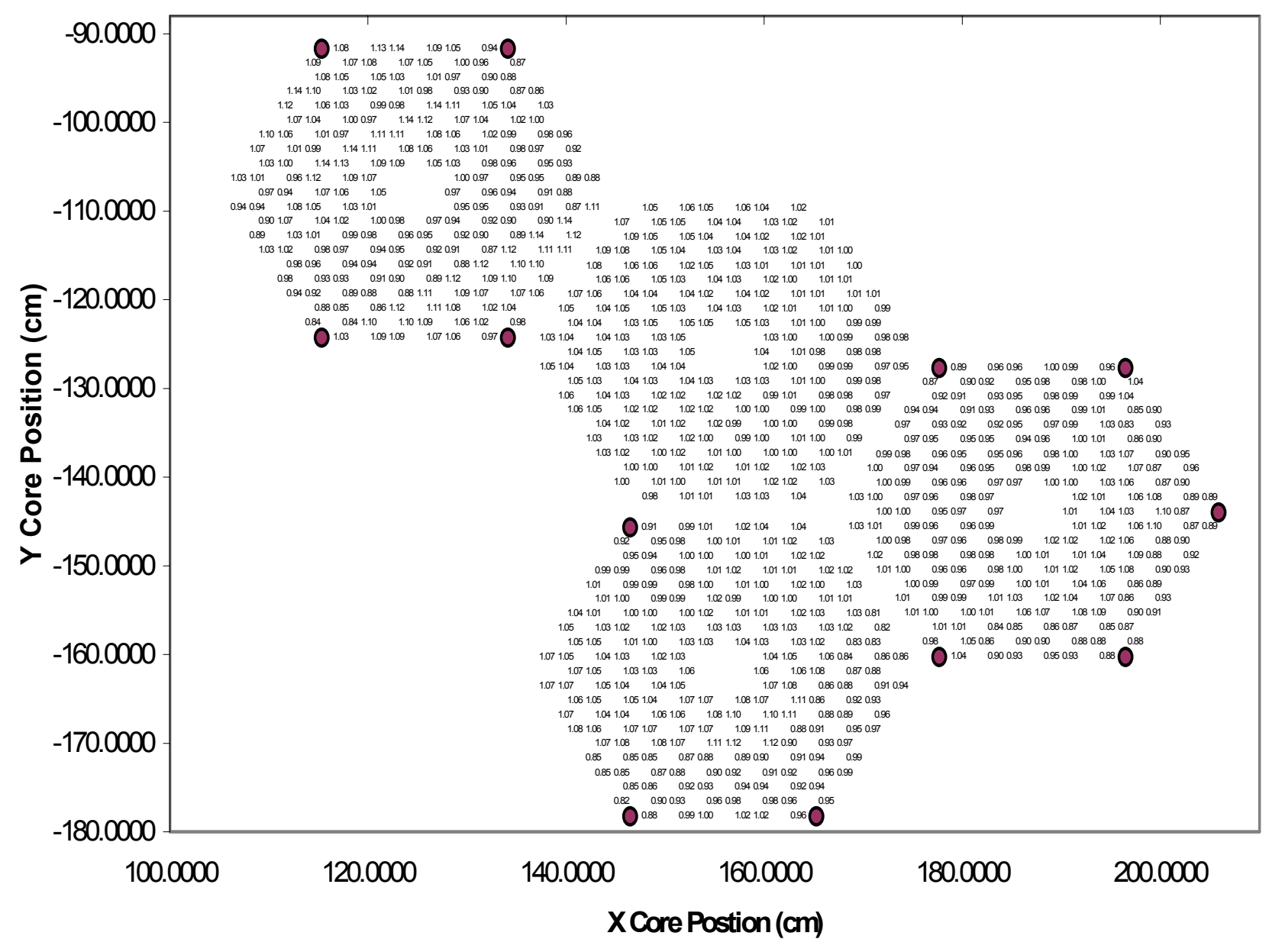

Figure 31. Fuel rod peak-to-average factors are shown in place of the bubbles.

might expect for the NGNP core, since any BOL loading scheme with the intention of flattening the axial power would probably produce a peak factor less than 1.30. In addition, the midplane peak would tend to flatten with burnup over the course of the power cycle.

Axial zone loading parametrics were performed with a simple two-enrichment (10 and $14 \mathrm{wt} \%$, $\mathrm{PF}=0.24715$ ) block scheme. The higher enrichment blocks were symmetrically placed in the top and bottom three axial layers, leaving the mid-core layers with the lower enrichment blocks. The goal was to progressively flatten the axial power profile by drawing core power to the axial ends. The peak-to-average was reduced to 1.26 for a 3(14\%)-4(10 wt\%)-3(14\%) top-to-bottom axial block configuration, demonstrating the feasibility of flattening through crude fuel zoning. More sophisticated axial loading schemes may involve both fresh and depleted elements with specific packing fractions and uranium loadings. 
fulht2, Axial Position vs. Axial Peaking

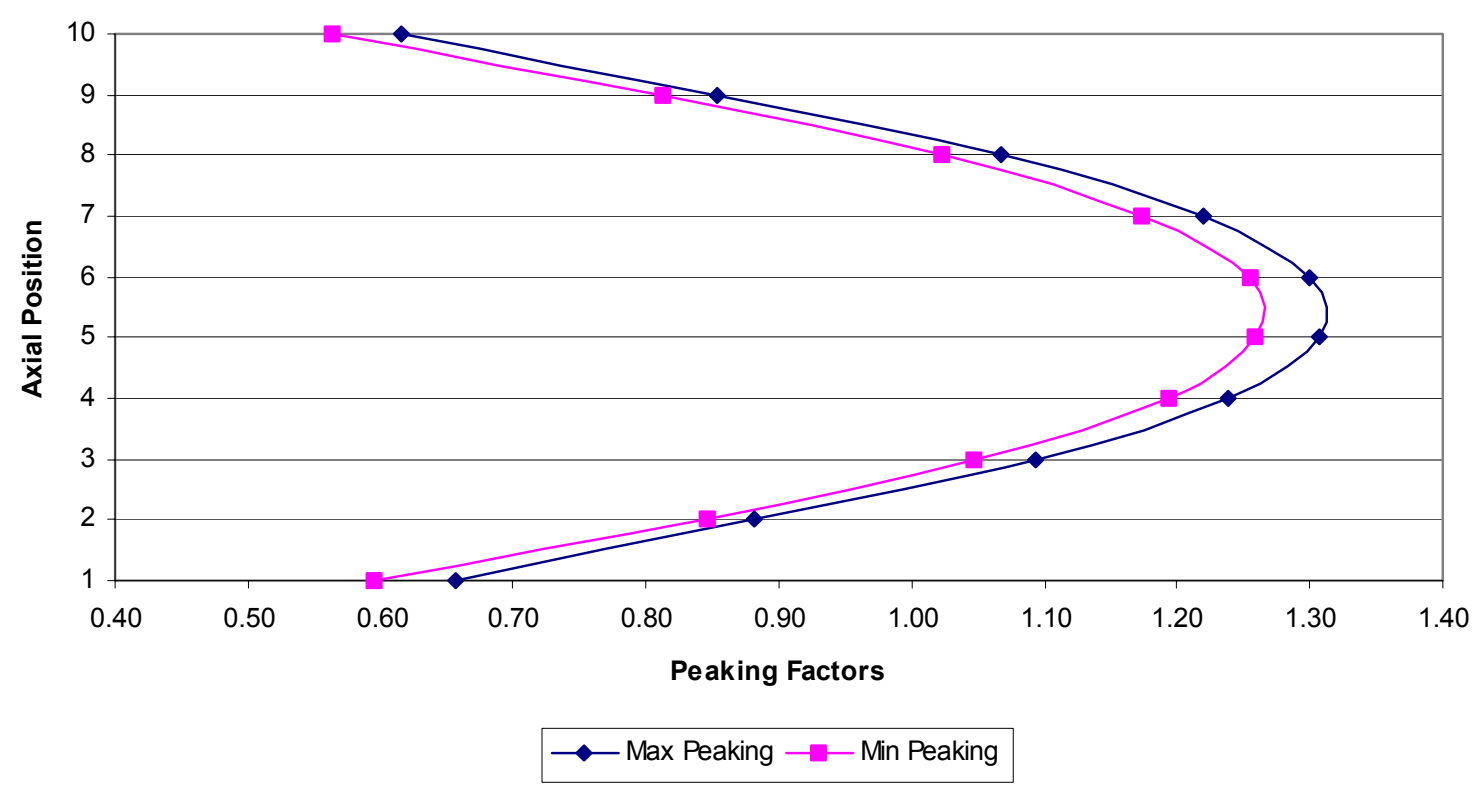

Figure 32. Axial fission power profile (block average).

\subsection{Core Depletion (Task 4)}

The goals of this section were two-fold: (1) to estimate radial power-peaking factors as a function of burnup and (2) determine if selected combinations of fresh and depleted block loadings in the annular core could allow the reactor to meet power cycle length and burnup requirements. The depletion calculations here focus on the initial core (once-through) and approximations to an equilibrium two-batch reload core, referred to as pseudo-equilibrium cores.

The JMOCUP code system was used to perform the depletion calculations with the 2D 1/12-core model, using fresh (BOL) and once-depleted 10 and $14 \mathrm{wt} \%$ enrichment fuel blocks with BOL loadings of 554 and $776 \mathrm{~g} \mathrm{U}-235$ per block, respectively. In addition, the 2D radial depletion calculations included the use of our "optimally-loaded" 10 and $14 \mathrm{wt} \%$ enrichment fuel blocks developed in Section 5.3 to see if the radial power-peaking factors remained suppressed over the burnup cycle. The depletion calculations were used primarily to predict fuel rod power-peaking at the core/reflector interfaces as a function of burnup, but also to estimate the core eigenvalue $\left(\mathrm{k}_{\mathrm{inf}}\right)$, power cycle length, fuel burnup, and radial power shift across the core as a function of burnup.

The fully explicit MCNP 1/12-core model (Figure 6) with an axial extent of one fuel block, all regular fuel blocks, and reflective boundaries applied along the radial and top and bottom surfaces to create an annular NGNP core of infinite axial extent, were also used here for the depletion calculations. Only three of the fuel blocks were depleted: one block in Ring 6, one in Ring 7, and one in Ring 8. Every fuel block in Ring 6 was assumed to be identically the same, as were those in Ring 7 and Ring 8. This means that all fuel blocks in Ring 6 were initially identical and were depleted at the same rate. Similarly, all blocks in Ring 7 were depleted simultaneously and at the same, as were the blocks of Ring 8. Fission power densities were calculated in 630 individual fuel rods, or 210 fuel rods in each of the three regular fuel blocks in order to determine the radial power-peaking. From the fuel rod power densities, the time-dependent radial power-peaking factors across the core could be calculated. 


\subsubsection{Initial Core Depletion}

The first depletion studies focused on the initial core or first NGNP core. For a once-through burnup, fuel block loadings were previously determined for both a uniform-loaded, unmitigated core (10 $\mathrm{wt} \%, \mathrm{PF}=0.24715,554 \mathrm{~g} \mathrm{U}-235$ per block) and an optimally loaded core (Section 5.3). Both loading schemes were estimated to approximately achieve the 540-day intended power cycle length.

Figure 33 shows the actual calculated letdown curves or core eigenvalue (k-infinity), versus burnup in terms of effective full power days (EFPD), for the two depletion calculations. The first curve labeled "10f(554)-10f(554)-10f(554)" refers to the first depletion calculation (uniform-loaded core) and is deciphered using the following notation:

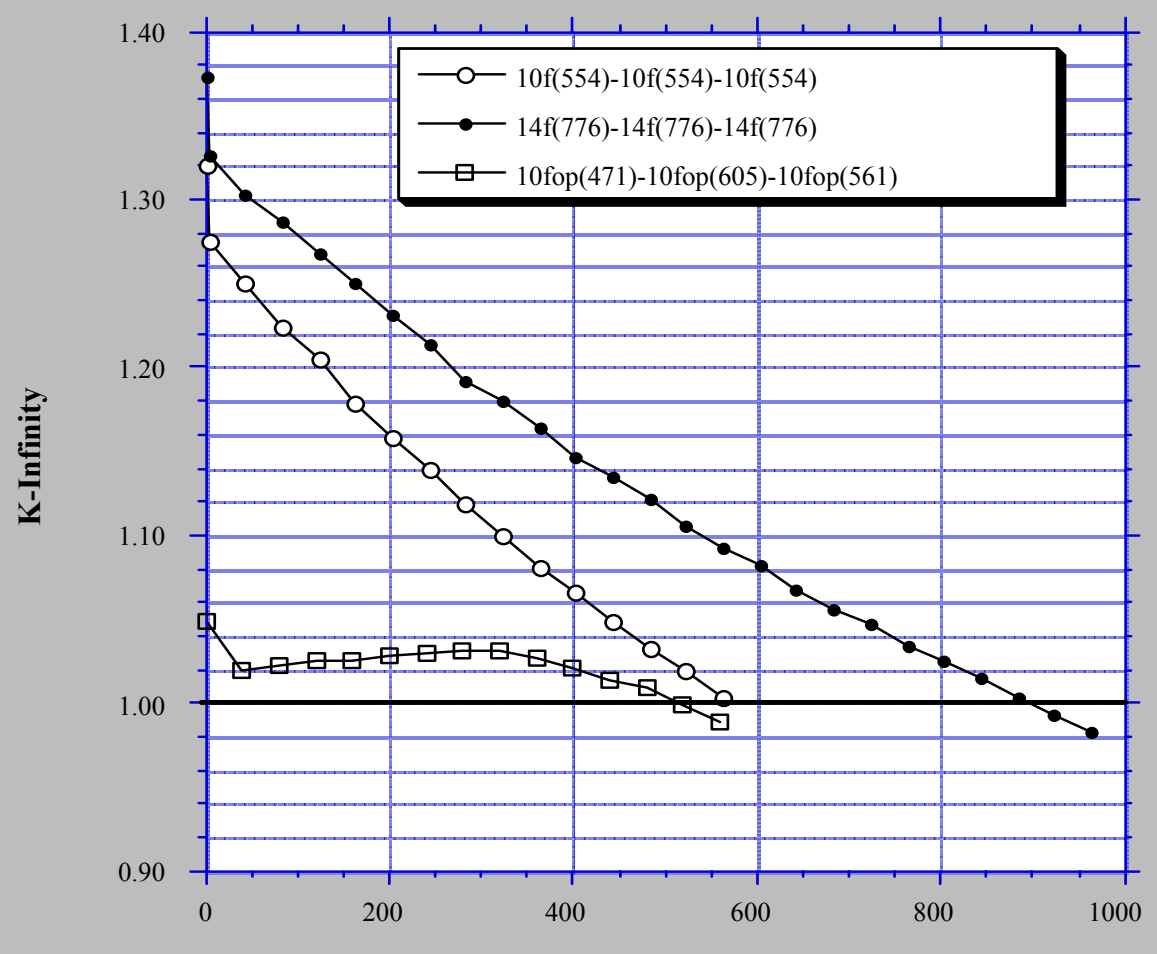

EFPD

Figure 33. Once-through or single-batch core depletion.

$$
\begin{array}{lll}
10 & = & \mathrm{wt} \% \mathrm{U}-235 \text { enrichment, in this case } 10 \mathrm{wt} \% \\
\mathrm{f} & = & \text { fresh fuel block } \\
\mathrm{d} & = & \text { depleted or once-burned fuel block } \\
\mathrm{op} & = & \text { optimized fuel block (mitigation applied) } \\
(554)= & \text { grams of U-235 per block at BOL, in this case } 554 \mathrm{~g} \mathrm{U} 235 .
\end{array}
$$

The first of the three entries (separated by hyphens) refers to Ring 6 fuel blocks, the second Ring 7 , and the third Ring 8. Similarly, the curve labeled "10fop(471)-10fop(605)-10fop(561)" corresponds to the second core depletion calculation (optimally-loaded core), where the fuel blocks in Ring 6 are fresh, optimized, and contain 471 grams U-235 per block or 10fop(471) designation. 
Figure 33 shows that the fresh uniform-loaded core (10f(554)-10f(554)-10f(554)) achieves a power cycle length of approximately 560 EFPD and meets the 540-day power cycle requirement. Similarly, the optimized core achieves approximately 520 EFPD just shy of the 540-day requirement. The optimized core falls short because there is slightly less initial total U-235 in the core relative to the uniform-loaded initial core. This shortfall would easily be overcome by increasing the U-235 loading slightly in the optimized fuel blocks. The end-of-cycle (EOC) burnup ranges from 60-65 GWD/MTU for the two NGNP initial core calculations. It should also be pointed out that a single size and single enrichment fissile fuel particle was assumed in the calculations.

Table 9 compares the maximum radial power-peaking factors in the two depletion calculations. The uniform-loaded core starts out at the relatively high value of 1.75 and over the course of the burnup decreases steadily down to 1.17 near the end of the power cycle. The decrease is attributed to U-235 burnout. The optimized core loading case however starts at 1.14 and increases slowly with burnup until end-of-cycle and reaches a value of only 1.25 . The peaking factor in this case remarkably remains relatively low over the entire power cycle, as desired. Figure 34 shows a plot of Table 50 data.

Table 9. Comparison of maximum power-peaking factors versus burnup.

\begin{tabular}{rccc}
\hline EFPD & $\begin{array}{c}\text { Uniform Core Loading } \\
\text { 10f(554)-10f(554)-10f(554) }\end{array}$ & EFPD & $\begin{array}{c}\text { Optimized Core Loading } \\
\text { 10fop(471)-10fop(605)-10fop(561) }\end{array}$ \\
\hline 0 & 1.75 & 0 & 1.14 \\
43 & 1.70 & 80 & 1.16 \\
123 & 1.57 & 160 & 1.20 \\
203 & 1.51 & 240 & 1.24 \\
283 & 1.34 & 320 & 1.25 \\
363 & 1.26 & 400 & 1.24 \\
443 & 1.21 & 480 & 1.25 \\
523 & 1.17 & 560 & 1.28 \\
\hline
\end{tabular}

Also shown in Figure 33 is a uniform $14 \mathrm{wt} \% \mathrm{U}-235$ enrichment case comparable to the uniform $10 \mathrm{wt} \% \mathrm{U}-235$ case, but with much higher U-235 block loading ( $776 \mathrm{~g} / \mathrm{block})$. This core, with its higher U-235 and lower U-238 loading, can achieve a power cycle length of approximately 900 EFPD and a corresponding average block burnup of approximately $110 \mathrm{GWD} / \mathrm{MTU}$. At BOL, the maximum powerpeaking factor is 1.94, and decreases with steady burnup until the end of the 900 EFPD reaches 1.18.

Figure 34 also shows the maximum radial power-peaking factor for the fresh $14 \mathrm{wt} \%$ uniformloaded core depletion calculation, plus a fourth case involving $14 \mathrm{wt} \%, 776 \mathrm{~g} \mathrm{U}-235$ loading per block with a fresh driver fuel in Ring 7 and once-depleted (one power cycle exposure) in Rings 6 and 8. The fourth case could be a possible annular reload segment. Also, it is observed that the unmitigated, oncedepleted blocks can still achieve relatively high particle power-peaking factors upon a reload shuffle into Rings 6 or 8 from the Ring 7 driver annulus. And these once-depleted driver fuel blocks with no optimization (unmitigated); i.e., no particle-packing fraction zoning and burnable poisons, would need to be situated next to fresh optimized fuel blocks in Rings or 8 containing discrete burnable poison rods in order to depress the local thermal neutron flux and hence reduce the power-peaking in the once-depleted $14 \mathrm{wt} \%$ blocks. 


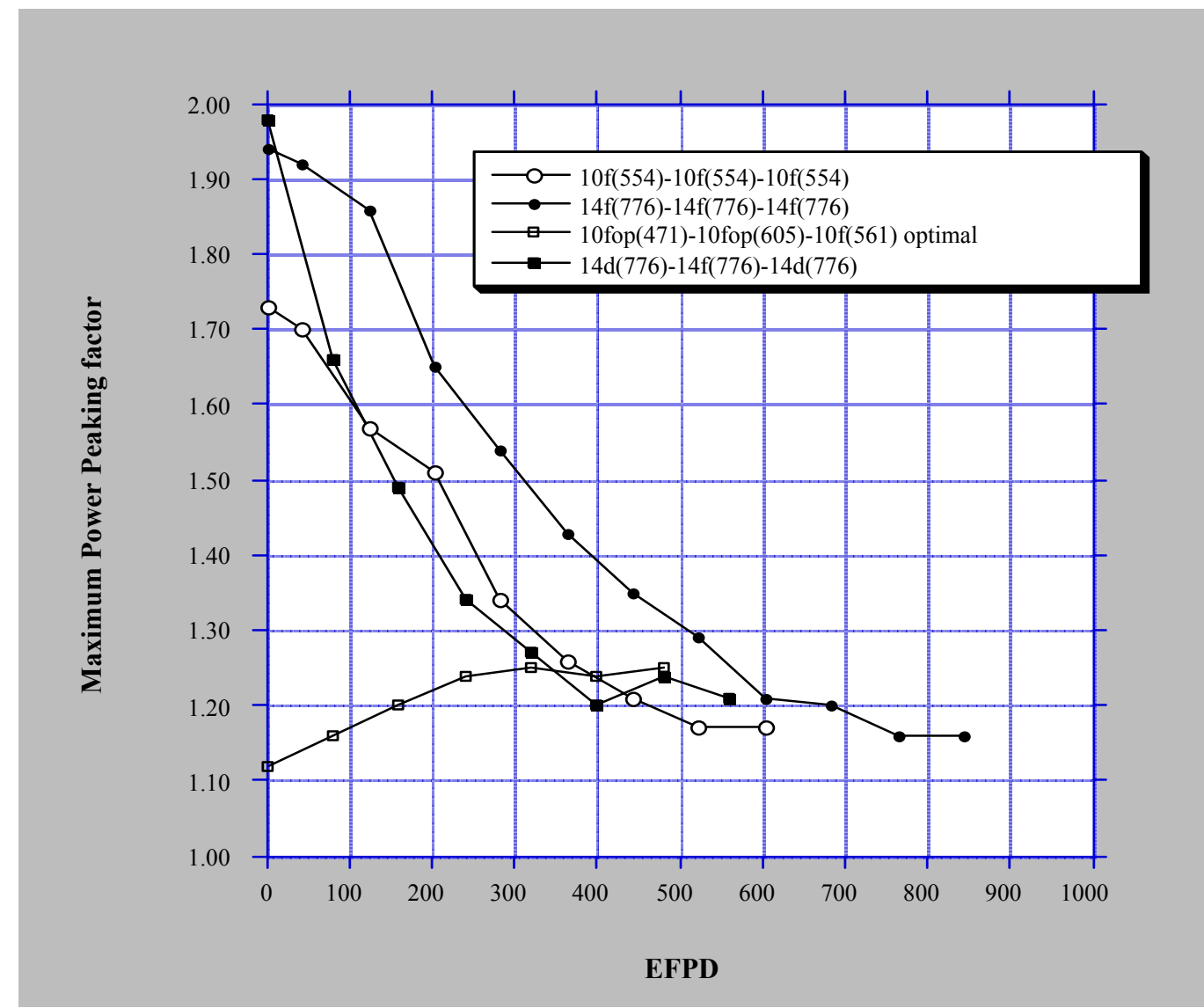

Figure 34. Maximum radial power-peaking factors as a function of burnup.

\subsubsection{Pseudo-Equilibrium Cores}

The pseudo-equilibrium core analysis here is based on a two-batch reload scenario. Approximately half of the core fuel blocks would be once-depleted (with approximately 540 EFPD and 65 GWD/MTU burnup) and the other half would be fresh fuel blocks. Although the JMOCUP is fully capable of handling multiple types of fuel blocks (fresh, depleted, different U-235 loadings, different enrichments, etc.) in any active core ring block location, as would be expected in the actual NGNP reload configuration, the depletion analyses here were restricted, for simplicity and due to lack of computer resources, to one block type in each of the three annular rings. In other words, all 30 fuel blocks in Ring 6 were assumed to be identical, all 36 Ring 7 blocks were identical, and all 36 Ring 8 blocks were identical. The depletion calculation then depleted just one block in Ring 6, 7, and 8, or all 210 fuel rods in each of the three fuel blocks. At the beginning of each depletion calculation, fresh, optimized, or depleted fuel compositions could be loaded as desired. Also, the depletion analyses focused primarily on combinations of fuel blocks with two BOL enrichments (10 and $14 \mathrm{wt} \% \mathrm{U}-235)$ and two U-235 block loadings (554 and $776 \mathrm{~g} \mathrm{U}-235$ per block).

Although the depletion calculations are limited to one block per ring and each ring has the same depleted composition as all the other blocks in that ring, the burnup characteristics of these cores are useful for estimating core k-infinity versus burnup for three-block radial core segments and combinations of these segments that might be part of an actual NGNP core reload configuration. In this light, many depletion calculations were performed using this three-block radial segment strategy to see which combinations of fuel blocks would meet the 540-day cycle length using fresh blocks from the initial core $(10 \mathrm{f}(554))$, depleted blocks from the initial core $(10 \mathrm{~d}(554)$, fresh initial core optimized blocks 
(10fop(XXX)), fresh 2-batch reload blocks (14f(776)), depleted 2-batch reload blocks (14d(776)), and optimized 2-batch reload blocks (14fop(XXX)). These calculations provided insight into possible NGNP transition and equilibrium core configurations, referred to here as pseudo-equilibrium core depletion studies.

Figure 35 shows eight combinations of three-block radial segments and the core k-infinity versus burnup (EFPD). The same three-block notation is used as described above. Several interesting observations and conclusions can be drawn from the Figure 35 letdown curves.

1. The second NGNP core or first reload for the initial core will require higher enrichment blocks than the initial core blocks (10f(554)). The second core, loaded with a combination of fresh and depleted $10 \mathrm{wt} \%$ fuel blocks (554 g U-235 per block), will not be sufficient to meet the 540-day power cycle. To show this, it is noted that the fresh $10 \mathrm{wt} \%$ core, $10 \mathrm{f}(554)-10 \mathrm{f}(554)-10 \mathrm{f}(554)$ from Figure 33, just slightly exceeds the 540 EFPD cycle length requirement, and therefore the use of any significant fraction of lower reactivity, once-depleted $10 \mathrm{wt} \%$ blocks will most certainly prevent the reload core from achieving a 540 power cycle. The two cases in Figure 35, 10d(554)$10 f(554)-10 d(554)$ and $10 d(554)-10 f(776)-10 d(554)$, both only reach approximately 300 EFPDs. These two letdown curves could be lengthened somewhat by placing additional fresh $10 \mathrm{wt} \%$ elements in Ring 6 and 8 intermixed with some fraction of depleted blocks, but will still not remain critical for 540 EFPDs. Increasing the U-235 content in Ring 7; i.e., case 10d(554)-10f(776)$10 \mathrm{~d}(554)$ relative to the $10 \mathrm{~d}(554)-10 \mathrm{f}(554)-10 \mathrm{~d}(554)$ case, improved the cycle length only

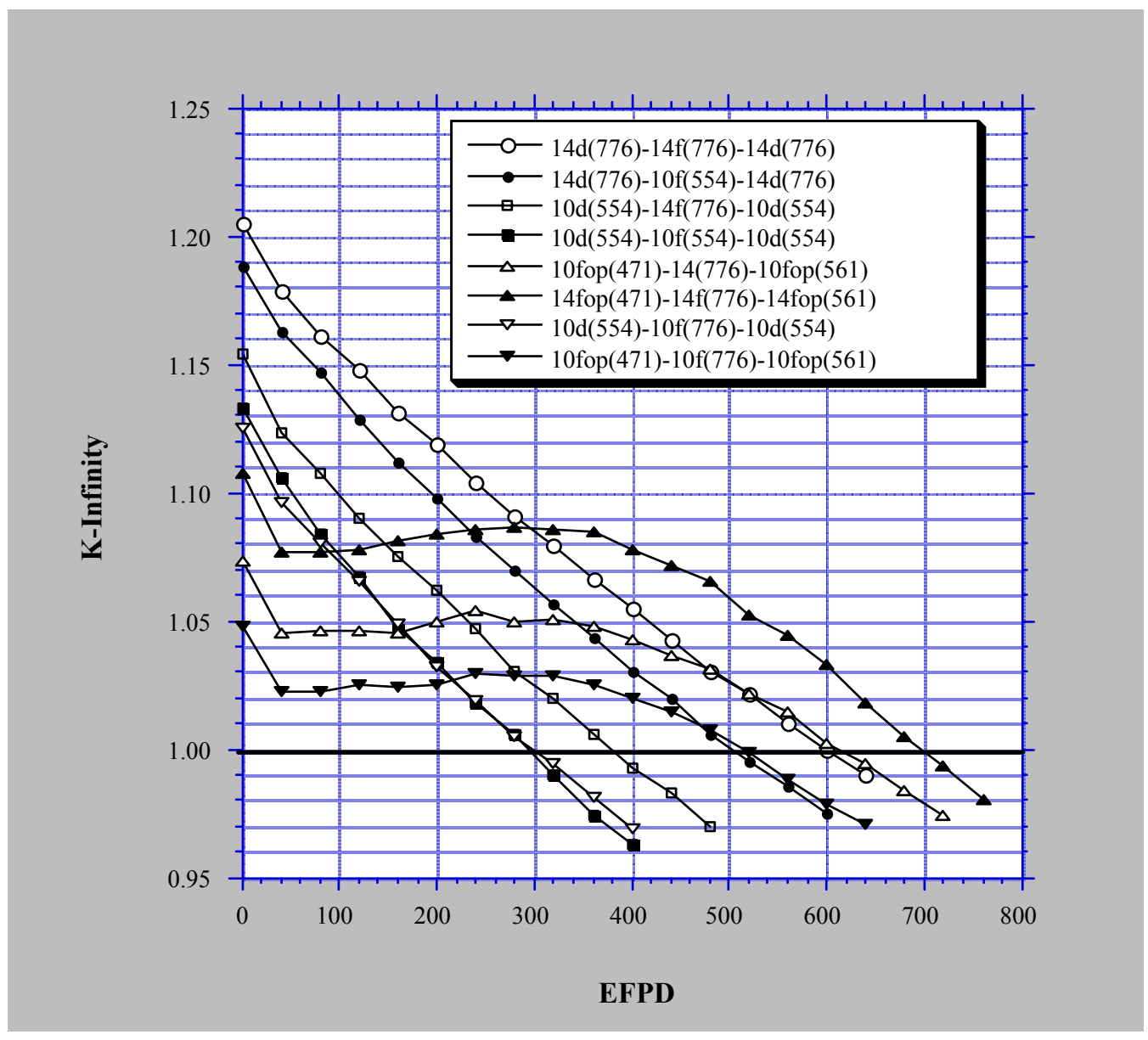

Figure 35. Core k-infinity versus burnup for a variety of three-block radial core loadings. 
insignificantly. The conclusion here is that a reload core will need some fresh fuel blocks with enrichment greater than $10 \mathrm{wt} \%$ to add reactivity to the core. This is why we chose the second and higher enrichment of $14 \mathrm{wt} \% \mathrm{U}-235$ for this study.

2. If Ring 7 driver fuel is increased in enrichment and loading ( $14 \mathrm{wt} \%, 776 \mathrm{~g} \mathrm{U}-235$ per block) and Ring 6 and 8 each have initial core, once-depleted fuel blocks, or case $10 \mathrm{~d}(554)-14 \mathrm{f}(776)$ $10 \mathrm{~d}(554)$, the core remains critical for approximately 380 EFPDs. This says that the reload still needs more fresh $14 \mathrm{wt} \%$ blocks in the core to meet cycle length. Noting that the case 10fop(471)14f(776)-10fop(561) will achieve approximately 600 EFPDs and easily meet cycle length, the first reload core would need to replace some of the 10d(554) blocks in Rings 6 and 8 with fresh optimally loaded 10 fop(471) and 10 fop(561) blocks or use slightly fewer 14 fop(471) and 14 fop $(561)$ block replacements in order to achieve the desired cycle length.

3. Of the eight depletion cases in Figure 34, five cases plus one from Figure 33 achieve approximately the 540 EFPD goal. These include:

14f(776)-14f(776)-14f(776) with 900 EFPD (Figure 33)

14fop(471)-14f(776)-14fop(561) with 700 EFPD (Figure 34)

10fop(471)-14f(776)-10fop(561) with 620 EFPD (Figure 34)

$14 \mathrm{~d}(776)-14 \mathrm{f}(776)-14 \mathrm{~d}(776)$ with 600 EFPD (Figure 34)

10fop(471)-10f(776)-10fop(561) with 530 EFPD (Figure 34)

14d(776)-10f(554)-14d(776) with 520 EFPD (Figure 34).

All six cases have fresh fuel in Ring 7. It is assumed that reload cores would be driven primarily by fresh, high loaded 10 or $14 \mathrm{wt} \%$ enriched fuel blocks. Rings 6 and 8 would then be dominated by depleted, lower loaded fuel blocks, lower enrichment blocks, or optimized fuel blocks with burnable poison and packing fraction zones to reduce the radial power-peaking factors and improve neutron economy.

4. The third NGNP core or second reload core would contain once-depleted $14 \mathrm{~d}(776)$ fuel blocks. Two three-block segments; namely, 14d(776)-10f(554)-14d(776) and 14d(776)-14f(776)-14d(776) both contain $14 \mathrm{~d}(776)$ blocks and achieve 520 and 600 EFPD cycle lengths. These $14 \mathrm{~d}(776)$ depleted blocks would need to be placed adjacent to either 10fop(554) or 14fop(776) in order to reduce power-peaking in the 14d(776) blocks in Rings 6 and 8.

5. Based on the Figure 35 results, the two-batch core reload is a definite possibility using either or both 10 or $14 \mathrm{wt} \%$ enrichment fuel particles with packing fractions less than $25 \%$. Another use for the 10 and $14 \mathrm{wt} \%$ fuel blocks would be for axial power flattening as well.

Currently, only 2D radial depletion calculations have been performed, but 3D depletion calculations are possible with the existing Monte Carlo depletion methodology here. 


\section{Thermohydraulics Study (4-Ring Annular Core)}

Although the bulk of the analytical work focused on the neutronic aspects of the prismatic NGNP reactor core and the particle fuel, a short $\mathrm{T} / \mathrm{H}$ analysis was performed to evaluate a four-ring annular active core relative to the standard three-ring GT-MHR/NGNP cores. The question to be answered was whether or not a four-ring annular core would improve the reactor core transient behavior and still achieve some very attractive neutronic features.

In order to answer this question, RELAP5-3D/ATHENA models developed last year were modified to include a fourth active core ring (Figure 36). The graphite inner reflector graphite or Ring 5 with 24 fuel columns was converted into an additional fueled zone or fourth active core ring, along with six extra outer graphite reflector blocks in Ring 8 that also became fuel blocks. Of the possible model modifications, these modifications were easiest to implement in order to increase the active core radial dimension.

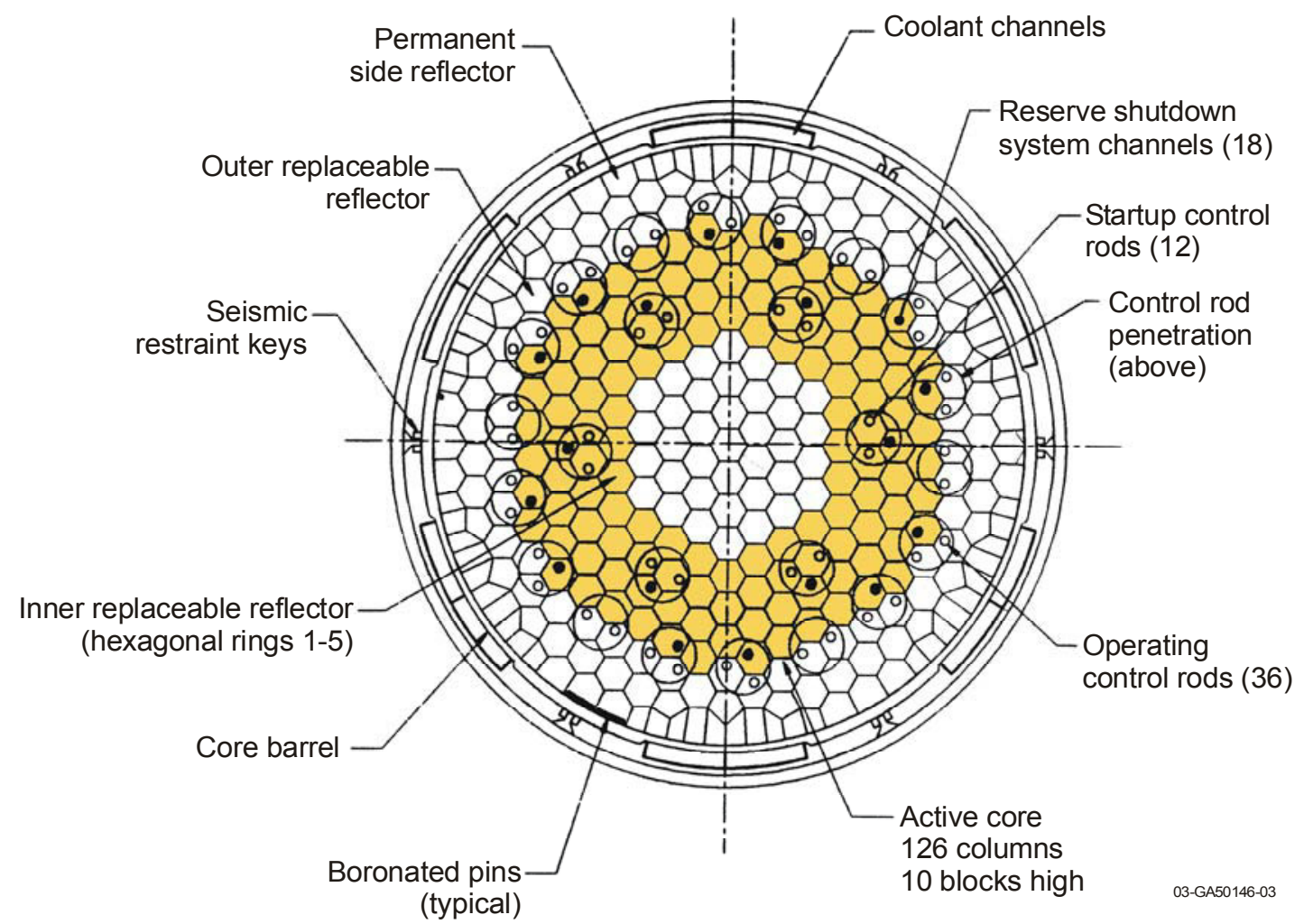

Figure 36. The proposed four-ring GT-MHR/NGNP active core.

From the fuel particle and neutronic point of view, the four-ring core offers some very attractive features. First, the core average power density drops significantly from approximately 6.6 to $5.1 \mathrm{~W} / \mathrm{cc}$, resulting in a correspondingly lower average particle power in the core. Second, the overall particle packing fractions in the core could be reduced, too. This was an important concern initially when it was realized that the current state of the AGR program fabrication process might have long-term particlepacking fraction limitations, particularly for the smaller 350-micron kernel particles. Third, with 4 fuel rings, a relatively simple in-out fuel management scheme could be envisioned where the two inner fuel rings (Rings 6 and 7 or the driver fuel) would be shuffled to the two outer fuel rings upon reload (Rings 5 and 8). Since the two inner rings contain $30+36$ or 66 fuel columns and the two outer rings contain $24+42$ or 66 fuel columns, a two-batch reload with a simple in-out shuffle looked promising. 
Two RELAP5-3D/ATHENA calculations of a prismatic core NGNP were performed to preliminarily indicate effects of adding this fourth ring of fuel to the core. These calculations used the previous 3-channel (or 3-ring) model (102 fuel assemblies in three rings) and a recently developed 4channel model (132 fuel assemblies in four rings). The dimensions of the core barrel and reactor vessel were unchanged.

Steady state calculations were performed for both models. The principal conditions were a core power of $600 \mathrm{MW}$, a nominal coolant inlet temperature of $490{ }^{\circ} \mathrm{C}$, a coolant outlet temperature of $1000{ }^{\circ} \mathrm{C}$, and a core bypass flow of $10 \%$. A uniform radial power density was used for both cases, and the axial power profile was a chopped cosine with a 1.2 peak-to-average ratio.

Both models then simulated a low-pressure conduction cooldown transient. The boundary conditions were the same as in previous analyses, with a 10-second blowdown from operating to atmospheric pressure and a reactor scram signal being generated at the start of the transient.

Figure 37 shows the core power from the two calculations, evidence that the same power was used in both. Figure 38 shows the peak fuel temperature from each calculation. The 4-channel model had a peak value of $1784^{\circ} \mathrm{C}, 145^{\circ} \mathrm{C}$ hotter than the 3 -channel case. Figures 39 and 40 show the peak fuel temperatures in each of the fueled rings. The outer ring, ring 8 , had nearly the same temperature in both cases. Reflector temperatures near the core midplane are shown in Figure 41, showing that the outer reflector temperatures were close together but the inner reflector temperatures were not. The inner reflector follows the temperature of the innermost fuel ring, so the 4-channel model had a hotter inner reflector. The peak reactor vessel temperature, shown in Figure 42, was slightly higher in the 4-channel case. This also resulted in a slightly higher heat removal rate in the RCCS, as seen in Figure 43.

The 4-ring results show maximum fuel temperatures above the $1600{ }^{\circ} \mathrm{C}$ under the transient accident conditions in all fuel rings, except the outer ring, Ring 8, where the temperatures remain approximately the same in both the 3-and 4-ring cases. The interior rings were successively hotter in the 4-channel model than in the 3-channel model. The principal reason is that there was a longer conduction path from the inner ring out to the reactor vessel; the smaller inner reflector heat sink also contributed. The 4-channel model had a peak value of $1784^{\circ} \mathrm{C}, 145^{\circ} \mathrm{C}$ hotter than the 3 -channel case.

Although the 4-ring GT-MHR/NGNP core transient analysis shows that an increase in the active core radial dimension, at least under the assumed modeling conditions, increases the transient temperatures above the $1600^{\circ} \mathrm{C}$ limit, it can be deduced conversely that, perhaps making the active core radial dimension thinner, may be the design path to take in the future to reduce transient temperatures and increase the safety margin. The individual fuel block flat-to-flat dimension could be reduced in the 3-ring core to achieve this goal. The design would, however, have to balance the reduced number of block fuel rod locations with an increase in particle packing fraction and/or enrichment and/or fuel rod radius. Again to optimize the NGNP, further design parametric studies would necessarily need to be performed.

The results of these calculations indicate that the additional fourth fuel ring will increase the peak transient temperature by nearly $150^{\circ} \mathrm{C}$, compared to the base three fueled rings model. The increase in the conduction distance to the ultimate heat sink and the reduction of the size of the interior heat sink are the main reasons for the higher temperatures. For the four-ring core annulus to work, the fuel block would need to be redesigned; namely, the flat-to-flat dimension would need to be smaller to accommodate four rings with the same core annulus thickness, but this is currently beyond the scope and schedule. The T/H analysis would also indicate that a thinner core annulus could possibly decrease the maximum fuel temperature under the transient conditions, but would result in higher average core power densities, greater particle-packing fractions, and ultimately greater particle average powers. 


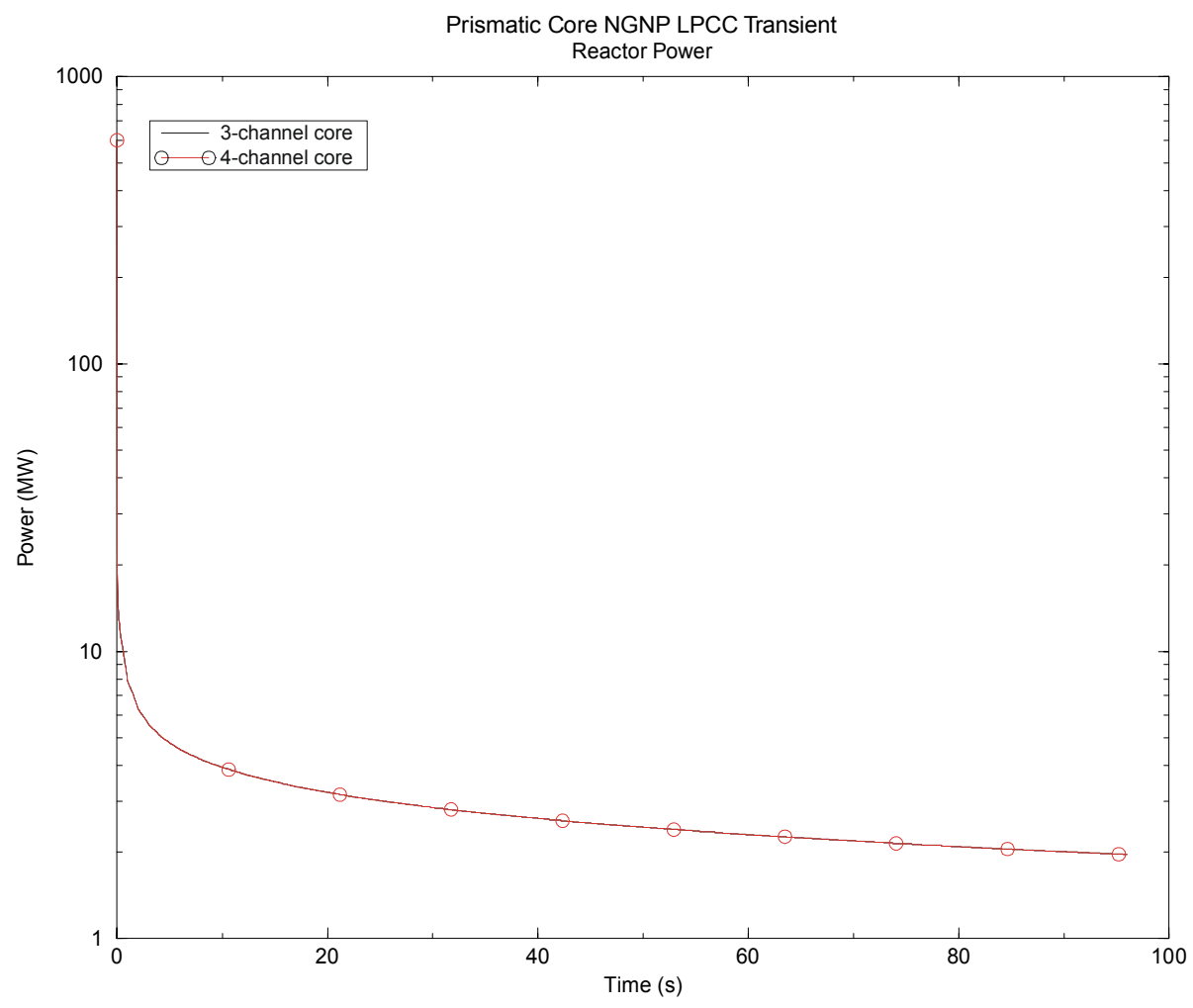

Figure 37. Transient core power for the 3- and 4-channel models.

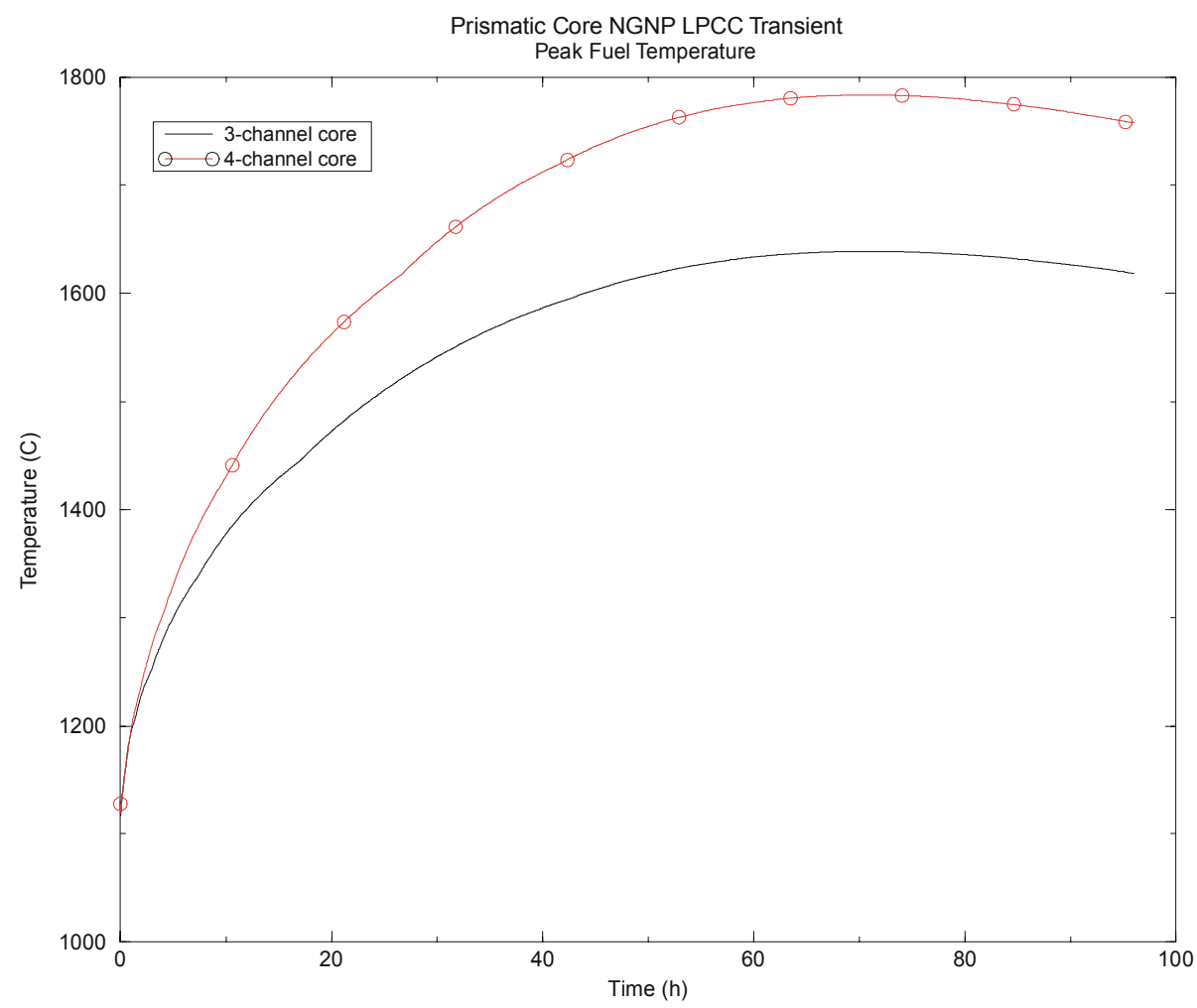

Figure 38. LPCC peak fuel temperatures for the 3- and 4-channel models. 


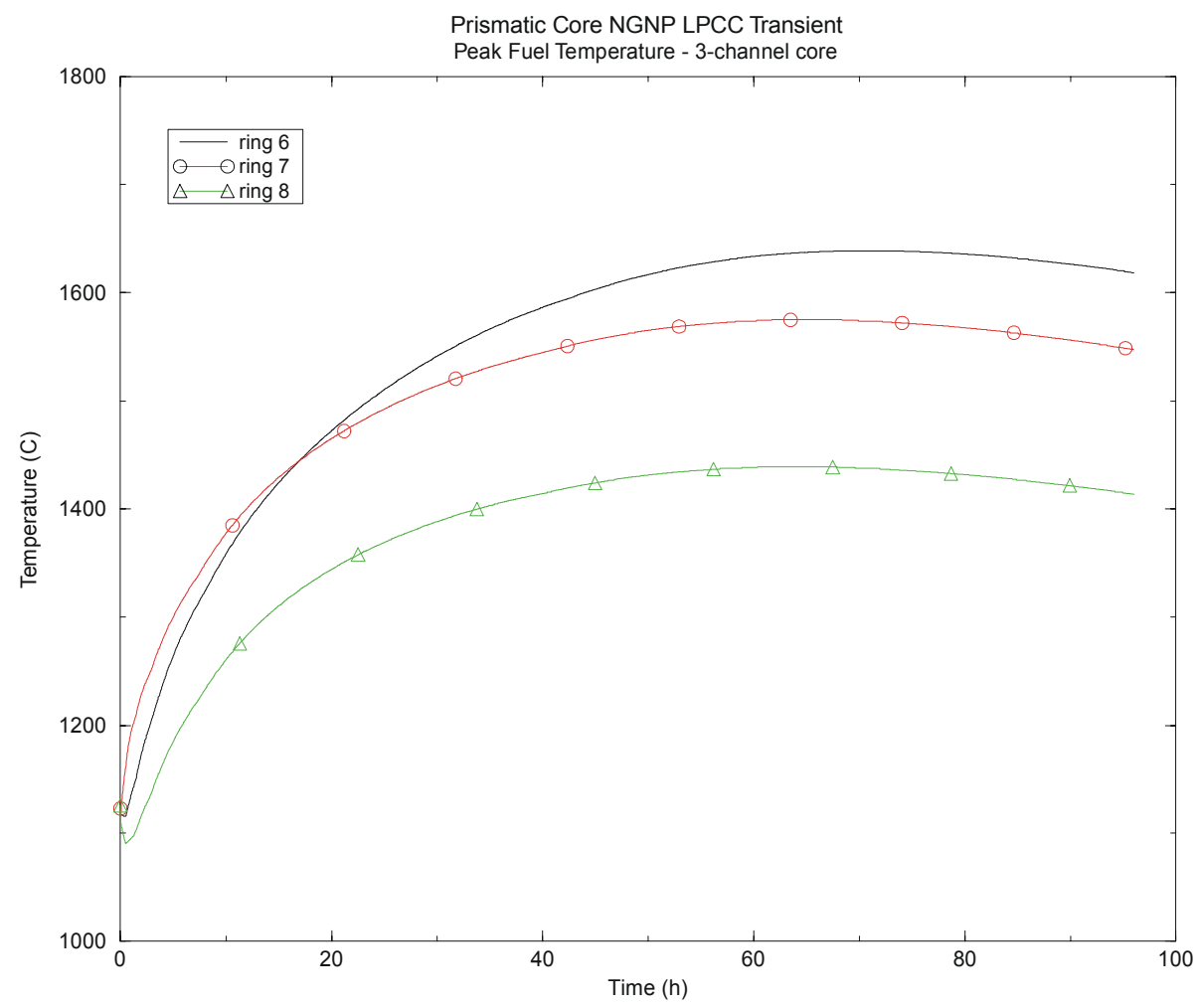

Figure 39. LPCC peak fuel temperatures for the 3 fueled rings.

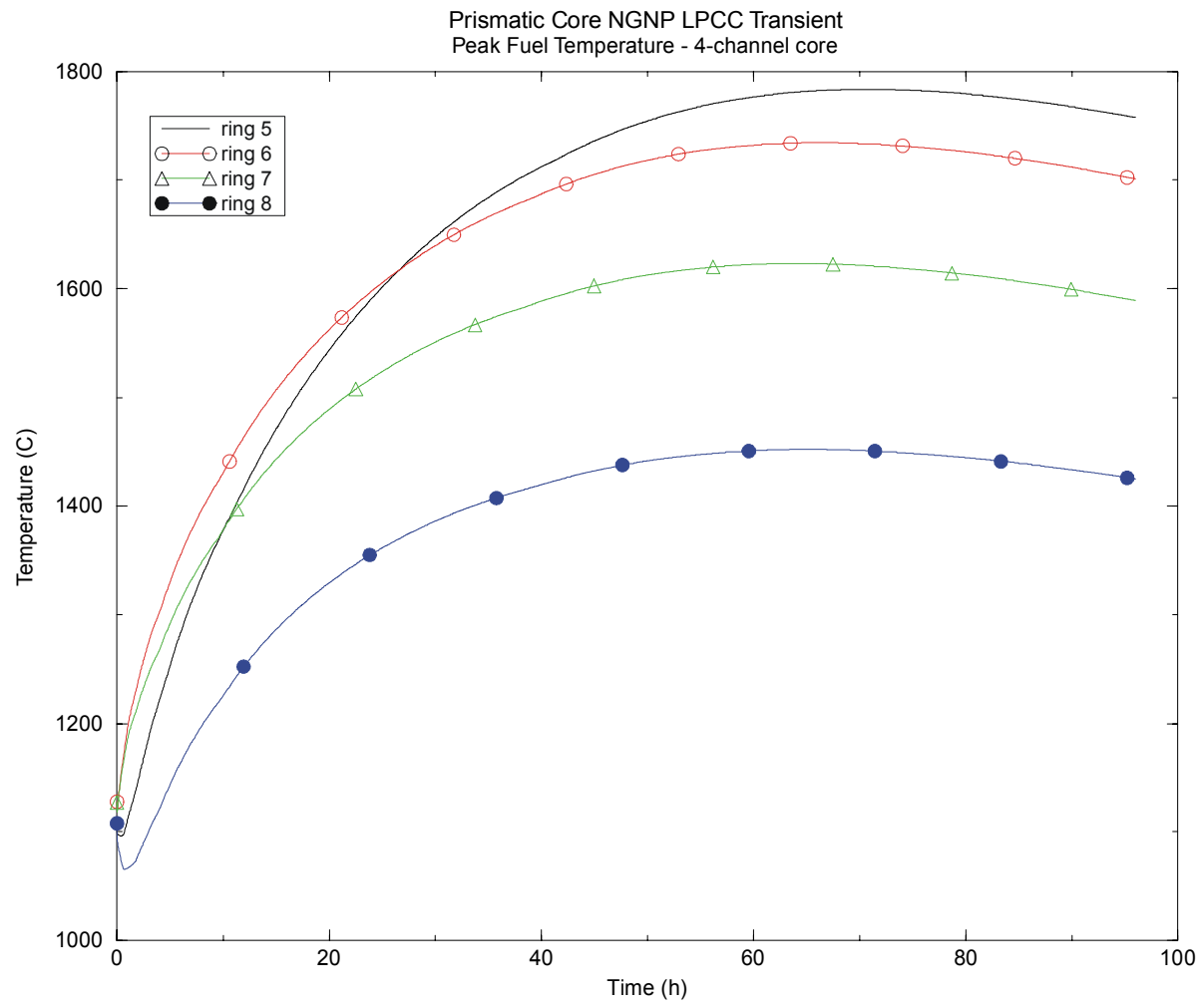

Figure 40. LPCC peak fuel temperatures for the 4 fueled rings. 


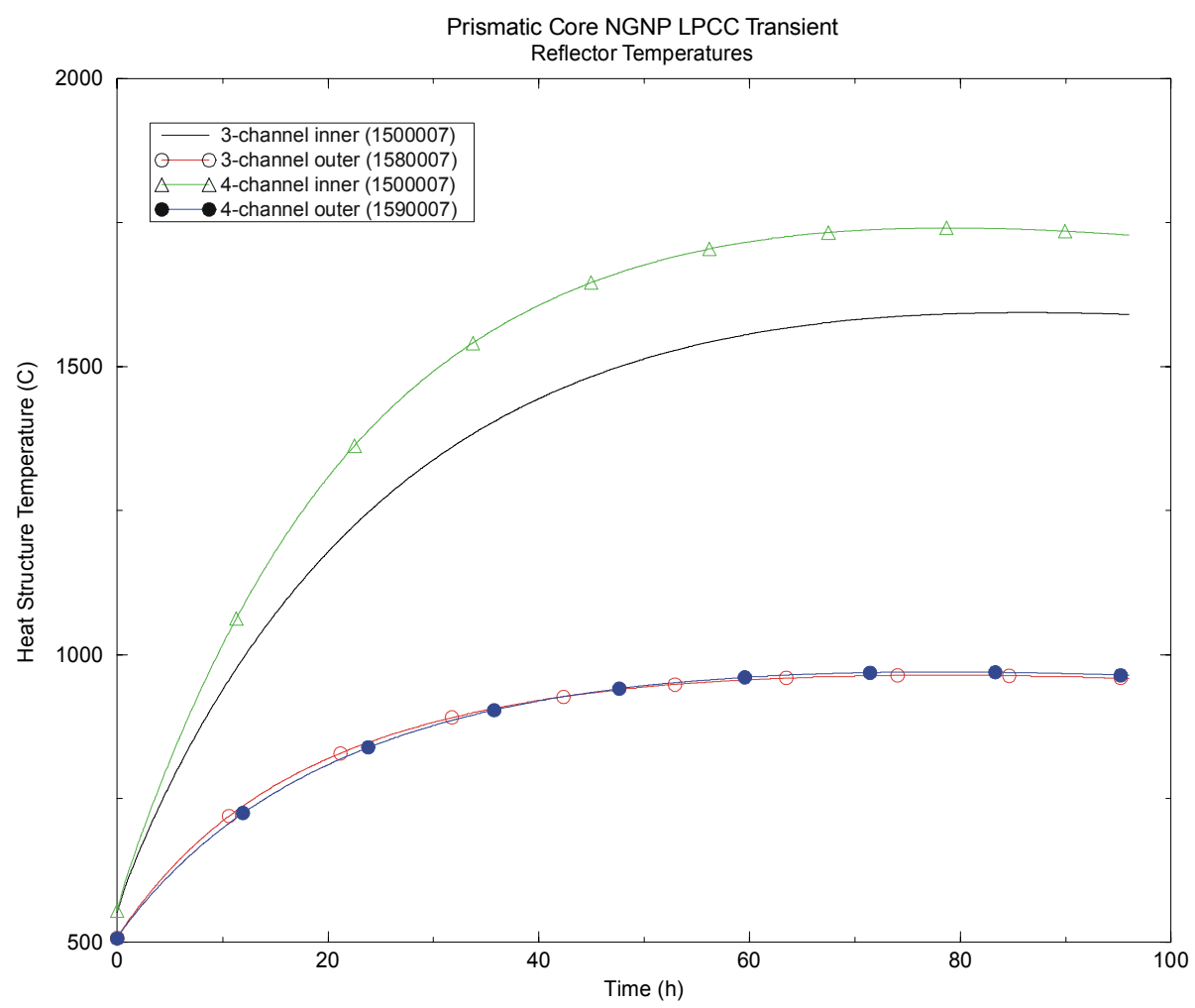

Figure 41. LPCC inner and outer reflector temperatures for the 3-and 4-channel models.

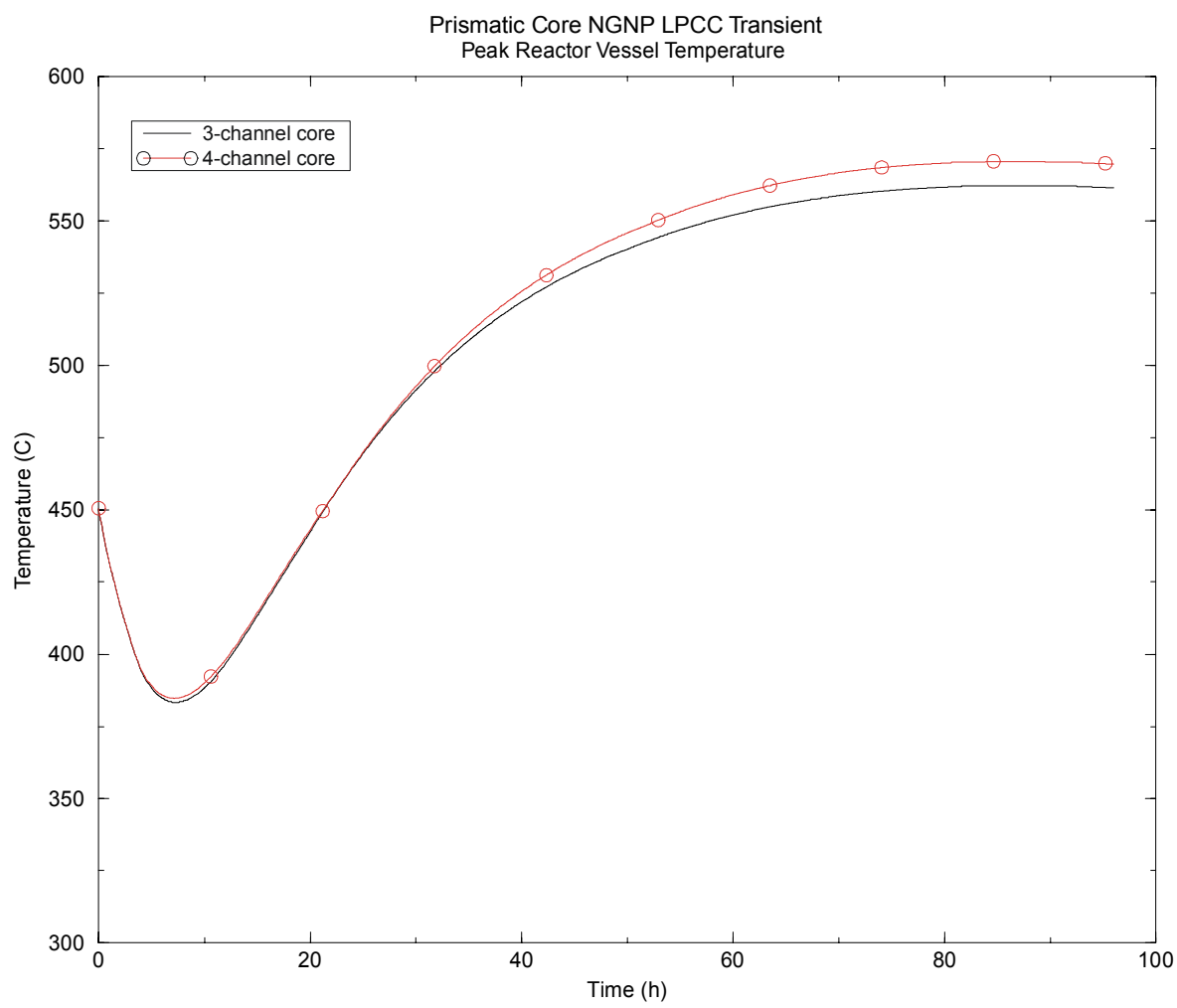

Figure 42. LPCC peak reactor vessel temperatures for the 3- and 4-channel models. 


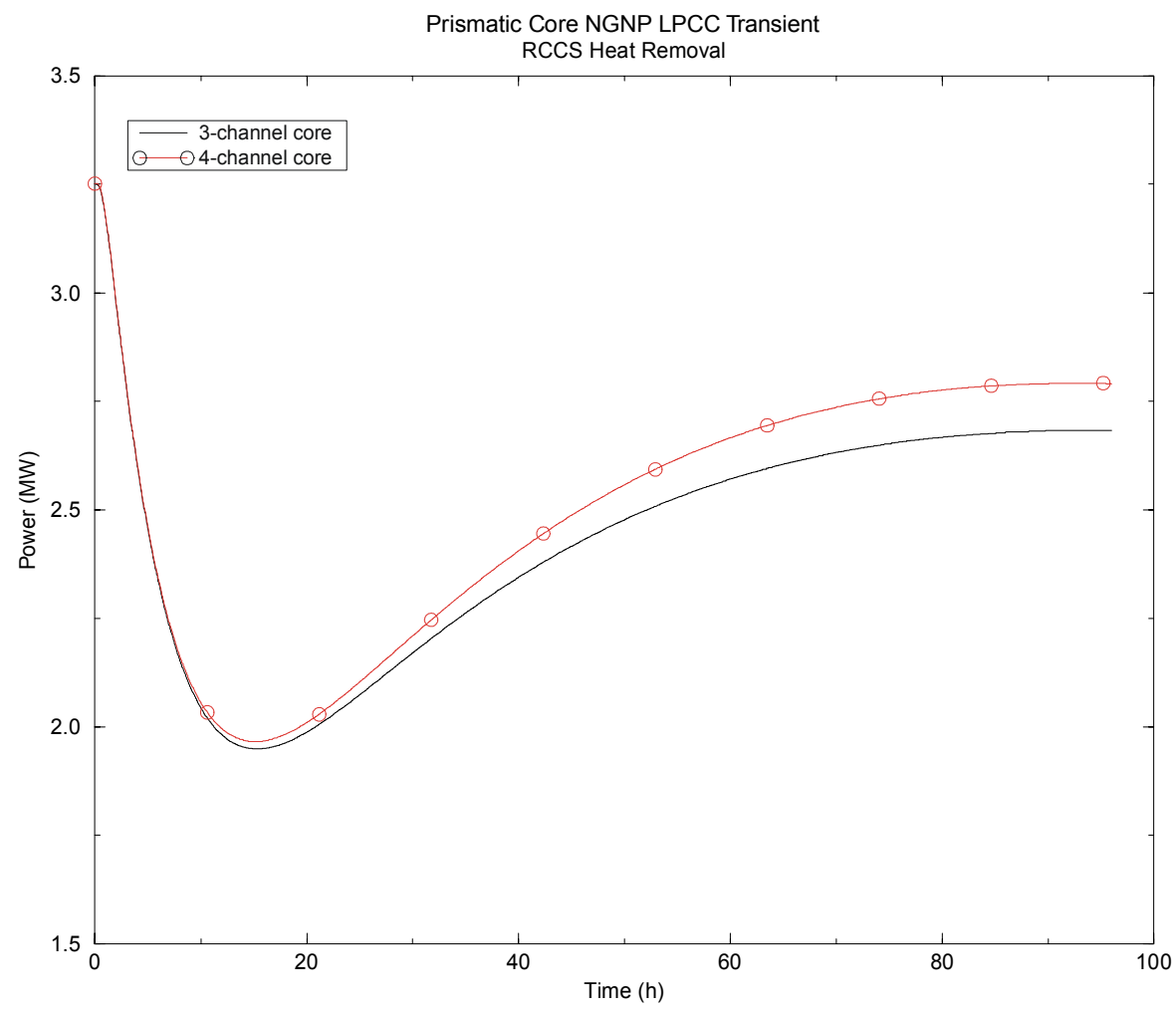

Figure 43. LPCC RCCS heat removal for the 3- and 4-channel models. 


\section{CONCLUSIONS}

From results of the neutronic studies, it is apparent that the fuel particle variable design space is quite broad and flexible enough to accommodate the current prismatic NGNP reactor design requirements. Multiple fuel particle design solutions are possible. This means many different combinations of particle-packing fraction, enrichment, and kernel size are possible for the NGNP core. While this is good news for the future design of the NGNP reactor, it leaves the immediate need for specific particle design information and the development of the Fuel Specification somewhat open ended.

However, with the current compact fabrication limitation on the particle-packing fraction $(<35 \%)$ and the potential need for heavily loaded fuel blocks for two- and three-batch core reloads to achieve the 18-month power cycle, a larger diameter fuel kernel is probably the right direction to take the particle design. For these reasons, we chose to increase the current 350 -micron fissile particle kernel diameter to a 425 -micron diameter. This new kernel is mid-range in a $375-475$ micron range that could provide the same heavy metal loading advantage, and yet still be within the historical and successful fissile particle design envelope.

It is also clear from the parametric sensitivity studies and the core depletion calculations that a single fissile particle is sufficient for the NGNP reactor design. The proposed binary particle system of the GT-MHR with both a fissile and fertile particle is not necessary. This will reduce NGNP programmatic fuel development, fabrication, and irradiation costs significantly. Based on the analyses herein, it appears as if a single fissile particle size with a single enrichment could also be possible with block loadings and radial power peaking, controlled completely by particle packing fraction. What the single enrichment would be (for example, $14 \mathrm{wt} \%$ as used in the analyses herein, is a possibility) and whether or not two enrichments might provide some additional burnup or cost advantage remain to be explored further.

For the NGNP initial core, fuel blocks with the 425 -micron particle, $10 \mathrm{wt} \%$ enrichment, and packing fractions of approximately $25 \%$ can achieve the goal power cycle length. The particles could be a single 425-micron diameter particle with a single enrichment. It should also be pointed out that the 350micron particles with $10 \mathrm{wt} \%$ enrichment would also work fine; however the required particle-packing fractions would be slightly higher at $33.5 \%$, but still less than the $35 \%$ limit. Although these initial core blocks are designed for once-through $65 \mathrm{GWD}$ /MTU burnups, higher burnups can be achieved by reuse in reload cores (for example, the second and third NGNP transition cores).

For the transition cores and the equilibrium core, fresh reload fuel blocks with enrichments greater than $10 \mathrm{wt} \%$ and uranium loadings greater than $554 \mathrm{~g} \mathrm{U}-235$ per block (initial core) will be required for two- and three-batch reloads. For a two-batch reload, the higher reactivity required can be achieved with a 425-micron particle, $14 \mathrm{wt} \%$ enrichment, particle-packing fractions less than $25 \%$, and a loading of approximately $776 \mathrm{~g} \mathrm{U}-235$ per block. Burnups on these twice-burned or two-cycle reload blocks would approach $120 \mathrm{GWD} / \mathrm{MTU}$. Again, the 350-micron particle would also work, but with a packing fraction of approximately $34 \%$ approaching the current PF limit and increasing fabrication cost.

A three-batch reload however would not be possible with the 350 -micron particle at $14 \mathrm{wt} \%$, because the uranium loading requirement would drive the particle-packing fraction past the $35 \%$ limit up to $43 \%$. However, increasing the enrichment to 20 -wt $\%$ enrichment would drive the packing fraction back down to approximately $33 \%$, and once again the 350-micron kernel particle would be acceptable.

Increasing the fuel kernel diameter does allow for more flexibility in fuel block loading and lower particle enrichments. Lower enrichment may improve fuel cycle costs, and needs to be addressed in a future economic study. 
For the prismatic NGNP once-through cycles, the following fuel parameters are recommended (see Table 10):

Table 10. Recommended fuel parameters for once-through cycles.

\begin{tabular}{ll}
\hline \multicolumn{1}{c}{ Parameter } & \multicolumn{1}{c}{ Value } \\
\hline Kernel diameter & 425 microns \\
Enrichment & $10 \mathrm{wt} \%$ \\
Packing fraction & $<35 \%$ \\
Cycle length & $540 \mathrm{EFPD}$ \\
Discharge burnup & $>70,000 \mathrm{MWD} / \mathrm{MTU}$ \\
U-235 loading & $500-600$ grams/block \\
Burnable absorbers & Zoned, $\mathrm{B}_{4} \mathrm{C}$ \\
\hline
\end{tabular}

The significant radial power-peaking at the inner and outer reflector/core interfaces can be greatly reduced by using particle-packing fraction zoning and discrete burnable poison rods. Based on the powerpeaking mitigation and optimization studies herein; for example, three packing fraction zones in Ring 6 blocks, one in Ring 7, and two in Ring 8, work well. One of the zones for blocks in Rings 6 and 8 would necessarily be the first 4 or 5 fuel rod rows of fuel pins adjacent to the reflector/core interface. The discrete burnable poison rods would be located in selected corners of the hexagonal fuel blocks in Rings 6 and 8, primarily. The poison rods would be loaded with small amounts of boron- 10 in the form of $\mathrm{B}_{4} \mathrm{C}$ (boron carbide) particles. These rods actually play a dual role by helping to depress the local thermal flux and consequently the local power-peaking factors, and hold down excess core reactivity. At beginning-oflife conditions, the optimally loaded fuel blocks would create radial peaking factors of no more than approximately 1.15 , and based on depletions calculations, this factor would not rise beyond a factor of approximately 1.25 by end-of-cycle.

Two-dimensional fully explicit Monte Carlo models with individual fuel particles modeled in regular or spiral arrays were used to predict particle peak-to-average values in the maximum powerpeaking and highest thermal flux gradient fuel compact in the of the annular core. The predicted maximum peak-to-average factors across the regular particle array were less than 1.05 at BOL conditions. The individual particle peaking in any core compact, however, is expected to increase with burnup, due to a buildup of Pu-239 in the peripheral particles. For example, at a burnup of 118 GWD/MTU burnup, a relatively small number of particles would experience a peaking factor as high as 1.20 , but the bulk of the compact particles would have a peak-to-average of less than 1.06 .

A maximum axial power-peaking factor has been estimated to be approximately 1.30 using 3D Monte Carlo models of the NGNP core. It is believed that this factor is conservative and could be readily reduced, even with simple axial loading schemes to flatten axial power.

A conservative total power-peaking factor for individual fuel particles in the GT-MHR and NGNP cores can be estimated to be the product of the individual compact $(1.05 * 1.20=1.26)$, radial $(1.25)$, and axial (1.30) peaking factors. The total power-peaking factor can be conservatively estimated to be approximately 2.1. Individual particle powers in the GT-MHR and the NGNP are relatively low, due to the low average core power density of $6.6 \mathrm{~W} / \mathrm{cc}$. Even with the total power-peaking factor of 2.1 applied, the peak particle power will not exceed $150 \mathrm{~mW} /$ particle. This is much less than the $250 \mathrm{~mW} /$ particle goal for the NGNP. 


\section{REFERENCES}

1. A Technology Roadmap for Generation IV Nuclear Energy Systems, Generation IV International Forum, December 2002.

2. Technical Program Plan for the Advanced Gas Reactor Fuel Development and Qualification Program, ORNL/TM-2002/262, April 2003.

3. NGNP Point Design-Results of the Initial Neutronics and Thermal-Hydraulic Assessments During FY-03, Revision 1, Idaho National Engineering and Environmental Laboratory, INEEL/EXT-03-00870, September 2003.

4. Gas Turbine-Modular Helium Reactor (GT-MHR) Conceptual Design Description Report, Revision 1, Report 910720, GA Project No. 7658, General Atomics, San Diego, CA, July 1996.

5. T. K. Kim, W. S. Yang, M. A. Smith, T. A. Taiwo, and H. S. Khalil, Assessment of Monte Carlo and Deterministic Codes for Next Generation Nuclear Plant (NGNP) Core Modeling, Argonne National Laboratory Gen IV Report, April 15, 2004.

6. T. K. Kim, W. S. Yang, T. A. Taiwo, and H. S. Khalil, Whole-Core Depletion Studies in Support of Fuel Specification for Next Generation Nuclear Plant (NGNP) Core, Argonne National Laboratory Gen IV Report, April 15, 2004.

7. "MCNP4C Monte Carlo N-Particle Transport Code System," contributed by Los Alamos National Laboratory, Los Alamos, New Mexico, February 29, 2000, distributed as package CCC-700 by Oak Ridge National Laboratory.

8. A. G. Croff, ORIGEN2 - A Revised and Updated Version of the Oak Ridge Isotope Generation and Depletion Code, ORNL-5621, Oak Ridge National Laboratory, July 1980.

9. R. S. Babcock, D. E. Wessol, C. A. Wemple, S. C. Mason, “ The MOCUP Interface: A Coupled Monte Carlo/Depletion System,” EG\&G Idaho, Inc., Idaho National Engineering Laboratory, presented at the 1994 Topical Meeting on Advances in Reactor Physics, Vol. III, Knoxville, TN, April 11-15, 1994. 